\title{
Impacto multidimensional de la pandemia en las juventudes indígenas de Yucatán
}

Silvana Larrea-Schiavon

Population Council

Suhayla Bazbaz

Fabiola Romero-Gamboa

Population Council

Isabel Vieitez Martínez

Population Council

Follow this and additional works at: https://knowledgecommons.popcouncil.org/departments_sbsr-pgy How does access to this work benefit you? Let us know!

\section{Recommended Citation}

Larrea-Schiavon, Silvana, Suhayla Bazbaz, Fabiola Romero-Gamboa, and Isabel Vieitez Martínez. 2022. "Impacto multidimensional de la pandemia en las juventudes indígenas de Yucatán." Ciudad de México: Population Council y Cohesión Comunitaria e Innovación Social (CCIS). 


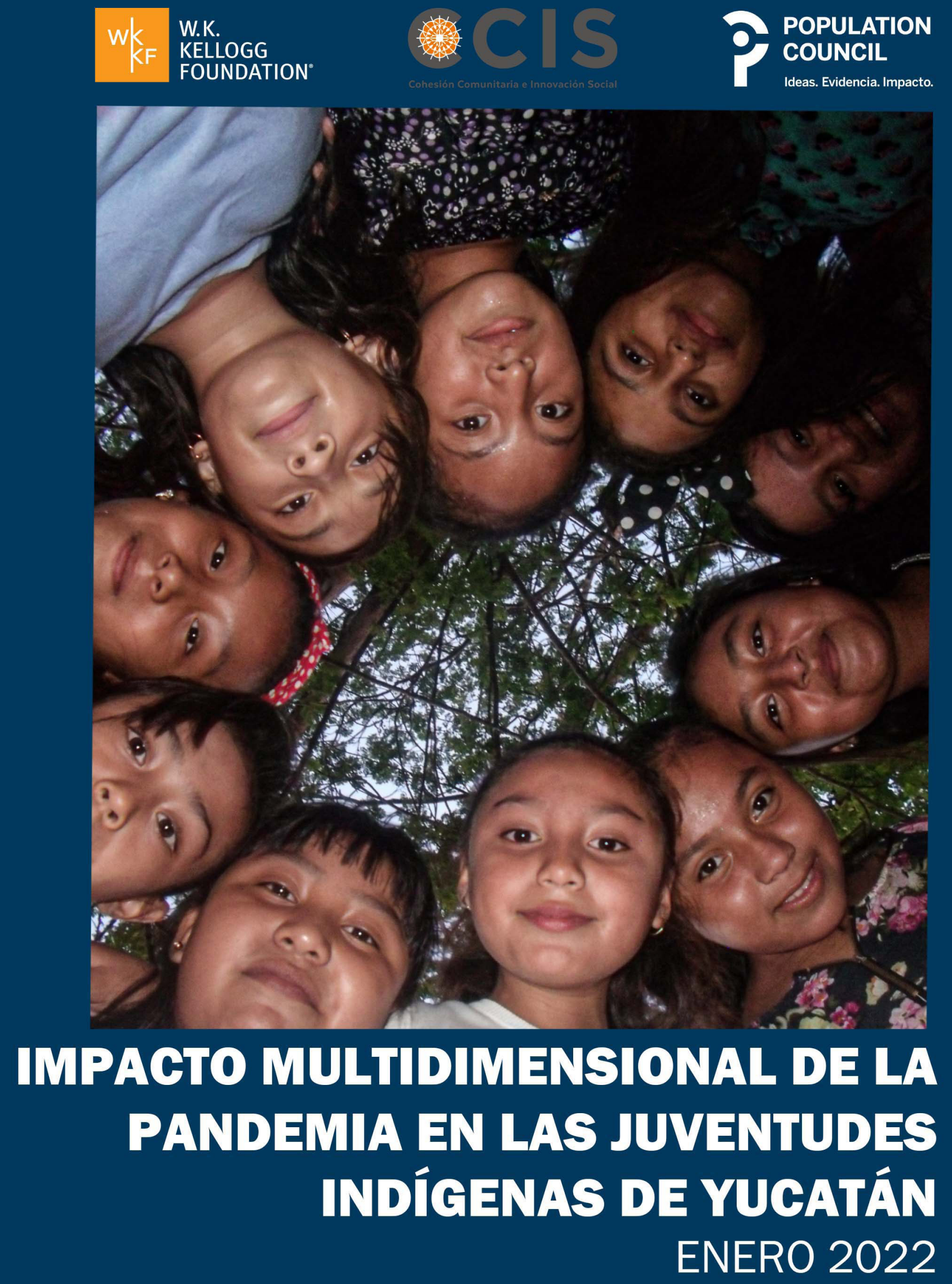

Population Council México Cohesión Comunitaria e Innovación Social 
El Population Council trabaja para resolver problemas críticos de salud y desarrollo, desde detener la propagación del VIH hasta mejorar la salud reproductiva y garantizar que las y los jóvenes tengan más oportunidades para llevar una vida más plena y productiva. A través de investigaciones de carácter biomédico, de ciencias sociales y de salud pública en 50 países, trabajamos con nuestras organizaciones socias para ofrecer soluciones que conduzcan a políticas, programas y tecnologías más eficaces que mejoren las vidas en todo el mundo. Establecida en 1952 y con sede en Nueva York, el Population Council es una organización no gubernamental sin fines de lucro precidida por una junta directiva internacional. Desde 1979, el Population Council ha trabajado en México para mejorar la salud reproductiva a través de investigaciones de alta calidad, evaluación de programas y alianzas técnicas con instituciones de gobierno a nivel estatal y federal y con organizaciones de la sociedad civil.

Cohesión Comunitaria e Innovación Social AC (CCIS) es una asociación civil sin fines de lucro constituida en 2009, con el objeto social de fortalecer la cohesión comunitaria y de fomentar la innovación social. CCIS ha creado un enfoque, estrategias, indicadores, herramientas, índices, programas, proyectos e iniciativas de cohesión comunitaria útiles para distintas agendas de acción pública. CCIS ha trabajado en 26 entidades federativas de la República Mexicana.

Este es el segundo año consecutivo en el que el Population Council y Cohesión Comunitaria e Innovación Social colaboran para visibilizar el impacto de la pandemia en municipios indígenas de la región. En 2020, el Population Council publicó un estudio sobre el impacto de la pandemia en población indígena de Chiapas y Yucatán y CCIS publicó diversos reportes sobre las decisiones y medidas adoptadas por los gobiernos estatales de Chiapas, Yucatán, Campeche y Quintana Roo en el contexto de la emergencia sanitaria por COVID-19.

Population Council

Blvd. Adolfo Ruiz Cortines 3720, Torre III

Piso 8, Suite/Oficina 8A123

Colonia Jardines del Pedregal

Álvaro Obregón

Ciudad de México

C.P. 01900

Tel: +525559998630

Cohesión Comunitaria e Innovación Social AC

Ciudad de México, México

Tel: +525519090005

email: info@cohesioncomunitaria.org

Citar como: Larrea-Schiavon Silvana, Bazbaz Suhayla, Romero-Gamboa Fabiola, Vieitez Isabel. 2022. "Impacto multidimensional de la pandemia en las juventudes indígenas de Yucatán” Ciudad de México: México: Population Council y Cohesión Comunitaria e Innovación Social (CCIS). 


\section{Índice}

04. agradecimientos

05. Resumen ejecutivo

13. INTRODUCcIóN

18. metodología

24. REsultados

Perfil Sociodemográfico de las personas

encuestadas.

Programas, medidas y decisiones adoptadas por los gobiernos estatal y municipal en el contexto de la emergencia sanitaria en el periodo de enero a Junio de 2021. Impactos multidimensionales de la pandemia.

Educación

Trabajo y economía Familiar

Salud mental

Salud sexual y reproductiva

Violencia

COVID-19 y Juventudes

50. RECOMENDACIONES Y CONSIDERACIONES FINALES 


\section{Agradecimientos}

Agradecemos a la Fundación W.K. Kellogg y especialmente a Quetzalli Sotelo, Daniela Fernández y Alejandra Garduño por creer en el proyecto, brindarnos el apoyo y recursos necesarios para llevarlo a cabo y el constante impulso por seguir trabajando con y para las personas que viven en la Península.

Agradecemos también la participación de Diana Navarro, Christian Estrella (coordinadora local del estudio), las seis mentoras del proyecto Abriendo Futuros y las seis encuestadoras que colaboraron con el Population Council durante la planeación e implementación del estudio. Sus aportaciones para el diseño de la encuesta, así como todo el trabajo realizado fueron clave para lograr llegar a las juventudes en los seis municipios participantes. Gracias a Cecilia Medina (mentora en Chacsinkín), Susana Guzmán (mentora en Tixméhuac), Suemi Chan (mentora en Cantamayec), Lilia Cano (mentora en Maní), Silvia Chan (mentora en Teabo) y Viviana Chan (mentora en Mayapán), así como a las seis encuestadoras: Deysi Jaqueline Mendoza Dzul, Guadalupe Cuxin Pech, Lorena Dzib, María Fernanda Ku Matus, Marianela Ic May y Martha Consepción Cauich. Agradecemos también a todas las organizaciones que nos apoyaron en la diseminación de la encuesta a través de sus redes.

Asimismo, agradecer a las personas adolescentes y jóvenes que nos brindaron su tiempo para contestar la encuesta y que compartieron con nosotras sus percepciones y experiencias sobre cómo la pandemia ha impactado sus vidas y las de sus familias. También agradecemos a aquellas juventudes, instituciones de gobierno y organizaciones de la sociedad civil que nos acompañaron en los conversatorios donde presentamos los resultados del estudio. Esperamos que los resultados aquí presentados puedan ser de utilidad para identificar distintas áreas de oportunidad en las diferentes comunidades que puedan apoyar en la disminución del impacto de la pandemia de COVID-19. 


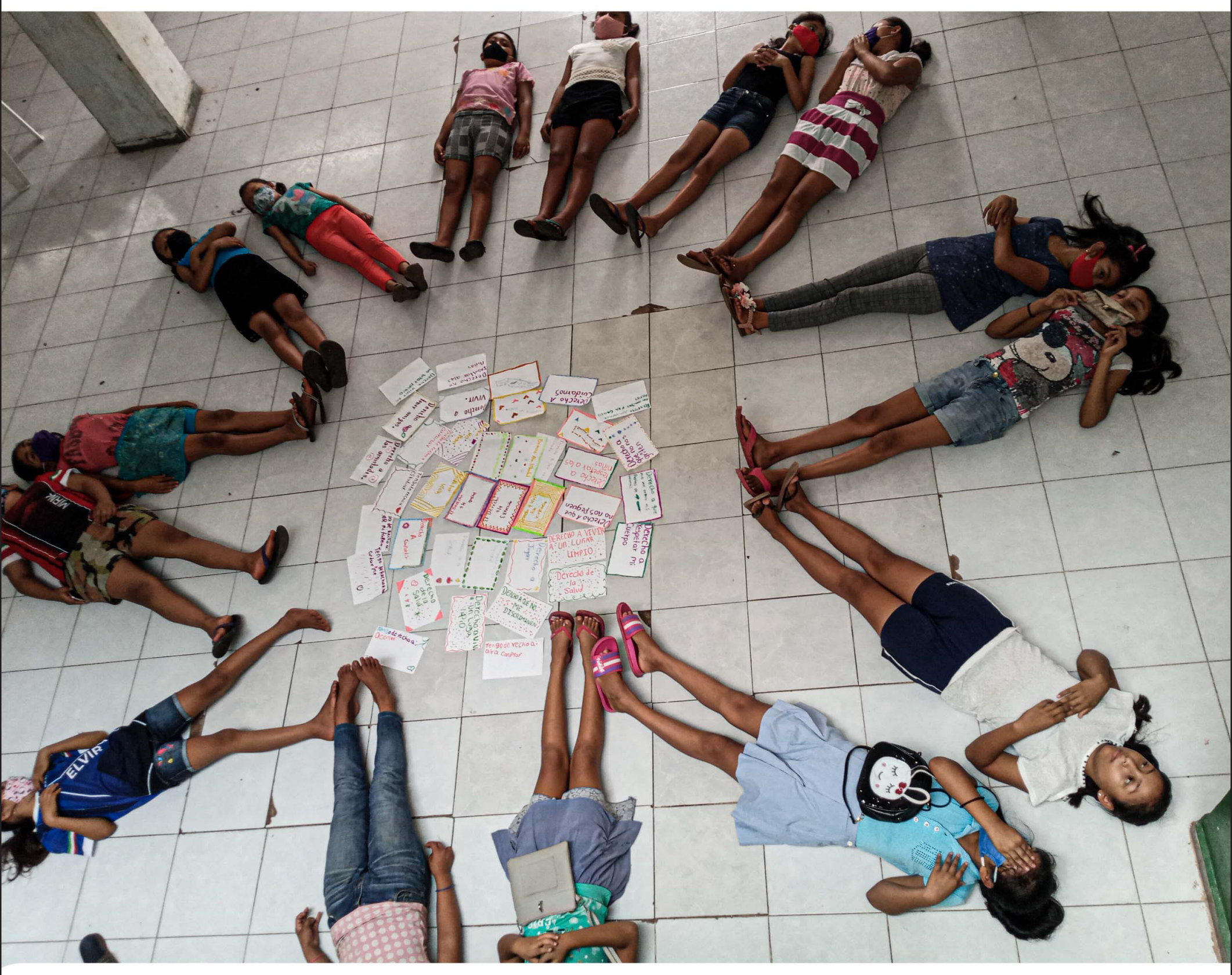

\section{RESUMEN EJECUTIV}


as juventudes son una de las poblaciones que se han visto y se verán más afectadas -por los impactos a largo plazo de la pandemia, más aún para aquellas personas jóvenes que viven y/o son parte de comunidades que han sido históricamente excluidas, como los pueblos y comunidades indígenas. Cada día contamos con más evidencia sobre el impacto de la pandemia en las juventudes en México y en otros países del mundo. Sin embargo, todavía hay poca información sobre el impacto en juventudes indígenas. Por este motivo, el objetivo del presente estudio es analizar el impacto de la pandemia en múltiples dimensiones de la vida de juventudes indígenas que viven en seis municipios localizados en Yucatán y mapear las decisiones y medidas relacionadas con juventudes adoptadas por el gobierno del estado de Yucatán en el contexto de la emergencia sanitaria por COVID-19 y de la reactivación económica, entre enero y junio 2021. Esta información es relevante para orientar y redirigir medidas y acciones de instituciones y personas tomadoras de decisiones en la región, así como para el diseño de nuevas estrategias y políticas públicas basadas en evidencia que se enfoquen a reducir las necesidades aún no atenidad de las juventudes indígenas.

\section{Programas, decisiones y medidas adoptadas por los gobiernos estatal y municipales en el contexto de la emergencia sanitaria en el periodo de enero a junio de 2021}

A través de la búsqueda en fuentes oficiales de información -disponibles y accesibles al público vía electrónica- de programas, medidas y decisiones que fueron adoptadas entre enero y junio del 2021, se identificaron más de 922 decisiones o medidas adoptadas por el gobierno del estado de Yucatán en el contexto de la emergencia sanitaria por COVID-19 y la reactivación económica. El $76 \%$ de las medidas y decisiones identificadas son de carácter sanitario, $7 \%$ se relacionan con programas 0 acciones de apoyos y subsidios y $3 \%$ son de carácter presupuestal y de inversión. También se identificó que $85 \%$ de las decisiones o medidas adoptadas en este periodo se relacionan con la emergencia sanitaria, el 14\% con la reactivación económica y el $1 \%$ con las emergencias meteorológicas.

En la búsqueda, no se identificaron programas o acciones dirigidos específicamente a personas adolescentes y jóvenes como principal población objetivos. Paralelamente, sí se identificaron programas que excluían de manera explícita a personas jóvenes menores de 18 años.

\section{Características sociodemográficas de las personas encuestadas}

En total 1,195 personas adolescentes y jóvenes completaron la encuesta en línea implementada entre julio y agosto del 2021. Del total de participantes que completaron la encuesta $27 \%(\mathrm{n}=320)$ eran adolescentes de entre 14 y 17 años y 73\% eran personas jóvenes de entre 18 y 29 años ( $n=875)$. 56\% de las personas adolescentes y $60.5 \%$ de las jóvenes se identificaron como mujeres. Con respecto a la etnicidad, más del $90 \%$ de las personas en ambos grupos de edad se reconocieron como indígenas, de las cuáles 99\% se identificaron como parte del pueblo Maya y $65 \%$ reportaron hablar una lengua indígena.

\section{Principales hallazgos}

En este resumen ejecutivo presentamos los principales hallazgos. En el reporte extenso se reportan todos los resultados identificados a través del estudio.

\section{Educación}

- De las personas que asistían a la escuela 
antes del inicio de la pandemia, $2.8 \%$ de las y los adolescentes, $12.8 \%$ de las personas jóvenes de entre 18 y 24 años y $2.4 \%$ de las personas de entre 25 y 29 años ya no se encontraban estudiando al momento de la encuesta,

- $62.3 \%$ del total de las y los participantes no tenían acceso a WiFi privado en sus hogares.

- De las personas que se encontraban estudiando al momento de la encuesta, $82.7 \%$ de adolescentes reportó que durante el cierre de las escuelas tomaba las clases y realizaba las actividades escolares a través de WhatsApp y $83.5 \%$ de personas jóvenes siguió estudiando a tavés de plataformas en línea.

- Entre las personas adolescentes y jóvenes que seguían estudiando desde el inicio de la pandemia, $32 \%$ estaba en desacuerdo con que tenían los recursos necesarios para acceder y enviar sus tareas y con que habían entendido sus clases y tareas durante el cierre de las escuelas.

- Aproximadamente $10 \%$ de las personas adolescentes y jóvenes que participaron en la encuesta y seguían estudiando al momento de la encuesta, reportaron que desde el inicio de la pandemia han pensado seriamente en abandonar la escuela.

- Se identificaron dos programas implementados a nivel estatal enfocados a la educación: Impulso Escolar y la entrega de mobiliario, equipamiento, mantenimiento y ampliación de espacios educativos. Estos programas tienden a enfocarse en estudiantes de escuelas públicas de ciertos niveles educativos, sin cubrir necesariamente todos los niveles de educación básica obligatoria.

- No se identificaron programas, decisiones o medidas enfocados a prevenir o reducir la deserción escolar o promover la reinserción escolar, y tampoco programas, decisiones o medidas que abordaran las necesiadades específicas de algunos grupos de juventudes, como las mujeres.

\section{Trabajo y economía familiar}

- Del total de participantes, 24\% de adolescentes y 55\% de jóvenes de entre 18 y 29 años se encontraba trabajando al momento de la encuesta. Entre las personas jóvenes, un mayor porcentaje de hombres comparados con las mujeres tenían un trabajo.

- La pandemia impactó la vida laboral de las personas participantes, disminuyedo los ingresos que perciben, las horas de trabajo realizadas y la demanda de productos que venden.

\section{$85 \%$}

del total de participantes consideró que es más o mucho más difícil como persona jóven conseguir trabajo desde el inicio de la pandemia en comparación con antes de la pandemia.

- Siete de cada 10 participantes identificaron que por lo menos una persona en su hogar (incluyéndose) ganaban menos al momento de la encuesta de lo que ganaban antes del inicio de la pandemia.

- El $25 \%$ de las personas adolescentes y $19 \%$ de las personas jóvenes percibe que el ingreso familiar es insuficiente con respecto a lo que el hogar necesita gastar para sostener a la familia.

- A nivel estatal, se identificaron dos programas 
enfocados a la seguridad alimentaria, el Programa de Asistencia a la Comunidad en Vulnerabilidad y Discapacidad y el Programa de Seguridad Alimentaria. Por otro lado, se identificaron 20 programas, medidas y decisiones enfocadasal empleoy reactivación económica. Por último, se identificaron diversos programas para el apoyo a personas emprendedoras (Microyucs), así como programas dirigidos a la protección del empleo turístico, la activación empresarial y artesanal, programas de apoyo al campo y desarrollo rural y programas de apoyo a la actividad apícola y a la producción de fibra de henequén.

- Todos los programas identificados excluyen de manera explícita y directa a las y los adolescentes de entre 15 y 17 años (que en México se consideran en edad legal para trabajar), sin justificar dicha exclusión con criterios objetivos, razonables y proporcionales.

\section{Salud mental}

\section{$19.2 \%$}

de las mujeres adolescentes y

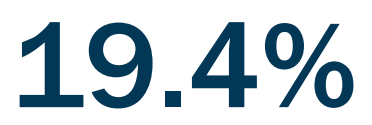

de las mujeres jóvenes

se han sentido aisladas siempre o casi siempre desde el inicio de la pandemia, comparado con $4.3 \%$ de los hombres adolescentes y $11.4 \%$ de los hombres jóvenes.

- Las mujeres en ambos grupos de edad también reportaron haberse sentido más estresadas y ansiosas desde el inicio de la pandemia, comparadas con los hombres.
- Las principales estrategias mencionadas por las y los participantes para manejar los sentimientos de ansiedad y estrés debidos a la pandemia fueron ayudar más con las actividades y tareas en sus hogares, hacer deporte, dibujar, escuchar música, hablar con sus amistades y familiares, y aprender nuevas actividades.

- Se identificó la implementación por parte del gobierno federal y del gobierno estatal de líneas telefónicas gratuitas con el objetivo de orientar y ofrecer apoyo emocional a la población, así como la implementación del programa ConTacto Joven. No se identificaron medidas 0 decisiones adicionales para prevenir o atender problemas de salud mental en el estado, particularmente en el contexto de la emergencia sanitaria.

\section{Salud sexual y reproductiva}

- Tres de cada diez personas jóvenes tuvieron acceso a información sobre métodos anticonceptivos desde el inicio de la pandemia. El acceso a esta información lo obtuvieron principalmente a través de personal de salud.

- Casi 9 de cada 10 personas participantes que intentaron acceder a un método anticonceptivo desde el inicio de la pandemia lograron tener aceso a ellos. Sin embargo, un porcentaje importante accedió a ellos a través de la compra directa en farmacias (39\% de las mujeres jóvenes y $64 \%$ de los hombres jóvenes), lo que representa un gasto considerable para las juventudes y compromete su asequibilidad para quienes no tienen los recursos para comprarlos.

- Casi tres de cada diez personas jóvenes mencionaron que percibían que su acceso a servicios de salud sexual y reproductiva se habían visto afectados y $7 \%$ que se habían 
visto muy afectados desde el inicio de la pandemia.

- $29 \%$ del total de mujeres que estaban embarazadas al momento de la encuesta o que habían estado embarazadas en algún momento desde el inicio de la pandemia $\mathrm{n}=60$ no buscaban un embarazo. El principal motivo por el que quedaron embarazadas aún cuando no estaban buscando un embarazo fue el no haber utilizado un método anticonceptivo.

- Se conoce que en ciertos municipios operan los Servicios Amigables para adolescentes. Sin embargo, en las fuentes oficiales de información del gobierno del estado no se identificaron programas, decisiones 0 medidas adicionales relacionadas con la salud sexual y reproductiva de las juventudes implementadas durante la pandemia.

\section{Violencia}

- El $4.1 \%$ del total de personas participantes reportaron haber experimentado violencia en sus hogares por lo menos una vez en su vida. Las mujeres jóvenes (18+ años) son las que reportaron haber experimentado violencia en mayor frecuencia (6.3\%).

- El 38\% de las personas participantes que han experimentado violencia en sus hogares, reportaron que la violencia había aumentado a partir del inicio de la pandemia.

- La mayoría de las juventudes no reportan los actos de violencia a las que son sujetas en sus hogares. La principal razón para no reportar los eventos de violencia en sus hogares fue porque el evento no les pareció algo tan grave como para reportarlo (60\%).

- Del total de participantes 2.2\% han experimentado violencia de pareja por lo menos alguna vez en su vida. Ocho de cada diez participantes que reportaron haber experimentado violencia de pareja por lo menos alguna vez en su vida son mujeres.

- Del total de personas que han experimentado violencia de pareja por lo menos una vez en la vida, 59.3\% no han reportado el evento a ninguna autoridad.

\section{$16 \%$}

del total de participantes han experimentado violencia digital por lo menos una vez en la vida. El principal grupo que ha experimentado este tipo de violencia son las mujeres adolescentes (18.9\%).

- El principal tipo de violencia digital experimentado por todas las personas son los apodos ofensivos. Para casi todos los tipos de violencia digital, las mujeres las experimentan con mayor frecuencia comparadas con los hombres.

- Casi 9 de cada 10 personas participantes que han experimentado violencia digital alguna vez en la vida, identificaron que este tipo de violencia había incrementado desde el inicio de la pandemia.

- Del total de personas participantes que habían experimentado violencia digital por lo menos una vez en la vida, $87.3 \%$ no reportó el evento. La principal razón para no reportarlo fue porque no sabían cómo o con quién reportarlo (65\%).

- Tanto el gobierno federal como el gobierno estatal implementaron líneas telefónicas para facilitar el reporte de violencia (principalmente de violencia hacia las mujeres y niñas). También se identificaron acciones estatales contra la violencia de 
género mediante el fortalecimiento de los institutos dedicados a proteger a la mujer.

- Sin embargo, no identificamos programas, medidas 0 acciones adicionales para prevenir o atender las violencias por razón de género, edad y orientación sexual. Tampoco identificamos estrategias centradas en la prevención y atención de la violencia digital ni en su incremento durante la pandemia.

\section{COVID-19 y juventudes}

- Se observó un grado de cumplimiento elevado con las medidas de prevención a un año y cuatro meses del inicio de la pandemia entre todas las personas participantes. Las medidas de prevención preguntadas en la encuesta fueron: lavado de manos, uso de gel antibacterial, uso de cubrebocas, mantener la sana distancia y salir de casa solo lo necesario.

Entre las y los adolescentes y personas jóvenes participantes, solamente $2.08 \%$ respondieron que no pensaban vacunarse contra la COVID-19. La principal razón por la cual no se vacunarían es porque les da miedo que les de COVID-19 si se vacunan.

\section{Recomendaciones}

Recomendaciones generales sobre los programas, medidas y decisiones tomadas por el gobierno estatal para hacer frente al impacto de la pandemia en las juventudes

1. Divulgar proactivamente las decisiones 0 medidas adoptadas en fuentes oficiales de información y en otros canales y medios adecuados para las juventudes indígenas, asegurando la pertinencia cultural de la información y el uso de lenguaje común y no técnico.
2. Abstenerse de adoptar decisiones o medidas, relacionadas con programas, que suponen una distinción, restricción, exclusión o preferencia, no basada en criterios objetivos, razonables o proporcionales que tenga como objeto o fin anular o menoscabar derechos de las personas adolescentes (12 a 17 años) y jóvenes (12 a 29 años).

3. No restringir o limitar el acceso a programas de apoyos o subsidios a población residente, incluir a poblaciones móviles (p.ej. migrantes internas, migrantes internacionales, desplazadas internas forzadas, refugiadas y solicitantes de asilo)

4. Ampliar la cobertura y población objetivo de los programas para que distintas juventudes se puedan ver beneficiadas por ellos (e.j., la cobertura del programa Impulso Escolar a todos los niveles de la educación obligatoria para estudiantes en escuelas tanto públicas y privadas de familias con ingresos por debajo de la línea mínima de bienestar).

5. Evaluar la implementación de las decisiones o medidas en y desde los territorios, así como la satisfacción o insatisfacción de las personas adolescentes y jóvenes titulares de derechos atendidas (contraloría social) -y de las no atendidas-.

6. Incorporar las voces de las juventudes y sus necesidades y derechos en la planeación y diseño de programas y estrategias que estén dirigidos a esta población.

7. Promover el aprendizaje horizontal entre organizaciones de la sociedad civil que trabajan en los territorios y las instituciones de gobierno, para intercambiar buenas prácticas y lecciones aprendidas sobre los programas que han sido o están siendo implementados. 
Recomendaciones específicas con base

en las necesidades y problemáticas

identificadas por las juventudes que

participaron en el estudio

1. Promover el acceso a internet y tecnologías de la información (no solo celular sino también computadora o tablet) en las comunidades con menor acceso a estos recursos, particularmente entre mujeres adolescentes y jóvenes.

2. Implementar programas dirigidos a prevenir la deserción escolar y promover la reinserción escolar, con énfasis en jóvenes de 18 a 24 años.

3. Impulsar la creación de empleos y retención de personas jóvenes (más allá del emprendurismo y empresariado) en trabajos dignos, libres y seguros, con salarios justos y acceso a seguridad social que les permitan desarrollarse personal y profesionalmente en sus propias localidades, sin tener que migrar para poder ingresar al mercado laboral.

4. Considerar acompañamiento y asesoría para las y los jóvenes para facilitar la comprensión y cumplimiento de criterios de elegibilidad requisitos para poder aplicar a un programa de gobierno de apoyos o subsidios.

5. Promoverestrategias de desarrolloeconómico solidario con la participación de diversos sectores, incluyendo las organizaciones de la sociedad civil que ya trabajan en estas comunidades.

6. Difundir en los municipios, mediante campañas de comunicación y otras estrategias, la importancia de la salud mental, así como información para facilitar la detección oportuna de problemas de salud mental graves (e.j., depresión mayor, trastornos de ansiedad generalizados y conductas suicidas).

7. Ampliar el acceso a tratamiento psicológico y psiquiátrico gratuito y de calidad en las comunidades y municipios (particularmente en los rurales y periurbanos), con enfoque de género y de derechos humanos.

8. Implementar estrategias a nivel escolar para la detección oportuna de problemas de salud mental entre la población estudiantil.

9. Evaluar a mayor profundidad las barreras de acceso a los servicios de salud sexual y reproductiva para las personas jóvenes, con enfoque de género, pertinencia cultural y diversidad sexual y garantizar el acceso a los mismos sin discriminación.

10. Implementar estrategias específicas para disminuir las barreras en el acceso a los servicios de salud sexual y reproductiva en las comunidades y municipios.

11. Trabajar hacia la disminución de tabúes existentes alrededor de la sexualidad entre las personas de las comunidades y municipios, para que las juventudes puedan vivir y disfrutar su sexualidad libre, segura y sin prejuicios.

12. En servicios de salud públicos de las comunidades y municipios, asegurar el acceso gratuito a todos los métodos anticonceptivos, así como a servicios de orientación sobre métodos anticonceptivos para que las jvuentudes tengan todo el conocimiento y herramientas para elegir libremente los métodos de su elección y asegurar el acceso a los mismos.

13. Promover acciones para fomentar normas de género y masculinidades positivas en las comunidades y municipios, revirtiendo los prejuicios y estereotipos y la imposición de roles de género.

14. Fortalecer el conocimiento sobre los distintos tipos de violencia, incluyendo la violencia de género y la violencia digital.

15. Implementar programas para la prevención y atención de las violencias en las 
comunidades y municipios que respondan a las necesidades de las mujeres adolescentes y jóvenes, pero también de juventudes que no se identifican como mujeres cis (hombres, comunidad trans, agénero, bigénero y no binaria).

16. Promover el derecho de acceso a la justicia, incrementar, diversificar y difundir los mecanismos de denuncia en las comunidades y municipios -que sean realmente confidenciales y que no revictimicen a las personas que realizan la denuncia, particularmente a las mujeresy asegurar la capacidad institucional para recibir, canalizar, atender y resolver las denuncias. 
l estado de Yucatán se encuentra localizado en la región sur de México y está compuesto por 106 municipios. El estado cuenta con un total de 2,320,898 habitantes (1.8\% del total de la población nacional). Aproximadamente 13\% de la población en el estado tiene entre 15 y 29 años. En el estado, $23.7 \%$ de la población habla una lengua indígena (siendo la más frecuente el Maya) y $3.0 \%$ se considera afromexicana o afrodescendiente. Los tres municipios con mayor número de población son Mérida, Kanasín y Valladolid (Instituto Nacional de Estadística y Geografía, 2021a).

Con respecto a las características educativas y económicas de la población en general que viven en el estado:

\section{$5.3 \%$}

de las personas de 15 años y más no cuenta con escolaridad

\section{$49.8 \%$}

cuenta con escolaridad básica

$$
22.6 \%
$$

con escolaridad media superior

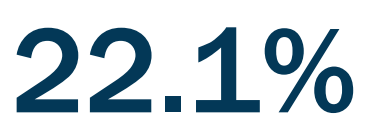

con escolaridad superior

Así mismo, 93\% de adolescentes de entre 12 a 14 años y $47.5 \%$ de personas de entre 15 y 24 años asisten a la escuela. Con respecto al aspecto laboral, entre la población de 12 años y más económicamente activa, 99.1\% de las mujeres y $98.7 \%$ de los hombres se encuentra ocupada. De las personas no económicamente activas de
12 años y más, 34.5\% son estudiantes, 43.3\% se dedican a quehaceres del hogar, $10.9 \%$ son personas pensionadas o jubiladas, $4.3 \%$ son personas con alguna limitación física o mental que les impide trabajar y $7 \%$ son personas en otras actividades no económicas (Instituto Nacional de Estadística y Geografía, 2021a). Con relación a la disponibilida en el estado de tecnologías de la información en la vivienda, 88.4\% cuenta con un teléfono celular, 51.6\% con internet, $46.7 \%$ con televisión de paga, $37.5 \%$ con una computadora y $26.9 \%$ con línea telefónica fija (Instituto Nacional de Estadística y Geografía, 2021a).

\section{COVID-19 y Juventudes Indigenas}

Al 13 de noviembre de 2021 México tenía un total de 3,841,661 casos acumulados de COVID-19 y 290,872 muertes en todo el territorio nacional. Desde el inicio de la pandemia, los casos se han concentrado en personas mayores de 50 años (Johns Hopkins University, 2021). Sin embargo, aproximadamente $3.9 \%$ de los casos han sido diagnosticados en niñas, niños y adolescentes (Secretaría de Salud, 2021b).

La última actualización sobre casos de COVID-19 en población que se reconoce como indígena fue publicado en abril del 2021. Un total de 19,149 casos se han confirmado en toda la República en esta población ( 0.50\% del total de casos confirmados). La mediana de edad de los casos confirmados fue de 47 años y, del total de casos en esta población, 2,870 fueron identificados en personas adolescentes y jóvenes de entre 15 y 29 años $(14.9 \%$ del total de casos en población que se reconoce como indígena). Los tres estados con el mayor número de casos confirmados en en esta población son Yucatán ( $n=2,897$ casos), Ciudad de México ( $n=2,409$ casos) y Oaxaca ( $n=1,941$ casos) (Secretaría de Salud, 2021a) (ver Figura 1).

Las juventudes es una de las poblaciones que se ha visto y se verá más afectada por los impactos a largo plazo de la pandemia, más aún para aquellas juventudes que viven $\mathrm{y} / \mathrm{o}$ son parte 


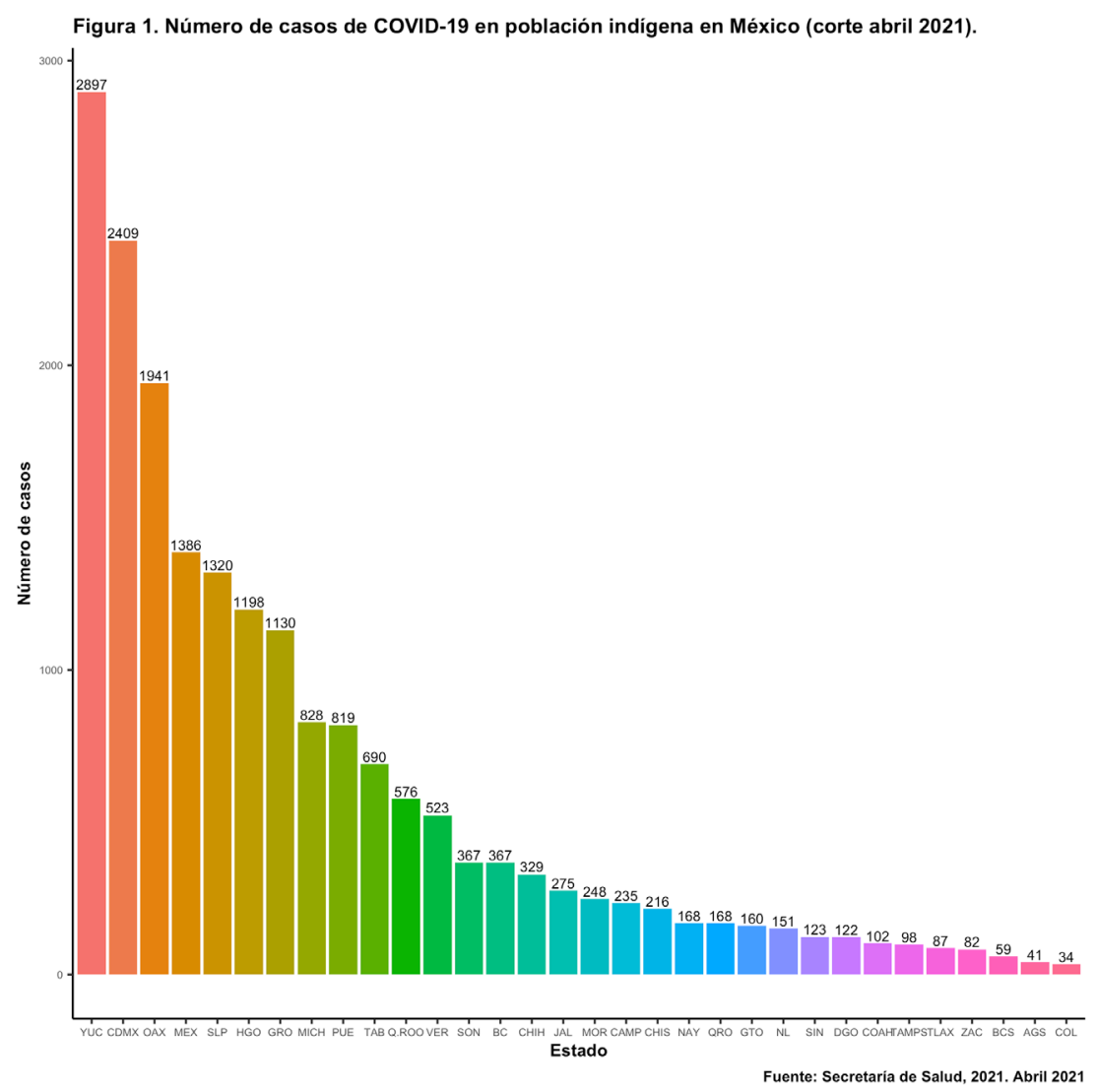

de comunidades que han sido históricamente excluidas, como las poblaciones indígenas. En junio del 2020, el Population Council en colaboración con CCIS realizaron un estudio para conocer el impacto de la pandemia en comunidades indígenas de Yucatán y Chiapas, así como las medidas y decisiones que habían sido implementadas por los gobiernos de estos dos estados para contrarestar el impacto de la pandemia.

En este estudio, realizado a pocos meses del inicio de la pandemia, identificamos ya impactos socioeconómicos importantes en las personas adolescentes y adultas que participaron en la encuesta. Por ejemplo, $15 \%$ de las mujeres adolescentes y $22 \%$ de los hombres adolescentes reportaron que no habían consumido su desayuno, comida y/o cena en el mes previo a la encuesta debido a que no había suficiente comida para toda la familia. Además, 51\% de las mujeres y $63 \%$ de los hombres encuestados reportaron haber perdido su principal fuente de ingreso desde el inicio de la pandemia. Sin embargo, solamente $31 \%$ de las mujeres y $32 \%$ de los hombres identificó contar con ahorros y menos del 50\% reportó producir cosecha o tener suficientes animales de patio para consumo propio (Vieitez Martínez et al., 2020).

Con respecto a la educación, la pandemia provocó el cierre masivo de las escuelas, con más de 1,200 millones de estudiantes afectados a nivel mundial. La mayoría de los países de la región de América Latina y el Caribe implementaron estrategias para continuar brindando educación gratuita (29 de 33 países). En México, el gobierno implementó diversas modalidades de educación a distancia (plataforma digital, radio y televisión), siendo el programa Aprende En Casa, la principal estrategia adoptada. De acuerdo con cifras del Instituto Nacional de Estadística y Geografía, en el ciclo escolar 2019-2020 2.2\% del total de niños, niñas, adolescentes y jóvenes (3 a 29 años de edad) inscritos en la escuela no completaron el ciclo escolar (Instituto Nacional de Estadística y Geografía, 2021b). En el estudio realizado por el Population Council y CCIS en 2020 se identificó que: 


\section{$24 \%$}

de las mujeres adolescentes y

$26 \%$

de los hombres adolescentes habían abandonado la escuela desde el inicio de la

pandemia y que

$75 \%$

de la población del estudio en este grupo de edad no tenía acceso a una conexión a internet en casa, lo que dificultaba su acceso a las actividades escolares en línea (Vieitez Martínez et al., 2020).

En cuanto a la salud mental, el contexto adverso generado por la pandemia, las pérdidas familiares, el aislamiento social, el cierre de escuelas, menor contacto con amistades y familiares, el aumento en el uso de sustancias y el menor acceso a servicios de salud mental son los principales factores identificados por medio de los cuales la pandemia tuvo y tendrá un impacto en la salud mental de las juventudes. Un estudio llevado a cabo por el Population Council (llamado VOCES-19) entre noviembre 2020 y febrero de 2021 con más de 55,000 juventudes identificó que un porcentaje importante de mujeres, hombres y personas jóvenes autoidentificadas como no binarias habían presentado síntomas de depresión en las dos semanas previas a la realización de la encuesta (64\% de personas adolescentes y $71 \%$ de las personas jóvenes (Larrea-Schiavon et al., 2021). Por otro lado, el impacto a largo plazo de la disrupción en el acceso a servicios de salud sexual y reproductiva durante la pandemia en el número de embarazos no deseados y prácticas sexuales que aumentan la probabilidad de enfermedades de transmisión sexual deben ser aspectos por analizarse en el corto, mediano y largo plazo. Aún contamos con poca evidencia del impacto en la pandemia sobre estos indicadores, principalmente en población que se reconoce como indígena.
Por último, en todo el mundo (incluyendo México) se observó un incremento de la violencia hacia las mujeres y niñas desde el inicio de la pandemia. Análisis realizados a pocos meses del inicio de la pandemia mostraban un aumento en el número de llamadas realizadas al número de emergencias 911 de entre 30\% y 100\% (dependiendo del estado), así como un aumento del $5 \%$ en el ingreso de mujeres a albergues para atender casos de violencia y del $60 \%$ en el apoyo y asesoría telefónica brindada (Fernández Nieto, 2020). Existe poca información sobre el aumento de la violencia intrafamiliar hacia las juventudes durante la pandemia. Un estudio llevado a cabo por UNICEF en 2020 en cinco países de Latino América, incluyendo México, identificó que 21\% de adolescentes participantes reportaron un aumento de las discusiones en sus hogares durante el aislamiento social (UNICEF, 2020). Igualmente, el estudio VOCES-19 identificó porcentajes similares de incremento en la violencia en sus hogares hacia esta población desde el inicio de la pandemia; aproximadamente $27 \%$ de adolescentes de entre 15 y 17 años y jóvenes de entre 18 y 24 años que reportaron haber experimentado violencia en algún momento en su vida identificaron un incremento de la violencia desde el inicio de la pandemia (Larrea-Schiavon et al., 2021). 
Cada día contamos con más evidencia sobre el impacto de la pandemia en las juventudes en México y en otros países del mundo. Sin embargo, la información sobre el impacto en juventudes indígenas es muy escasa.

Como se mencionó anteriormente, estas juventudes se encuentran en una mayor situación de desventaja al compararlas con juventudes no indígenas, asociado al rezago económico en los municipios donde viven, la presencia de menores oportunidades educativas y laborales en sus comunidades, y la falta de acceso a internet y tecnologías de la información, entre otros múltiples determinantes. Por este motivo, es de suma importancia recopilar información sobre el impacto multidimensional que ha tenido la pandemia a un año y 4 meses de su inicio en juventudes indígenas que viven en estas comunidades, así como sobre la implementación de programas, decisión y medidas que estén respondiendo a las necesidades de este grupo poblacional.

Esta información es relevante para orientar y redirigir acciones y decisiones de personas tomadoras de decisiones en la región, así como para el diseño de nuevas estrategias que se enfoquen a reducir las necesidades aún no atenidad de las juventudes indígenas.
Los objetivos del presente estudio son los siguientes:

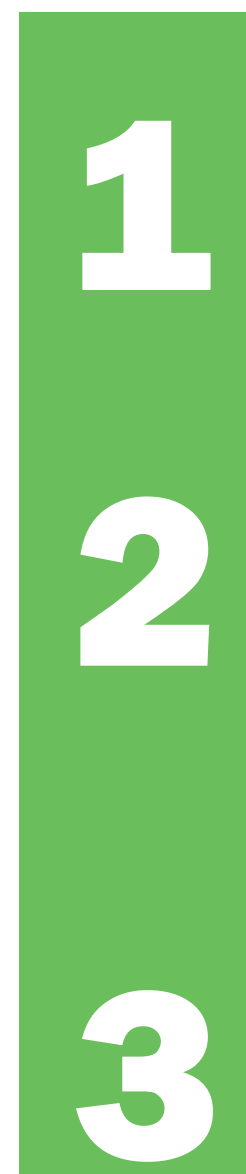

Analizar el impacto de la pandemia en múltiples dimensiones de la vida de juventudes indigenas que viven en seis municipios localizados en Yucatán -Cantamayec, Chacsinkín, Maní, Mayapán, Tixméhuac y Yaxcabá.

Mapear las decisiones y medidas relacionadas con juventudes adoptadas por el gobierno del estado de Yucatán en el contexto de la emergencia sanitaria por COVID-19 y de la reactivación económica, entre enero y junio 2021

Identificar aquellas necesidades y derechos que no están siendo atendidos actualmente por estos programas, decisiones y medidas, con la finalidad de proveer evidencia a personas tomadoras de decisiones sobre dónde sería necesario dirigir más esfuerzos para disminuir el impacto de la pandemia y proveer de más y mejores oportunidades para el desarrollo personal y profesional de las juventudes indígenas en Yucatán. 


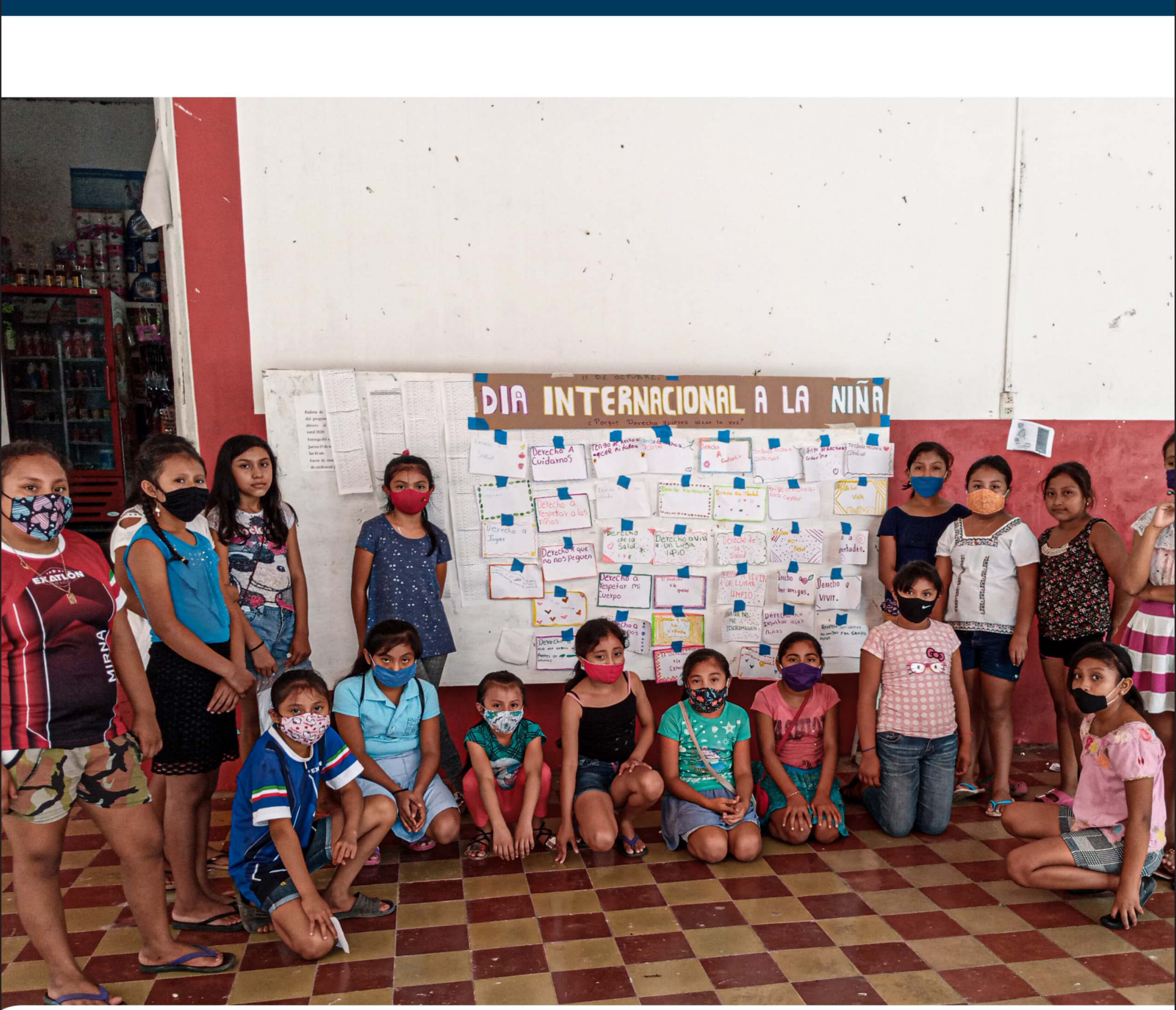

\section{METODOLOGIA}


Para cumplir con los objetivos presentados, se llevaron a cabo dos estudios complementarios:

1. Encuesta transversal en línea de corte cuantitativo con población adolescente de entre 14 y 17 años y población jóven de entre 18 y 29 años en seis municipios de Yucatán con presencia de población que se reconoce como indígena

2. Mapeo de programas, decisiones y medidas relacionadas con juventudes implementadas por el gobierno estatal y los gobiernos municipales de los seis municipios seleccionados para el estudio

La metodología de ambos estudios se describe de manera separada en esta sección. En un primer momento se describe la metodología de la encuesta transversal y en un segundo momento la metodología para el mapeo de programas, decisiones y medidas.

\section{Encuesta transversal}

La población objetivo del estudio fueron adolescentes de entre 14 y 17 años de edad y personas adultas jóvenes de entre 18 y 29 años de edad que se encontraran residiendo en alguno de los seis municipios seleccionados al momento de la encuesta. La encuesta fue implementada entre julio y agosto del 2021.

\section{Selección de los municipios}

La selección de los seis municipios para este estudio se hizo con base en los 20 municipios que participaron en el estudio realizado por el Population Council en junio de 2020. De la lista

\begin{tabular}{|c|c|c|c|c|c|c|c|}
\hline Municipio & $\begin{array}{l}\text { Población } \\
\text { total }(2015)^{1}\end{array}$ & $\begin{array}{l}\text { Población total de } \\
\text { entre } 10 \text { y } 29 \text { años } \\
(2015)^{1}\end{array}$ & $\begin{array}{l}\text { Grado de } \\
\text { margniación de } \\
\text { los municipios } \\
(2010)^{2}\end{array}$ & $\begin{array}{l}\text { Tasa de } \\
\text { fertilidad en } \\
\text { adolescentes } \\
\text { de entre } 15 \\
-19 \text { años X } \\
1,000 \\
(2015)^{1}\end{array}$ & $\begin{array}{l}\text { Indice de } \\
\text { positividad } \\
\text { de casos de } \\
\text { covid-19 } x \\
1,000 \\
\text { habitantes }^{3}\end{array}$ & $\begin{array}{l}\text { Porcentaje } \\
\text { del total de } \\
\text { casos de } \\
\text { Covid-19 } \\
\text { en Yucatán }\end{array}$ & $\begin{array}{l}\text { Número de } \\
\text { participantes } \\
\text { en la } \\
\text { encuesta de } \\
\text { Junio } 2020\end{array}$ \\
\hline Cantamayec & 2,519 & 1,011 (40.1) & Muy alta & 291.9 & 1.1 & 0.01 & 57 \\
\hline Chacskinkín & 3,015 & 1,193 (39.5) & Alta & 230.2 & 2.6 & 0.03 & 48 \\
\hline Chumayel & 3,308 & $1,192(36.0)$ & Alta & 110.4 & 7.8 & 0.11 & 1 \\
\hline Maní & 5,637 & $2,042(36.2)$ & Alta & 235.7 & 2.3 & 0.05 & 32 \\
\hline Mayapán & 3,700 & $1,566(42.3)$ & Muy alta & 246.3 & 0.2 & 0.004 & 57 \\
\hline Muna & 12,722 & $4,415(34.7)$ & Media & 338.0 & 5.9 & 0.34 & 1 \\
\hline Oxkutzcab & 31,202 & 11,909 (38.1) & Media & 654.4 & 2.9 & 0.41 & 2 \\
\hline Peto & 25,264 & $9,545(37.7)$ & Media & 528.2 & 8.3 & 0.94 & 2 \\
\hline Sacalum & 4,819 & 1,741 (36.1) & Media & 308.1 & 4.7 & 0.10 & 1 \\
\hline Tahdziu & 5,111 & 2,142 (41.9) & Muy alta & 367.3 & 0.7 & 0.01 & 2 \\
\hline Teabo & 6,551 & 2,566 (39.1) & Alta & 187.5 & 10.5 & 0.31 & 48 \\
\hline Tekax & 42,440 & 15,778 (37.1) & Media & 685.3 & 9.7 & 1.85 & 1 \\
\hline Ticul & 40,161 & $14,390(35.8)$ & Media & 793.5 & 18.7 & 3.39 & 2 \\
\hline Tixméhuac & 4,813 & 1,791 (37.2) & Alta & 217.7 & 1.6 & 0.03 & 17 \\
\hline Valladolid & 80,313 & $34,061(42.4)$ & Media & $1,091.6$ & 22.0 & 7.9 & 1 \\
\hline Yaxcabá & 15,203 & $5,798(38.1)$ & Muy alta & 494.8 & 2.9 & 0.20 & 20 \\
\hline \multicolumn{8}{|c|}{$\begin{array}{l}\text { Referencias: } \\
\text { 1.Instituto Nacional de Estadística y Geografía. Encuesta Intercensal 2015. México. Disponible en: https://www.inegi.org.mx/programas/intercensal/2015/ } \\
\text { 2.Secretaría de Desarrollo Social. Sistema de Apoyo para la Planeación del PDZP. México, 2010. } \\
\text { Disponible en: http://www.microrregiones. gob.mx/catloc/Default.aspx?tipo=clave\&campo=mun\&valor=31 } \\
\text { 3.CONACYT. COVID-19 México. Información General. México. Disponible en: https://datos.covid-19.conacyt.mx }\end{array}$} \\
\hline
\end{tabular}


de 20 municipios participantes en la encuesta realizada en 2020 , se hizo la selección de los seis municipios más afectados con base en las siguientes características: (1) número de población de entre 10 y 29 años; (2) grado de marginación del municipio; (3) tasa de fertilidad en adolescentes de entre 15 y 19 años; e, (4) índice de positividad de casos de COVID-19 en los municipios por cada 1,000 habitantes (ver Tabla 1). Se utilizaron los datos de la Encuesta Intercensal 2015 y no del Censo 2020 ya que, al momento del diseño del estudio y selección de los municipios, estos datos aún no se encontraban disponibles. Los municipios seleccionados fueron Cantamayec, Chacsinkín, Maní, Mayapán, Tixméhuac y Yaxcabá.

\section{Cálculo y selección de la muestra}

El tamaño de la muestra para cada uno de los seis municipios se calculó con base al tamaño de la población de entre 10 y 29 años, con un nivel de confianza del 95\% y un márgen de error del $5 \%$. Con base en este cálculo, el número total de participantes fue de 1,996 adolescentes y personas jóvenes (ver Tabla 2). La selección de la muestra fue por conveniencia, debido a que no contábamos con un listado de personas jóvenes que vivieran en los municipios participantes ya que la principal forma en la que se diseminó la encuesta fue a través de estrategias en línea (ver sección sobre estrategias de recolección de la información).

Tabla 2. Tamaño de la muestra por municipio.

\begin{tabular}{|lc|}
\hline Municiplo & Número de particlpantes \\
\hline Cantamayec & 279 \\
\hline Chacsinkín & 291 \\
\hline Maní & 360 \\
\hline Mayapán & 349 \\
\hline Tixméhuac & 356 \\
\hline Yaxcabá & 361 \\
\hline Total & 1,996 \\
\hline
\end{tabular}

La encuesta fue totalmente anónima y abarcó el impacto de la pandemia en las juventudes en las siguientes dimensiones: educación, trabajo y economía familiar, salud mental, salud sexual y reproductiva y violencia. Además, incluimos un apartado para conocer sobre la disposición de las juventudes a vacunarse contra la COVID-19 y las razones por las cuáles no se vacunarían.

\section{Estrategias de recolección de la información}

Para disminuir el riesgo de contagio de COVID-19 y procurar proteger tanto a las encuestadoras como a las personas participantes, la principal estrategia de recolección de información fue la aplicación de encuestas en línea a través de la plataforma Survey Monkey. Para alcanzar el mayor número posible de personas en cada municipio, se contrató a una encuestadora por municipio. Las encuestadoras eran mujeres residentes en cada uno de los municipios seleccionados. Previo a la implementación del estudio, se capacitó a las encuestadoras sobre el objetivo del estudio, la plataforma de Survey Monkey, medidas de prevención de COVID-19 (en caso de que tuviéramos que salir a campo para realizar las encuestas), ética en la investigación y confidencialidad de datos e información personal. Antes del inicio del estudio, se les realizó un estudio de PCR para la detección de COVID-19, con su previo consentimiento. Además, se les brindó un kit de protección personal que consistió en cubrebocas, gel antibacterial, toallitas desinfectantes con cloro y caretas. Las encuestas fueron compartidas a través de las redes sociales de Abriendo Futuros y CCIS, a través de redes de juventudes que estuvieran presentes en los municipios participantes y a través de WhatsApp entre grupos de juventudes con los que las encuestadoras estuvieran en contacto en sus respectivos municipios.

En agosto 2021, se tomó la decisión de que las encuestadoras salieran a campo para buscar a más juventudes que quisieran participar en la encuesta. Se les brindó un teléfono celular y recargas telefónicas para que las juventudes pudieran utilizar ese celular para contestar 
la encuesta. Adicionalmente, se solicitó a las personas participantes que compartieran la liga a la encuesta entre sus amistades y contactos que pensaran les gustaría participar en la ésta (estrategia de bola de nieve).

\section{Mapeo de programas, decisiones y} medidas adoptadas por el gobierno estatal y los gobiernos municipales

El mapeo de programas, decisiones y medidas adoptadas por el gobierno del Estado de Yucatán y por los gobiernos municipales se llevó a cabo, por CCIS, a través de fuentes oficiales de información, disponibles y accesibles electrónicamente. En el caso del orden estatal se consultó el diario oficial, los boletines 0 comunicados de prensa y los videos publicados en redes sociales. En el caso del orden municipal se consultó el sitio electrónico del ayuntamiento, en los casos en los que existe, y redes sociales. El periodo de análisis fue entre enero y junio del 2021. Se identificaron y consideraron únicamente aquellos programas, decisiones - medidas que estuvieran relacionados con la emergencia sanitaria por COVID-19. La reactivación económica y/o la emergencia meteorológica. Cada una se clasificó por ámbito y tipo.

\section{Discusión participativa de los resultados}

Los resultados del estudio fueron compartidos a través de dos conversatorios. El primer conversatorio se llevó a cabo en octubre del 2021 con juventudes que viven en Yucatán. Un total de 20 personas participamos en este conversatorio.

Las opiniones y experiencias de las juventudes fueron sistematizadas y se incluyen como parte de los resultados del estudio en un apartado específico. Así mismo, con permiso previo de las personas participantes al conversatorio, se incluyen algunas citas textuales de sus experiencias durante la pandemia a lo largo del reporte, para ilustrar las necesidades y retos a los cuáles se han enfrentado en este período. El segundo conversatorio fue llevado a cabo con representantes de instituciones estatales de gobierno y organizaciones de la sociedad civil. Este segundo conversatorio se llevó a cabo a principios de noviembre del 2021 y participamos un total de 30 personas. Las instituciones estatales de gobierno que asisiteron al conversatorio fueron: La Secretaría de Educación, Secretaría de Salud, Comisión de Derechos Humanos del Estado de Yucatán, la Secretaría Estatal de las Mujeres, y la Secretaría Estatal de la Cultura. Las organizaciones de la sociedad civil participantes fueron: Fundación para la Equidad de Género, Apis Sureste A.C. Fundación para la Equidad, Unidad de Atención Psicológica, Sexológica y Educativa para el Crecimiento Personal, A.C. (Unasse), Ko'ox Tani Fundación para el desarrollo comunitario y la inclusión social, A.C. Red por los Derechos de la Infancia en México (Redim), CIAS por la Paz, A.C. Así también acudieron profesores y profesoras investigadores del Centro de Investigación Regional Dr. Hideyo Noguchi de la Univesidad Autónoma de Yucatán. Se contó también con la representación de autoridades municipales como Maní, Yaaxcabá y Cantamayec.

\section{Análisís de la información}

La investigadora principal descargó la base de datos de-identificada del sitio de internet Survey Monkey una vez finalizado el periodo de recolección de información. Se realizó un análisis descriptivo por separado para el grupo de personas adolescentes y el grupo de personas jóvenes (18 años y más). En cada grupo de edad se hicieron comparaciones entre hombres y mujeres para conocer si existían diferencias por género para las variables analizadas. Valores de p menores a 0.05 fueron considerados como significativos. Los resultados se analizaron por cada una de las dimensiones estudiadas, para facilitar la identificación de necesidades y comparar estas necesidades con los programas, medidas y decisiones adaptadas por el gobierno estatal y los gobiernos municipales. Los comentarios expresados por las juventudes en el conversatorio fueron sistematizados y se incluyen en el documento como parte de las estrategias adoptadas por las comunidades para hacer frente al impacto de la pandemia. Una vez analizadas las necesidades percibidas 
por las juventudes y los programas, medidas y decisiones implementadas por los gobiernos, se procedió a identificar las áreas de oportunidad o necesidades aún no atendidas. El listado de áreas de oportunidad se define en este reporte como recomendaciones y se encuentran en la sección final del documento.

\section{Consideraciones éticas}

Antes del inicio de la encuesta, se mostraba un consentimiento informado a las y los participantes, donde se explicaba el objetivo del estudio, las dimensiones preguntadas en la encuesta, la duración aproximada, beneficios y riesgos de participar en el estudio, la confidencialidad de su información y el uso de los resultados. También se explicitaba que todas las respuestas eran opcionales y que podían dejar de participar en la encuesta en el momento que así lo decidieran. La encuesta fue anónima, no se les solicitaban datos que pudieran identificarles para responder la encuesta. El estudio fue aprobado por el Comité de Ética e Investigación del Population Council

\section{Limitaciones del estudio}

La primera limitación del estudio es la estrategia de muestreo utilizada, ya que debido a que no fue una muestra representativa, los resultados no pueden ser generalizables al resto de las juventudes que viven en los municipios y en el estado. Sin embargo, los resultados dan luz sobre, por un lado, el impacto importante que ha tenido la pandemia en las juventudes desde su propia perspectiva y, por otro, guian algunas de las acciones de instituciones de gobierno y organizaciones que trabajan en estos y otros municipios de Yucatán, identificando áreas de oportunidad y estrategias que disminuyan el impacto a mediano y largo plazo de la pandemia para las juventudes indígenas en el estado.

Una segunda limitación es el sesgo de selección debido a que la encuesta fue una encuesta en línea. Es decir, es probable que se haya recabado más información de jóvenes con acceso a internet y tecnologías que permitieran contestar la encuesta y menos de jóvenes sin acceso a internet ni a estas tecnologías. Para disminuir este sesgo, se decidió que las encuestadoras salieran a campo a aplicar la encuesta con un celular que tuviera datos para acceder a internet. De esta manera, se pudo llegar a un mayor número de juventudes sin acceso a internet que probablemente, sin esta estrategia, no hubieran participado en la encuesta. Para futuras encuestas, es importante tomar en cuenta la limitante del acceso a internet y a tecnologías de la información en estos municipios con la finalidad de que todas las juventudes tengan la misma oportunidad de participar y expresar sus necesidades y preocupaciones.

Una tercera limitación es que la información relativa a los programas, decisiones y medidas refleja exclusivamente lo identificado en las fuentes revisadas. Esta no ha sido verificada en territorio. Lo que sucede en la práctica puede diferir sustancialmente. 


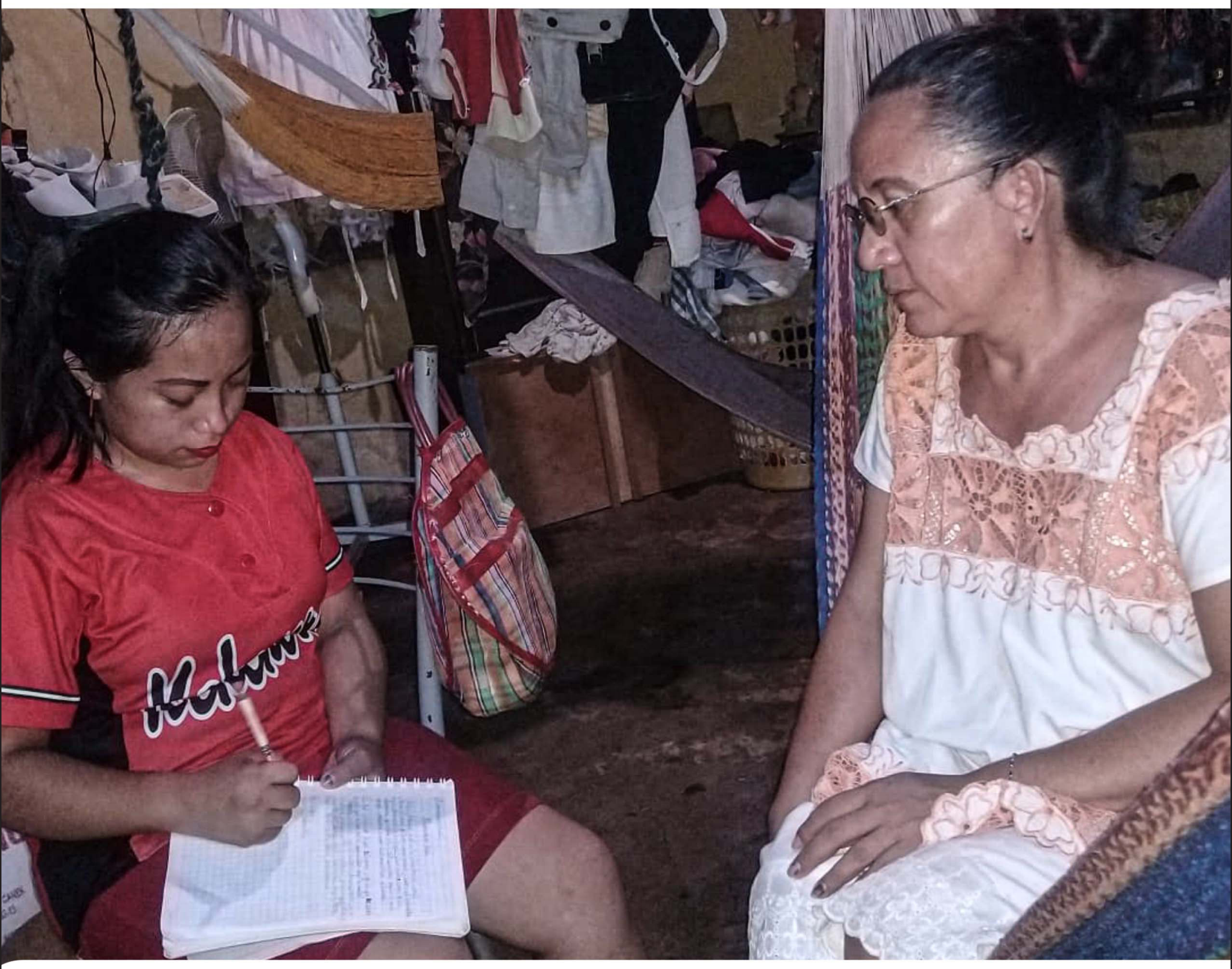

\section{RESULTADOS}


Perfil sociodemográfico de las

personas encuestadas

\section{Un total de \\ 1,925}

personas adolescentes y jóvenes

ingresaron a la encuesta, de las cuáles

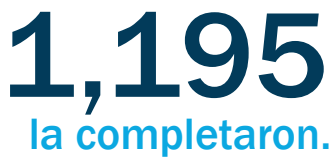

Del total de participantes que completaron la encuesta $27 \%(n=320)$ eran adolescentes de entre 14 y 17 años y 73\% eran personas jóvenes de entre 18 y 29 años ( $n=875$ ). $56 \%$ de las personas adolescentes y $60.5 \%$ de las jóvenes se identificaron como mujeres. Con respecto a la etnicidad, más del $90 \%$ de las personas en ambos grupos de edad se reconocieron como indígenas, de las cuáles 99\% se identificaron como parte del pueblo Maya y $65 \%$ reportaron hablar una lengua indígena (ver Tabla 3).

La mayoría de las y los adolescentes reportaron vivir en hogares biparentales (66\%) y aproximadamente 2 de cada 10 adolescentes vivía en un hogar con familia extendida. Al igual que para las personas adolescentes, entre las y los jóvenes de 18 a 24 años, la mayoría vivía en hogares biparentales (44\%). En este grupo, $7 \%$ vivía con su pareja y $11 \%$ vivía con pareja e hijos o hijas (sin diferencias significativas entre hombres y mujeres). En el caso del grupo de jóvenes de 25 a 29 años, la mayoría vivía con su pareja e hijos o hijas ( $44.3 \%$ de las mujeres y $38.9 \%$ de los hombres) (ver Tabla 3).

Respecto al estado civil, 98\% de las personas adolescentes reportaron ser solteras (con o sin pareja sentimental), sin diferencias significativas entre mujeres y hombres. En cuanto a las personas jóvenes, $68 \%$ de las mujeres y $78 \%$ de los hombres de entre 18 y 24 años reportaron ser solteros, mientras que $29 \%$ de las mujeres y $20 \%$ de los hombres en este mismo rango de edad reportó estar casado o viviendo en unión libre con su pareja. Para el caso de personas jóvenes de entre 25 y 29 años, la mayoría (70.5\% de las mujeres y 58.3\% hombres) reportó estar casada o viviendo en unión libre con su pareja (ver Tabla 3).

Para conocer un poco más sobre algunos indicadores de inequidades de género, se analizó la edad a la primera unión y el porcentaje de participantes que se casaron o unieron antes de los 18 años (uniones tempranas). Entre las personas participantes que se encontraban casadas o viviendo en unión libre ( $n=414)$, el promedio de edad a la primera unión fue 20 años (DE \pm 2.7 años), siendo este promedio significativamente menor entre las mujeres (19.7 años [DE \pm 2.6$]$ ) que entre los hombres (20.3 años [DE \pm 2.6$]$ ). De las 414 personas que se encontraban casadas o en unión libre al momento de la encuesta, 69 (16.6\%) se unió por primera vez antes de los 18 años, siendo este porcentaje significativamente mayor entre mujeres que entre hombres (76.8\% vs. $23.1 \%$; valor-p <0.05) (ver Tabla 1).

Programas, medidas y decisiones adoptadas por los gobiernos estatal

y municipales en el contexto de la emergencia sanitaria en el periodo de enero a junio de 2021

Se identificaron más de 922 decisiones o medidas adoptadas por el gobierno del estado de Yucatán entre enero y junio del 2021.

\section{$76 \%$}

de las medidas y decisiones identificadas son de carácter sanitario

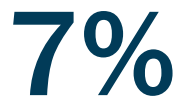

se relacionan con programas o acciones de apoyos y subsidios y

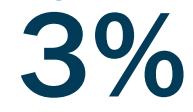

son de carácter presupuestal y de inversión. 


\begin{tabular}{|c|c|c|c|}
\hline & $\begin{array}{l}15-17 \\
\text { años } \\
n(\%)\end{array}$ & $\begin{array}{c}18-29 \\
\text { años } \\
n(\%)\end{array}$ & $\begin{array}{c}\text { Total } \\
n(\%) \\
N=1,195\end{array}$ \\
\hline $\begin{array}{l}\text { Edad promedio } \\
( \pm D E I)\end{array}$ & $15.7( \pm 0.96)$ & $23.5( \pm 3.4)$ & $21.3( \pm 4.5)$ \\
\hline Grupo de edad & $320(26.6)$ & 875 (73.2) & \\
\hline \multicolumn{4}{|l|}{ Género } \\
\hline Mujer & $179(55.9)$ & $530(60.6)$ & 709 (59.3) \\
\hline Hombre & 141 (44.1) & 345 (39.4) & $486(40.7)$ \\
\hline \multicolumn{4}{|l|}{ Municipio } \\
\hline Cantamayec & $19(5.9)$ & $177(20.2)$ & $196(16.4)$ \\
\hline Chacsinkín & $63(19.7)$ & $92(10.5)$ & $155(13.0)$ \\
\hline Maní & $40(12.5)$ & $94(10.7)$ & $134(11.2)$ \\
\hline Mayapán & $25(7.8)$ & $73(8.3)$ & $98(8.2)$ \\
\hline Tixméhuac & $80(25.0)$ & $245(28.0)$ & $325(27.2)$ \\
\hline Yaxcabá & $93(29.1)$ & $194(22.2)$ & $287(24.0)$ \\
\hline \multicolumn{4}{|l|}{ Etnicidad } \\
\hline $\begin{array}{l}\text { Se reconoce } \\
\text { como indigena }\end{array}$ & 291 (90.9) & 823 (94.1) & $1,114(93.2)$ \\
\hline $\begin{array}{l}\text { Habla una } \\
\text { lengua indigena }\end{array}$ & $166(57.0)$ & $557(67.7)$ & 723 (64.9) \\
\hline \multicolumn{4}{|l|}{ Tipo de hogar } \\
\hline Hogar biparental & 211 (65.9) & $278(31.8)$ & 489 (40.9) \\
\hline $\begin{array}{l}\text { Hogar (madre) } \\
\text { monoparental }\end{array}$ & $20(6.3)$ & $67(7.7)$ & $87(7.3)$ \\
\hline Familia extendida & $74(23.1)$ & $92(10.5)$ & $166(13.9)$ \\
\hline $\begin{array}{l}\text { Vive sola/o con } \\
\text { hijos/as }\end{array}$ & 0 & $10(1.1)$ & $10(0.84)$ \\
\hline Vive con pareja & $1(0.31)$ & $76(8.7)$ & $77(6.4)$ \\
\hline $\begin{array}{l}\text { Vive con pareja } \\
\text { e hijos/as }\end{array}$ & 0 & $250(28.6)$ & $250(20.9)$ \\
\hline Otro & $14(4.4)$ & $102(11.7)$ & $116(9.7)$ \\
\hline \multicolumn{4}{|l|}{ Estado civil } \\
\hline $\begin{array}{l}\text { Soltera/o } \\
\text { sin pareja }\end{array}$ & $247(77.2)$ & 265 (30.3) & $512(42.9)$ \\
\hline $\begin{array}{l}\text { Soltera/o } \\
\text { con pareja }\end{array}$ & $68(21.2)$ & $201(23.0)$ & 269 (22.5) \\
\hline $\begin{array}{l}\text { Casada/o o en } \\
\text { unión libre }\end{array}$ & $3(0.94)$ & $369(42.2)$ & $372(31.1)$ \\
\hline $\begin{array}{l}\text { Otro (separada/o, } \\
\text { divorciada/o } \\
\text { o viuda/o) }\end{array}$ & $2(0.62)$ & $30(3.4)$ & $32(2.7)$ \\
\hline \multicolumn{4}{|l|}{ Nivel educativo } \\
\hline Sin estudios & 0 & $1(0.11)$ & $1(0.08)$ \\
\hline $\begin{array}{l}\text { Primaria } \\
\text { incompleta }\end{array}$ & $6(1.9)$ & $19(2.2)$ & $25(2.1)$ \\
\hline $\begin{array}{l}\text { Primaria } \\
\text { completa }\end{array}$ & $40(12.5)$ & $35(4.0)$ & $75(6.3)$ \\
\hline $\begin{array}{l}\text { Secundaria } \\
\text { incompleta }\end{array}$ & $50(15.6)$ & $45(5.1)$ & $95(8.0)$ \\
\hline $\begin{array}{l}\text { Secundaria } \\
\text { completa }\end{array}$ & $141(44.1)$ & $177(20.2)$ & $318(26.6)$ \\
\hline $\begin{array}{l}\text { Bachillerato } \\
\text { incompleto }\end{array}$ & $68(21.3)$ & $120(13.7)$ & $188(15.7)$ \\
\hline $\begin{array}{l}\text { Bachillerato } \\
\text { completo }\end{array}$ & $7(2.2)$ & $294(33.6)$ & 301 (25.2) \\
\hline $\begin{array}{l}\text { Carrera técnica } \\
\text { incompleta }\end{array}$ & $1(0.31)$ & $19(2.2)$ & $20(1.7)$ \\
\hline $\begin{array}{l}\text { Carrera técnica } \\
\text { completa }\end{array}$ & 0 & $37(4.2)$ & $37(3.1)$ \\
\hline $\begin{array}{l}\text { Licenciatura } \\
\text { incompleta }\end{array}$ & $5(1.6)$ & $45(5.1)$ & $50(4.2)$ \\
\hline $\begin{array}{l}\text { Licenciatura o } \\
\text { posgrado } \\
\text { completo }\end{array}$ & 0 & $81(9.3)$ & 81 (6.8) \\
\hline
\end{tabular}

También se identificó que 85\% de las decisiones - medidas adoptadas en este periodo se relacionan con la emergencia sanitaria, el 14\% con la reactivación económica y el $1 \%$ con las emergencias meteorológicas.

Los programas, medidas y decisiones identificadas en el mapeo se dirigen a distintas poblaciones objetivo: 1) poblaciones sujetas titulares de derechos (e.j. personas jóvenes, personas con discapacidad, familias en condición de vulnerabilidad, entre otros grupos); 2) poblaciones definidas por la actividad económica o educativa que realizan (e.j. estudiantes, docentes, pescadoras, ganaderas, restauranteras, entre otros grupos); 3) personas empresarias y emprendedoras; 4) personal médico; 5) población de ciertos municipios, colonias, pueblos o barrios; 6) personas viajeras a Estados Unidos; y, 7) personas que forman parte de los rangos etarios definidos para la vacunación. También se observó que la cobertura geográfica de las decisiones y medidas varía. En ciertos casos están dirigidas a todo el Estado, en otros a ciertos municipios, regiones, colonias, pueblos o barrios.

No se identificaron programas 0 acciones dirigidos específicamente a personas adolescentes y jóvenes como principal población objetivos. Al contrario, se identificaron programas que excluyen de manera específica a población adolescente que se encuentra en edad legal para trabajar (15-17 años). Otro hallazgo fue que los programas o acciones identificadas en el mapeo están dirigidos a personas residentes en el estado, por lo cual excluye a personas en movilidad (e.j. personas migrantes internas de retorno a sus estados y personas migrantes mexicanas de retorno desde Estados Unidos). Tampoco identificamos algún programa de subisidios o apoyos específicamente dirigido a población indígena. 
Impactos multidimensionales

de la pandemia

\section{EDUCACIÓN}

Como se describió en la introducción, una de las dimensiones de la vida de las juventudes que se vió más impactada por la pandemia fue la educación. En esta dimensión, nos interesaba conocer, desde la propia voz de las juventudes, cómo la pandemia había impactado su decisión de seguir en la escuela, su acceso a las actividades escolares y tareas, si recibieron apoyos por parte del gobierno para seguir estudiando, qué estrategias habían implementado las familias y comunidades para que las y los adolescentes y jóvenes pudieran seguir estudiando y cuáles medidas y decisiones había implementado el gobierno para disminuir el impacto de la pandemia en esta dimensión.

\section{Acceso a tecnologías de la información}

Debido a que, durante el primer año y medio de la pandemia, la principal vía para poder seguir estudiando y tener acceso a las actividades escolares y tareas fueron las tecnologías de la información, nos interesaba conocer qué porcentaje de las juventudes encuestadas tenía acceso a dichas tecnologías.

Existe poco acceso a tecnologías de la información en los municipios, sobre todo entre mujeres. Cómo se observa en la Figura 2 , para todos los grupos de edad y en ambos géneros, las tecnologías a las cuáles las y los participantes tenían más acceso fueron a celulares inteligentes y televisión. Un porcentaje considerablemente menor de participantes tenía acceso a computadoras y tabletas. Para estas dos herramientas digitales, se observa un menor acceso a ellas entre mujeres jóvenes (1829 años) comparadas con los hombres en los mismos rangos de edad. Con respecto al acceso a internet, identificamos que $62.3 \%$ del total de las y los participantes no tenían acceso a WiFi privado en sus hogares. Un mayor porcentaje de mujeres adolescentes, comparadas con hombres adolescentes, identificaron tener acceso a WiFi en sus hogares $(42.4 \%$ vs. $36.1 \%)$, y un menor porcentaje de mujeres jóvenes (18+ años) identificaron tener acceso, comparado con los hombres en este mismo

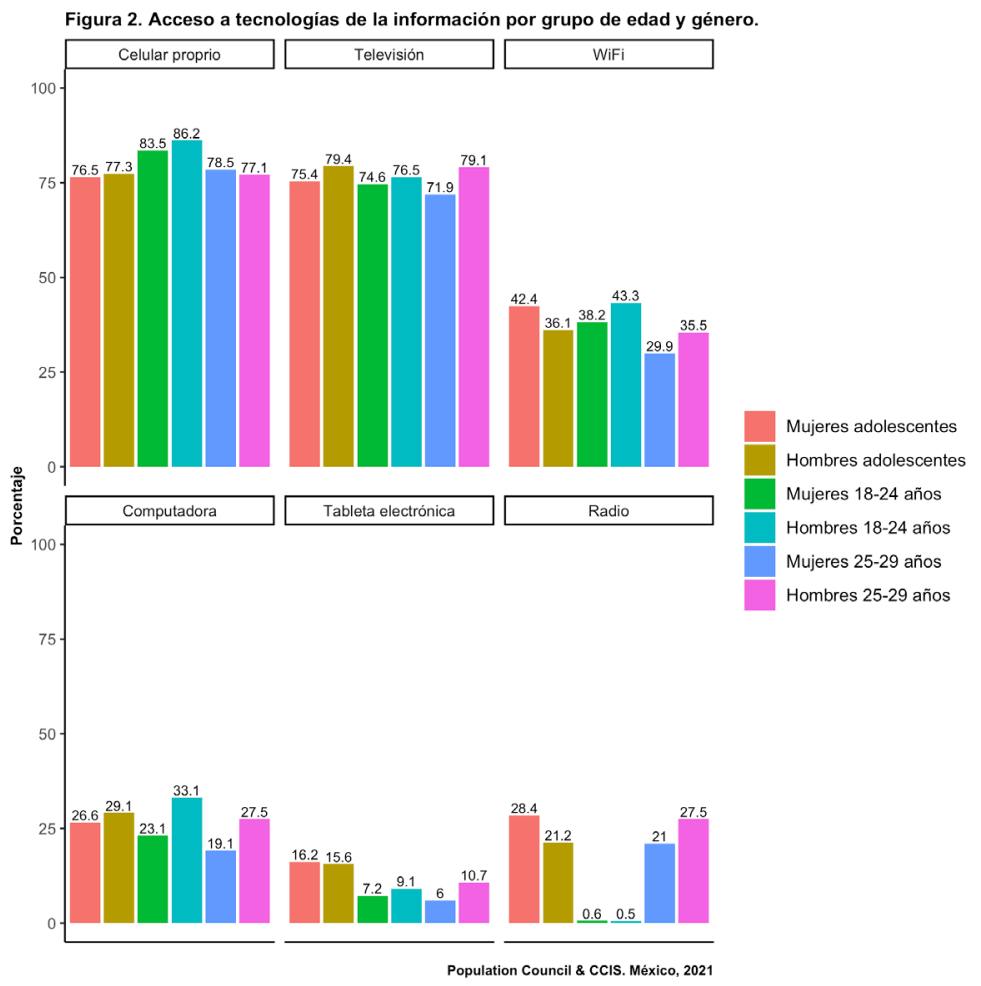


grupo de edad (34.9\% vs. 40\%). Es importante mencionar que ninguna de estas diferencias fue estadísticamente significativa, sin embargo, los datos muestran una tendencia hacia un menor acceso a tecnologías de la información entre mujeres en estos municipios.

"También una parte muy interesante fue lo económico, porque muchas de ellas [mujeres adolescentes] no tenían acceso a la economía de poder tener un aparato electrónico (como celular o computadora), entonces varias de ellas, dos de ellas, no pudieron seguir sus estudios. Pero este año, lo bueno rescatando de este 2021, buscaron como opciones de trabajar y estudiar".

Mujer joven, Cantamayec

\section{Deserción escolar}

Un mayor número de personas adolescentes que de personas jóvenes se encontraban estudiando al momento de la encuesta. $88.7 \%$ de las personas adolescentes, 31\% de las personas jóvenes de entre 18 y 24 años y $4.3 \%$ de las personas jóvenes de entre 25 y 29 años asistían a la escuela antes del inicio de la pandemia. Entre el total de personas que no se encontraba estudiando, el promedio de la edad a la que dejaron de estudiar fue a los 16.9 años (DE \pm 2.9 años), sin diferencias significativas entre mujeres y hombres.

En todos los grupos de edad se identificaron personas que dejaron de estudiar desde el inicio de la pandemia. Sin embargo, este porcentaje fue significativamente mayor entre personas participantes que tienen entre 18 y 24 años. De las personas que asistían a la escuela antes del inicio de la pandemia, $2.8 \%$ de las y los adolescentes ya no se encontraban estudiando al momento de la encuesta, al igual que $12.8 \%$ de las personas jóvenes de entre 18 y 24 años y $2.4 \%$ de las personas de entre 25 y 29 años. En ninguno de los grupos de edad se identificaron diferencias significativas para este indicador entre mujeres y hombres (ver Figura 3).

Entre las y los participantes que abandonaron la escuela después del inicio de la pandemia, las tres principales razones por las cuáles dejaron la escuela fueron haber terminado el último grado de estudio que querían estudiar (55\%), tener que empezar a trabajar y/o no tener dinero para seguir estudiando (21.4\%) y por la pandemia de COVID-19 (21.4\%).

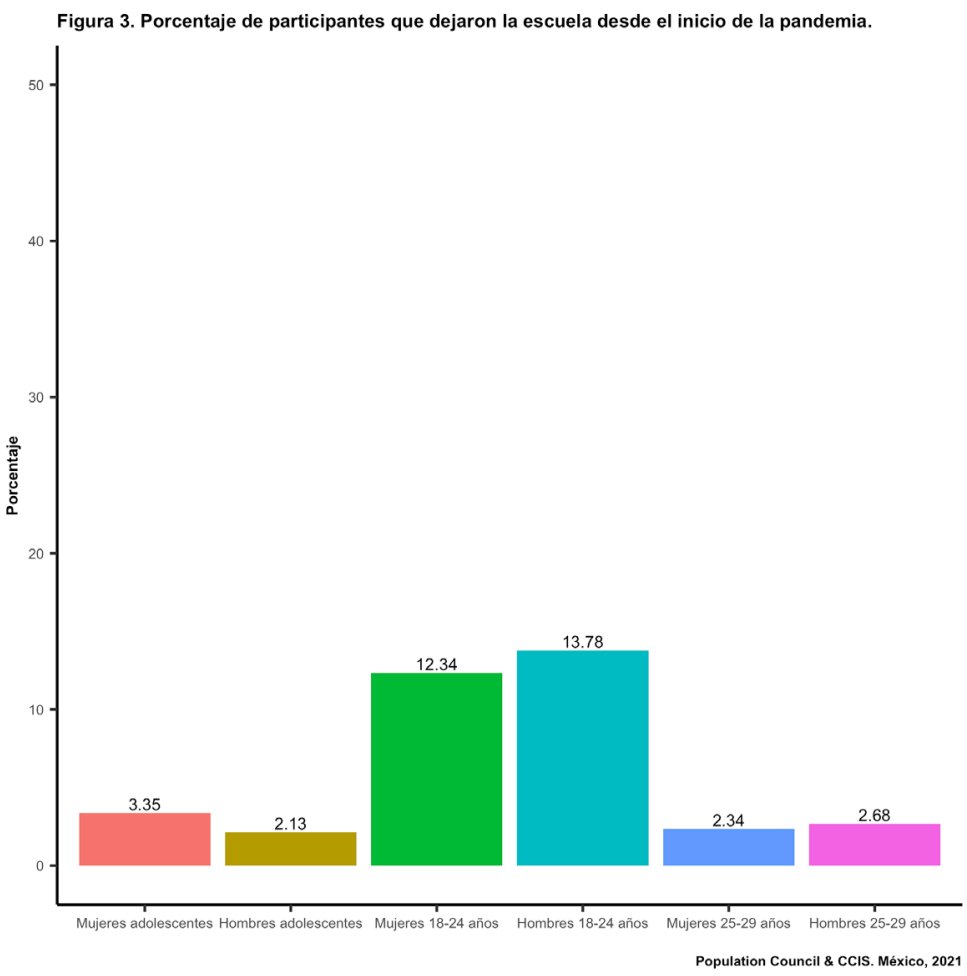


"Yo he participado con las adolescentes, he vivido su vida, he tenido sus experiencias de que, por ejemplo, en lo económico a veces no tienen qué comer porque quedó desempleado su papá o la mamá no tiene trabajo. Entonces, lo que optaron muchas familias, los adolescentes, dejaron la parte de educación, dejaron de estudiar y fueron a trabajar de domésticas. Regresaban cada mes, cada dos meses. Por eso le digo que la parte de educación y económico fue lo más afectado".

Mujer joven, Chacsinkín

\section{Retos encontrados para tomar clases durante el cierre de las escuelas}

Las principales tecnologías de la información utilizadas por las y los participantes durante el cierre de las escuelas fueron el WhatsApp y el uso de plataformas en línea. De las personas adolescentes ( $n=284$ ) que se encontraban estudiando al momento de la encuesta, $82.7 \%$ reportó que durante el cierre de las escuelas tomaba las clases y realizaba las actividades escolares a través de WhatsApp, 50.3\% a través de clases en línea, 14\% por medio de instrucciones impresas que les brindaba la escuela, $4.5 \%$ por televisión y $2.1 \%$ por You Tube. Entre las personas jóvenes que seguían estudiando al momento de la escuela ( $n=176)$, la mayoría siguió tomando sus clases a través de plataformas en línea (83.5\%) y $47.7 \%$ a través de WhatsApp (ver Figura 4).

"Cuando la pandemia inicia, las personas de mi comunidad no sabían utilizar a la perfección las tecnologías. El WhatsApp solo se utilizaba para mandar mensajes. No sabían como descargar archivos, como enviarlos. Entonces sí se vió como unas complicaciones al principio, en los principios de los meses sobre la educación en los niños. Muchos empezaron a no entregar tareas, no sabían como iba a estar esta parte de entregas, calificaciones y todo eso".

Mujer joven, Maní

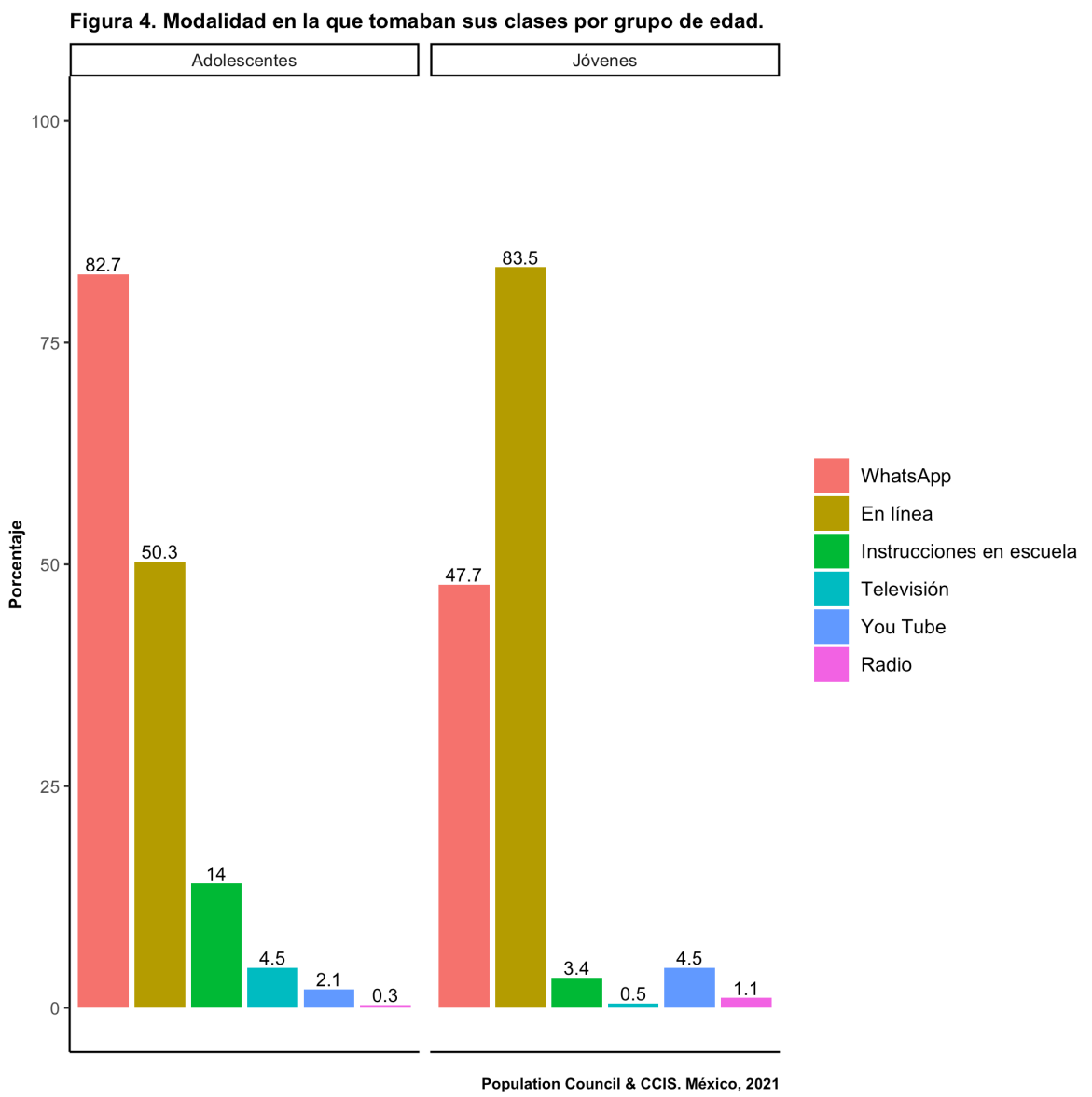


Las personas participantes que se encontraban inscritas en la escuela al momento de la encuesta identificaron diversos retos con relación a sus actividades escolares, sobre todo asociados a no poder acceder a sus clases y tareas y dificultades para entender las actividades escolares sin ayuda de terceras personas. A las personas participantes que seguían estudiando al momento de la encuesta se les preguntó en una escala del 1 al 5 (1 completamente en desacuerdo y 5 completamente de acuerdo) si consideraban que durante el cierre de las escuelashabían: 1) tenido los recursos necesarios para acceder y enviar las tareas; 2) entendido sus clases; $y, 3$ ) entendido sus tareas. Entre las y los adolescentes, $36.9 \%$ de las mujeres y $32.2 \%$ de los hombres estaba en desacuerdo con que habían tenido los recursos necesarios para acceder y enviar sus tareas, $41.9 \%$ de las mujeres y $25.2 \%$ de los hombres estaba en desacuerdo con que habían entendido sus clases (valor-p <0.05) y $41.6 \%$ de las mujeres y $24.6 \%$ de los hombres estaba en desacuerdo con que habían entendido sus tareas (valor-p <0.05). Entre las personas jóvenes (18+ años), 31.3\% de las mujeres y
$30.4 \%$ de los hombres estaban en desacuerdo con que habían tenido los recursos para acceder $\mathrm{y}$ enviar sus tareas, $30.3 \%$ de las mujeres $\mathrm{y}$ $24.6 \%$ de los hombres estaban en desacuerdo con que habían entendido sus clases y $29 \%$ de las mujeres y $27.5 \%$ de los hombres estaban en desacuerdo con que habían entendido las tareas (ver Figura 5).

\begin{abstract}
"Siento que no es lo mismo acoplarse a estar en la virtualidad y que te manden trabajo y tú no llegas a comprender. Siento que es una de las cosas que en lo personal a mí me ha afectado. Se me complica en algunas ocasionas entender algunas cosas que se nos asigna. Entonces es muy... es realmente difícil en lo personal...".
\end{abstract}

Mujer joven, Mayapán

Aproximadamente $10 \%$ de las personas adolescentes y jóvenes que participaron en la encuesta reportaron haber pensado seriamente en abandonar la escuela desde el inicio de la pandemia. A las y los participantes les

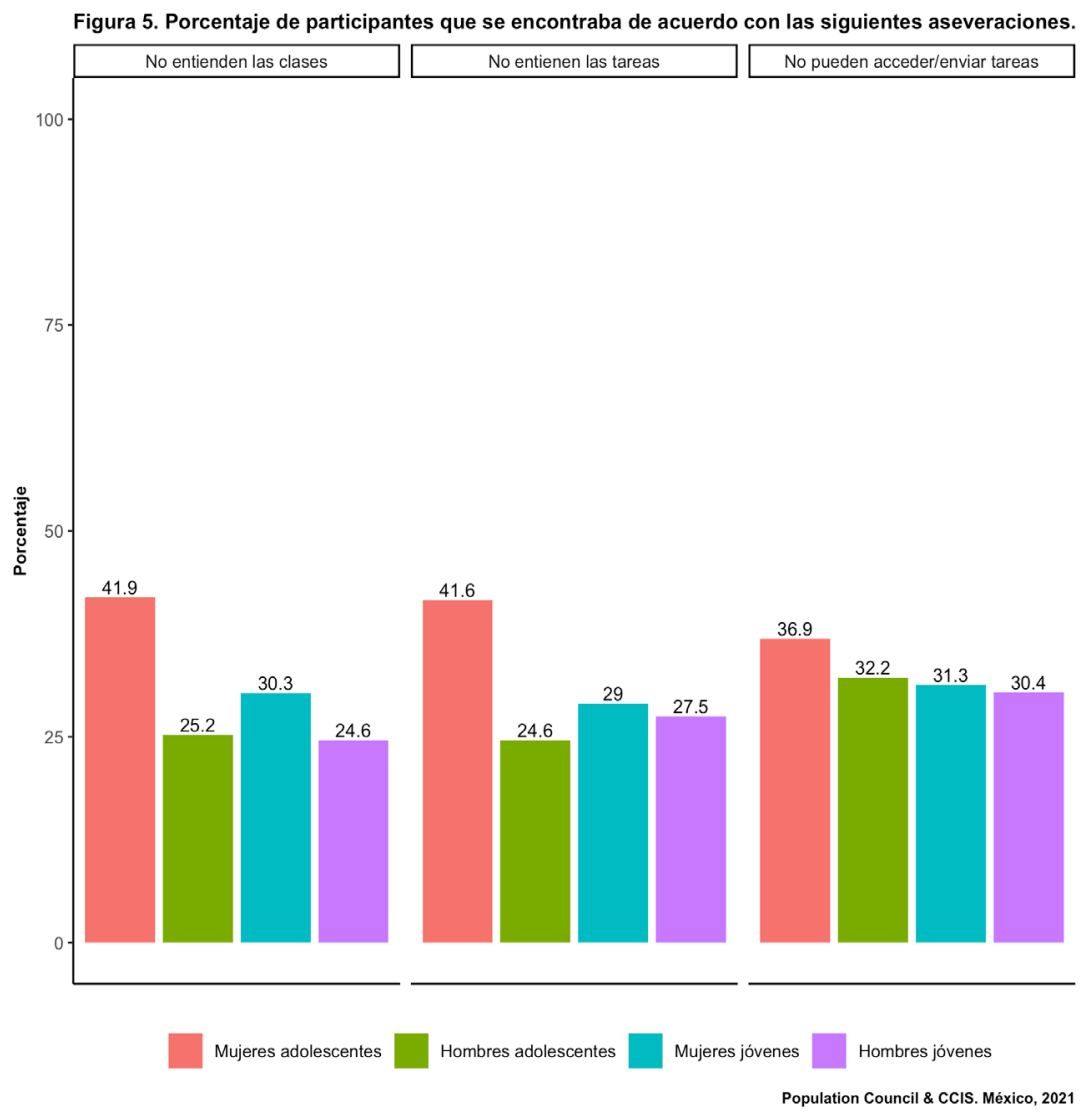


preguntamos si desde el inicio de la pandemia habían pensado seriamente en abandonar la escuela. Del total de adolescentes que seguían estudiando al momento de la encuesta, 8.1\% estaba pensando en abandonar la escuela $(9.5 \%$ de las mujeres y $6.3 \%$ de los hombres; valor-p $=0.28$ ). Entre las personas jóvenes, 14.2\% estaban pensando seriamente en abandonar la escuela $(15.8 \%$ de las mujeres y $12.9 \%$ de los hombres; valor-p $=0.23$ ). La principal razón por la que estaban pensando en abandonar la escuela, en todos los grupos de edad y tanto en mujeres como en hombres, fue porque sentían que desde que empezó la pandemia no estaban aprendiendo lo mismo ( $58 \%$ de las mujeres y $64.7 \%$ de los hombres; valor-p $=0.47$ ).

\section{Acceso a programas y apoyos del gobierno para seguir estudiando}

El programa Aprende en Casa fue la principal estrategia del gobierno para disminuir el impacto de la pandemia durante el cierre de las escuelas. Debido a esto, nos interesaba conocer si las personas encuestadas habían escuchado sobre el programa y si lo habían utilizado.

Del total de adolescentes que seguían estudiando al momento de la encuesta, $12.3 \%$ no habían escuchado sobre el programa $(13.4 \%$ de las mujeres y $11 \%$ de los hombres), $67 \%$ habían escuchado sobre el programa pero no lo habían utilizado $(63.7 \%$ de las mujeres y $70.9 \%$ de los hombres) y $19.7 \%$ lo había utilizado ( $22 \%$ de las mujeres y $16.5 \%$ de los hombres). En el grupo de jóvenes que seguían estudiando al momento de la encuesta, $14.8 \%$ no había escuchado sobre el programa $(9.9 \%$ de las mujeres y $22.9 \%$ de los hombres), $71.6 \%$ había escuchado sobre el programa pero no lo había utilizado $(75.3 \%$ de las mujeres y $65.7 \%$ de los hombres) y $11.9 \%$ había utilizado el programa (12.9\% de las mujeres y $11.4 \%$ de los hombres).

Con respecto a otros apoyos del gobierno para seguir estudiando, entre el total de participantes que seguían estudiando al momento de la encuesta,

\section{$55 \%$}

mencionó haber recibido un apoyo gubernamental para seguir estudiando en el ciclo escolar 2020-2021.

Un mayor porcentaje de adolescentes reportó recibir un apoyo encomparación con las personas jóvenes (63\% vs. 42\%). Los principales tipos de apoyos recibidos fueron becas para seguir estudiando (48\%) y en segundo lugar útiles escolares (9\%).

\section{Perspectivas de adolescentes y jóvenes sobre las estrategias implementadas en las comunidades para apoyarles en sus estudios}

Durante el conversatorio con personas jóvenes, las y los participantes reafirmaron que la educación era una de las principales dimensiones afectadas por la pandemia. La falta de acceso a internet y a tecnologías de la información fueron los principales desafíos identificados, así como la comprensión de tareas y actividades escolares. Otro desafío compartido durante el conversatorio es que las madres percibían que no tenían el conocimiento suficiente para explicar las actividades y tareas escolares a sus hijos e hijas, lo cual les causaba un sentimiento de preocupación y estaban a la expectativa de que las escuelas reabrieran pronto.

Una de las estrategias para que las personas adolescentes y jóvenes pudieran seguir con sus estudios durante el cierre de las escuelas fue la compra de ceulares por parte de las familias para que sus hijas e hijos pudieran tomar las clases en línea o a través de WhatsApp. Es importante mencionar que este gasto extra se hizo en un momento dónde la pandemia impactaba de manera importante la economía de las familias en estas comunidades. Otra estrategia fue la de compartir el gasto de la instalación de WiFi privado entre dos o más familias y compartir el internet entre ellas. Por otro lado, en algunas 
comunidades las y los docentes imprimían los materiales necesarios para las clases y actividades y dejaban copias en los cibercafés. De esta manera, las familias de las y los estudiantes podían ir a recoger las copias y no tenían que gastar en impresiones. Por último, se mencionó como en una comunidad docentes y familias se organizaban una vez al mes para entregarles el material, explicar las actividades a desarrollar durante ese periodo y resolver dudas.

Programas, medidas y decisiones con respecto a educación implementadas por los gobiernos estatal y municipales

Se identificaron un total de 9 programas, medidas y decisiones enfocados a la educación. De este total, 2 de los 9 programas fueron implementados por el gobierno estatal y 7 programas fueron implementados por el gobierno federal. Los dos programas implementados a nivel estatal fueron el de Impulso Escolar y la entrega de mobiliario, equipamiento, mantenimiento y ampliación de espacios educativos.

El programa Impulso Escolar tiene el objetivo de que las personas que viven con ingresos por debajo de la línea mínima de bienestar y con rezago educativo incrementen su ingreso monetario y accedan a políticas compensatorias en materia educativa a través de la entrega de paquetes escolares a niñas y niños. La población objetivo de este programa son estudiantes de escuelas primarias y secundarias públicas a cargo de la Secretaría de Educación y de los Centros de Atención Mútiple y estudiantes de las escuelas primarias a cargo del Consejo Nacional de Fomento Educativo.El objetivo del segundo programa es el de mejorar la infraestructura de los espacios educativos en el estado.

Dentro de los principales hallazagos para el tema educativo, se encontró que estos programas tienden a enfocarse en estudiantes de escuelas públicas y solo de educación básica. Por lo que, excluyen a estudiantes de escuelas privadas (pero cuyas familias tienen ingresos por debajo de la línea mínima de bienestar) y estudiantes de niveles educativos considerados como educación obligatoria. Además, no se identificaron programas, decisiones o medidas enfocados a prevenir o reducir la deserción escolar o promover la reinserción escolar, y tampoco programas, decisiones o medidas que abordaran las necesiadades específicas de algunos grupos de juventudes (e.j. mujeres y juventudes indígenas).

El objetivo del segundo programa es el de mejorar la infraestructura de los espacios educativos en el estado. Dentro de los principales hallazagos para el tema educativo, se encontró que estos programas tienden a enfocarse en estudiantes de escuelas públicas y solo de educación básica. Por lo que, excluyen a estudiantes de escuelas privadas (pero cuyas familias tienen ingresos por debajo de la línea mínima de bienestar) y estudiantes de niveles educativos considerados como educación obligatoria. Además, no se identificaron programas, decisiones o medidas enfocados a prevenir o reducir la deserción escolar o promover la reinserción escolar, y tampoco programas, decisiones o medidas que abordaran las necesiadades específicas de algunos grupos de juventudes (e.j. mujeres y juventudes indígenas).

\section{TRABAJO Y ECONOMÍA FAMILIAR}

Las medidas de mitigación y distanciamiento social implementadas para disminuir los contagios por COVID-19 tuvieron un impacto económico importante en las familias mexicanas. Durante varios meses, negocios considerados como no esenciales tuvieron que cerrar sus puertas al público y diversas empresas redujeron el número de personas trabajadoras, lo cual llevó a un incremento en las tasas de desempleo entre población considerada como económicamente activa. Con este estudio nos interesaba conocer el impacto de la pandemia en la economía familiar de las y los jóvenes participantes, así como las decisiones y medidas adoptadas por los gobiernos estatal y municipales para disminuir el impacto económico de la pandemia en Yucatán. 


\section{Juventudes y empleo}

Un porcentaje importante de adolescentes y jóvenes se encontraban trabajando al momento de la encuesta, siendo el porcentaje de personas empleadas mayor entre hombres jóvenes que entre mujeres jóvenes. Del total de participantes, $24 \%$ de adolescentes y $55 \%$ de jóvenes de entre 18 y 29 años se encontraba trabajando al momento de la encuesta. Entre las personas jóvenes, un mayor porcentaje de hombres comparados con las mujeres tenían un trabajo (69.9\% vs. $44.9 \%$; valor-p<0.05). Ocho de las 74 personas adolescentes que se encontraban trabajando tenían 14 años. Entre las y los participantes que se encontraban trabajando, 9\% no recibía un pago por el trabajo realizado, sin diferencias significativas por género.

Se observa la reproducción de estereotipos y roles de género en el tipo de trabajo realizado por los hombres y mujeres participantes en el estudio. El tipo de trabajos realizados por las y los participantes difiere con base en el género. Los tres principales trabajos realizados por los hombres fueron albañilería (26\%), trabajo en la milpa (15\%) y como empleados (10\%). Los tres principales trabajos realizados por las mujeres fueron trabajo doméstico (28\%), venta de alimentos y otros productos (26\%) y como empleadas (19\%) (ver Figura 6).

La pandemia impactó la vida laboral de las personas participantes, disminuyendo los ingresos que perciben, las horas de trabajo realizadas y la demanda de productos que venden. Al preguntar a las y los participantes que se encontraban trabajando sobre cómo la pandemia había afectado su trabajo, 46.7\% mencionó que desde el inicio de la pandemia sus ingresos habían disminuido, con un mayor porcentaje de hombres que identificó este impacto comparado con las mujeres $(49.5 \%$ vs. $44.7 \%$; valor-p<0.05) y $15 \%$ identificó que habían disminuido sus horas de trabajo (16\% de los hombres vs. $13 \%$ de las mujeres; valor-p<0.05). Finalmente, 9\% mencionó que desde el inicio de la pandemia había disminuido la demanda de los productos que venden $(11 \%$ de las mujeres vs. $6 \%$ de los hombres; valor-p<0.05).

Las juventudes participantes perciben que desde el inicio de la pandemia es mucho más difícil como joven conseguir trabajo. El 85\% del total de participantes consideró que es más o mucho más difícil como persona jóven conseguir trabajo desde el inicio de la pandemia en comparación con antes de la pandemia. No se observan diferencias significativas entre los grupos de edad y entre mujeres y hombres para este indicador.

\section{Trabajo en el hogar no remunerado en los hogares de las juventudes}

Las personas participantes perciben que son las mujeres las que dedican más horas al día a trabajos del hogar no remunerados y que esta situación no cambió a partir del inicio de la pandemia. En todos los grupos de edad, tanto las mujeres como los hombres perciben que efectivamente son las mujeres quienes dedican más horas al día a trabajos del hogar no remunerados. Por ejemplo, las y los participantes mencionaron que sus mamás dedican un promedio de 6.6 horas al día a trabajos del hogar no remunerados, mientras que sus papás dedican un promedio de 3.9 horas al día. La mayoría de las y los participantes (44\%70\% dependiendo del grupo de edad y género) perciben que desde el inicio de la pandemia el trabajo del hogar no remunerado lo siguieron realizando en mayor medida las mujeres.

\section{Economía familiar de las juventudes durante la pandemia}

La pandemia impactóla economía familiar de las juventudes participantes, sobre todo asociado a la disminución de ingresos en el hogar y pérdida de trabajo. Siete de cada 10 participantes identificaron que por lo menos una persona en su hogar (incluyéndose) ganaban menos al momento de la encuesta de lo que ganaban antes del inicio de la pandemia, sin diferencias significativas entre hombres y mujeres. Además, $25 \%$ identificaron que por lo menos una persona en su hogar (incluyéndose) había perdido su principal fuente de ingreso desde el inicio de la 


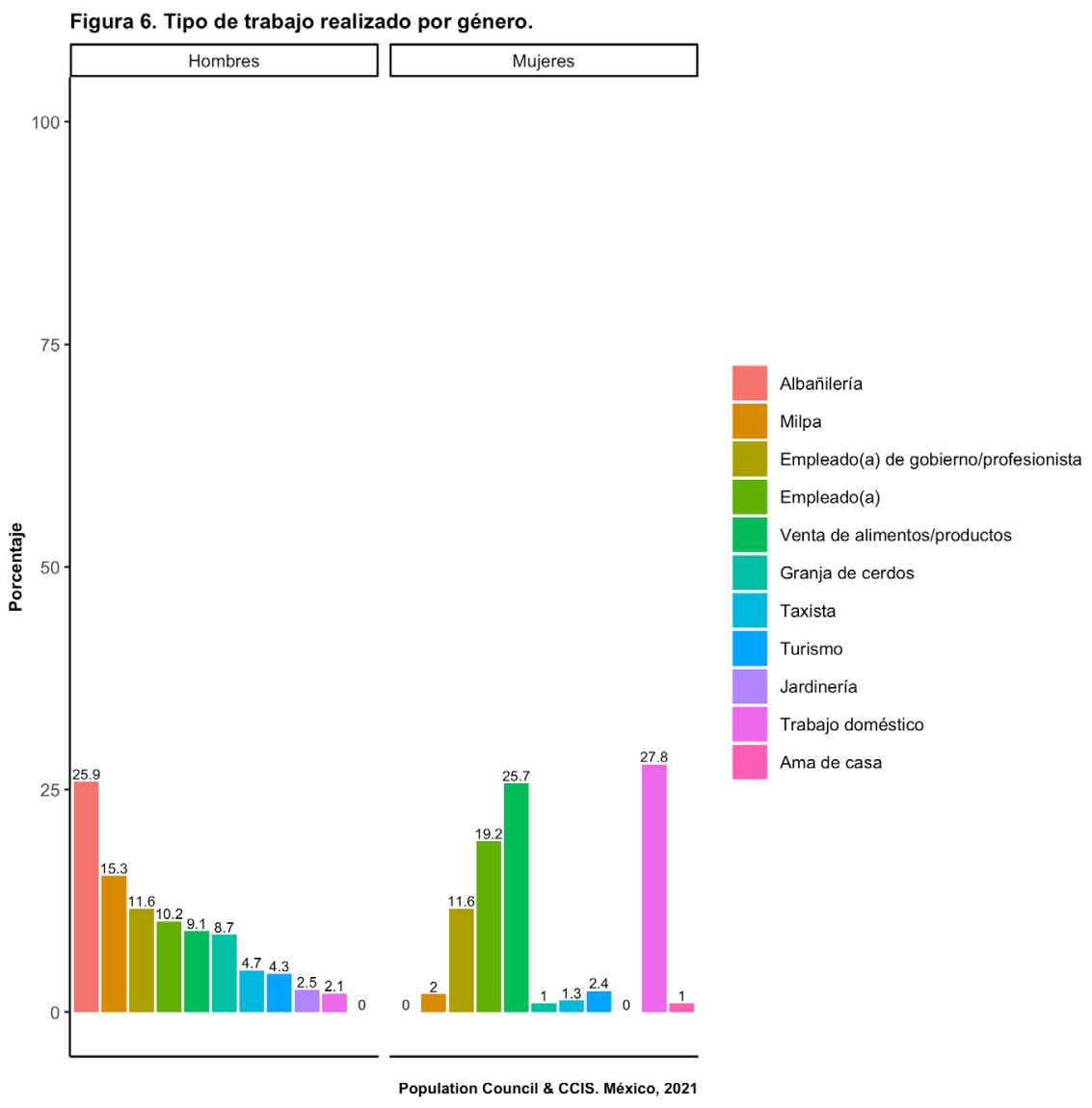

pandemia, con un mayor porcentaje de mujeres que identificó esto comparadas con los hombres (30\% vs. $18 \%$; valor-p<0.05).

Las y los participantes percibieron que desde el inicio de la pandemia los ingresos familiares son insuficientes para cubrir las necesidades básicas de sus hogares. El 25\% de las personas adolescentes (30\% de las mujeres y $20 \%$ de los hombres; valor-p<0.05) y $19 \%$ de las personas jóvenes (18\% de mujeres y $20 \%$ de hombres; valor-p $=0.38$ ) percibe que el ingreso familiar es insuficiente con respecto a lo que el hogar necesita gastar para sostener a la familia (e.j., para comprar comida, pagar la renta, comprar útiles escolares y medicinas, entre otras necesidades básicas) (ver Figura 7).

\section{Inseguridad alimentaria entre las} juventudes desde el inicio de la pandemia

Entre 3\% y $5 \%$ de las personas participantes no consumieron su comida, desayuno o cena por lo menos en una ocasión en el mes previo a la realización de la encuesta debido a que no había suficiente comida para todos los miembros de la familia. En la encuesta se les preguntó a las personas participantes si en el mes previo a la encuesta habían dejado de consumir su desayuno, comida $\mathrm{y} / \mathrm{o}$ cena debido a que no había suficiente comida para todas las personas en el hogar. Entre las personas adolescentes, $2.8 \%$ de las mujeres y $5 \%$ de los hombres mencionó no haber consumido algún alimento durante el mes previo a la encuesta (valor-p = 0.25). Entre las personas jóvenes, $5.3 \%$ de las mujeres y $4 \%$ de los hombres mencionó no haber consumido algún alimento durante el mes previo a la encuesta (valor-p $=0.33$ ). La mediana de veces que dejaron de consumir su desayuno, comida o cena en el mes previo a la encuesta fue de 4 veces para mujeres (rango: 3 - 5 veces) y de 5 veces para hombres (rango: 2 - 7 veces). 


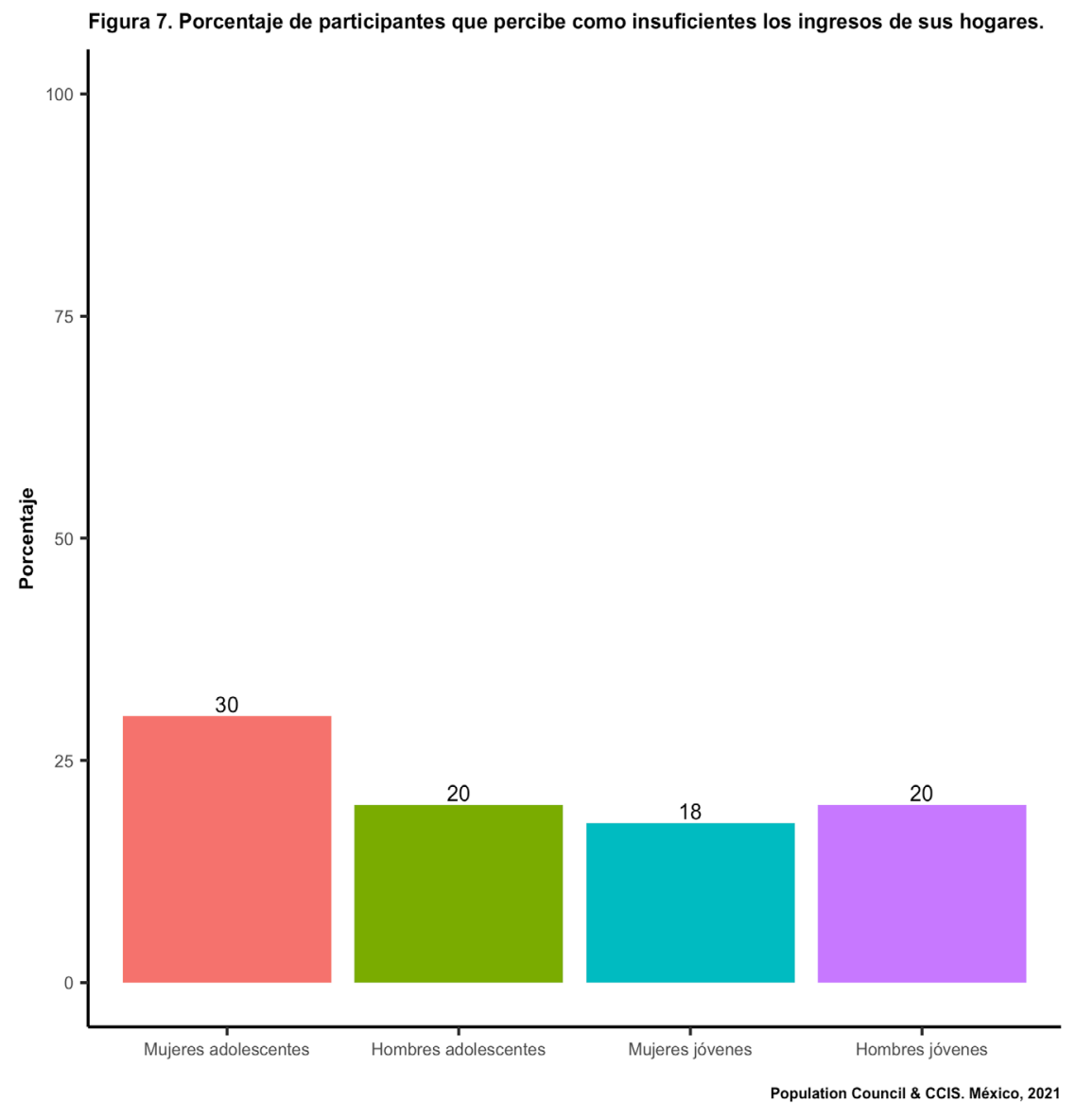

\section{Migración y pandemia en los municipios participantes}

Casi 2 de cada 10 participantes mencionaron que algún familiar había migrado fuera de la comunidad o de regreso a la comunidad desde el inicio de la pandemia, siendo el principal motivo para migrar la pérdida de trabajo. El $19 \%$ del total de participantes en la encuesta reportó que un familiar que vivía con ellas o ellos antes del inicio de la pandemia migró fuera de su municipio desde el inicio de la pandemia. Las principales razones por las cuáles las personas decidieron migrar fueron para buscar trabajo (77\%) y porque les ofrecieron un trabajo (9\%). Por otro lado, $16 \%$ de las personas participantes reportó que un familiar regresó a vivir con ellas y ellos a sus hogares desde el inicio de la pandemia. Las principales razones por las que sus familiares retornaron a la comunidad fueron por pérdida de trabajo (71\%), por una situación de salud (13\%) y para reunirse nuevamente con la familia (8\%).

\section{Acceso a programas y apoyos del gobierno para disminuir el impacto económico de la pandemia}

Desde el inicio de la pandemia, $26 \%$ de las personas adolescentes y jóvenes habían recibido un recurso, bien o servicio por parte de instituciones del gobierno para disminuir el impacto económico de la pandemia. Para el caso de las personas jóvenes, un menor porcentaje de mujeres comparadas con los hombres mencionaron haber recibido estos apoyos (23\% vs. $29 \%$; valor-p<0.05) (ver Figura 8 ).

Los principales apoyos recibidos por las y los participantes fueron programas de apoyo alimentario (70\%), apoyos económicos directos $(16 \%)$ y apoyos para unidades productivas, campesinas e insumos rurales (14\%). Solo $5 \%$ del total de personas participantes mencionó haber recibido algún tipo de seguro de desempleo desde el inicio de la pandemia. 


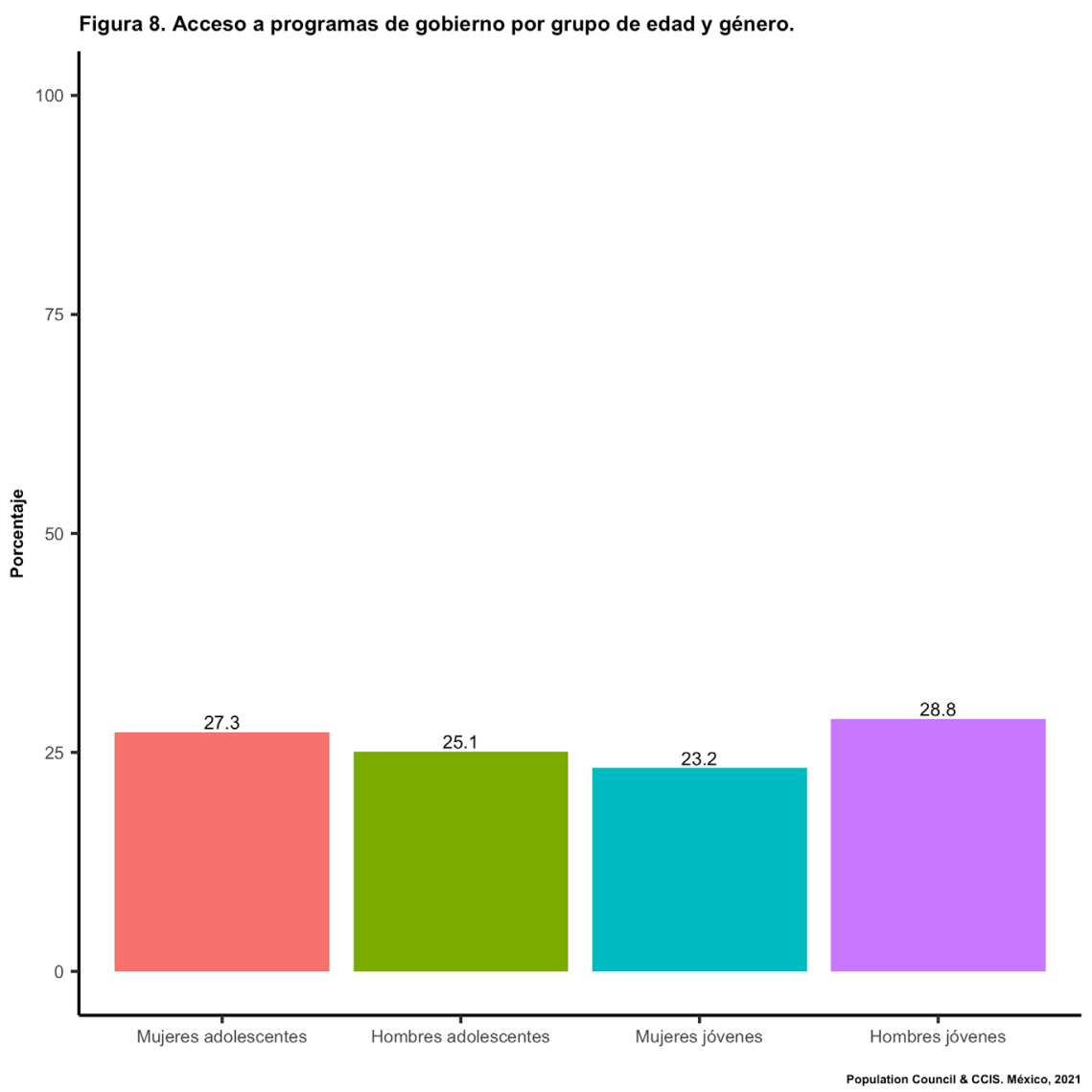

"Hablando de los programas de gobierno, había jóvenes que no podían acceder a esos programas. Hubo un mal manejo de los programas también en las comunidades.

Sobre todo con esto del seguro del desempleado, que cuando se dieron en ambas comunidades se priorizaron a las personas que, se puede decir así, que fueron como a conveniencia. Entonces sí notamos esta desigualdad que, conociendo el contexto de la comunidad, de las personas que realmente lo necesitaban, se les ofreció a personas que consideramos, no solo yo porque hasta otras personas lo consideraron, que no lo necesitaban".

Mujer joven, Maní.

Perspectivas de adolescentes y jóvenes sobre las estrategias implementadas para enfrentar el impacto económico de la pandemia en sus comunidades

Durante el conversatorio con juventudes llevado a cabo en octubre del 2021, las personas jóvenes mencionaron las estrategias que se habían implementado en sus comunidades para enfrentar el impato económico de la pandemia. Entre las estrategias mencionadas estuvieron el diseño y venta de artesanías en las comunidades, el incremento en el uso de redes sociales como un medio para la venta de productos, así como la creación de grupos específicos en las redes con este propósito, la creación de huertos en casa para la venta de productos y para el consumo en casa de los alimentos cultivados y la implementación de ferias locales en los municipios para la venta de los productos generados por las personas que viven en estos municipios, fomentando así la venta y consumo de productos locales.

Programas, medidas y decisiones para disminuir el impacto económico de la pandemia implementadas por los gobiernos estatal y municipales

A nivel estatal, se identificaron dos programas enfocados a la seguridad alimentaria, el Programa 
de Asistencia a la Comunidad en Vulnerabilidad y Discapacidad y el Programa de Seguridad Alimentaria. Por otro lado, se identificaron 20 programas, medidas y decisiones enfocadas al empleo y reactivación económica, como por ejemplo el seguro de desempleo, cuya población objetivo son personas de entre 18 y 65 años. Por último, se identificaron diversos programas para el apoyo a personas emprendedoras y para el empresariado (e.g., Microyucs), uno especialmente dirigido a mujeres, así como programas dirigidos a la protección del empleo turístico, la activación empresarial y artesanal, programas de apoyo al campo y desarrollo rural y programas de apoyo a la actividad apícola y a la producción de fibra de henequén.

En el análisis realizado se observó que los programas en este tema excluyen de manera explícita y directa a las y los adolescentes de entre 15 y 17 años (que en México se consideran en edad legal para trabajar), sin justificar dicha exclusión con criterios objetivos, razonables ni proporcionales. Por lo tanto, solo las personas jóvenes que tienen 18 años o más pueden beneficiarse de estos programas, pese a que conforme al marco jurídico mexicano son jóvenes las personas de 12 a 29 años y pueden trabajar las mayores de 15.

También es importante mencionar que no se identificaron programas específicamente dirigidos a personas que fueran migrantes de retorno, migrantes nacionales o internacionales, poblaciones desplazadas, refugiadas 0 solicitantes de asilo, es decir, los programas están específicamente dirigidos a personas residentes del estado, sin que se justifique dicha exclusión. Finalmente, tampoco identificamos algún programa de subisidios 0 apoyos específicamente dirigido a población indígena.

Durante el conversatorio, las personas jóvenes comentaron que el Programa de Seguridad Alimentaria (identificados como despensas) fue el que más llegó a las comunidades y fue distribuido por igual entre todas las familias. . También se mencionó que hay desconocimiento o desconfianza ante el programa de desempleo. Se percibe que este no es distribuido entre las personas que más lo necesitan, si no que hay otros criterios no objetivos para su distribución entre las personas de las comunidades. También se percibe que el trámite no se puede hacer en el mismo municipio, que toma mucho tiempo y la gran cantidad de documentos que solicitan para realizarlo.

\section{SALUD MENTAL}

La salud mental de las juventudes se ha visto y se verá gravemente impactada por la pandemia. En este estudio, nos interesaba conocer más sobre cómo las juventudes se han sentido y cuáles son los principales sentimientos que han experimentado en este casi año y medio desde el inicio de la pandemia, así como los programas, decisiones y medidas adoptadas por los gobiernos estatal y municipales relacionados con la salud mental de las juventudes en el estado.

\section{Principales sentimientos asociados a la pandemia}

Las personas adolescentes y jóvenes expresaron más sentimientos negativos que positivos al pensar en la pandemia. Para comprender mejor cómo se han sentido las personas adolescentes y jóvenes desde el inicio de la pandemia, les pedimos que escribieran los tres principales sentimientos que les venían a la mente cuándo pensaban en la pandemia. En todos los grupos de edad y tanto para mujeres como para hombres, los principales sentimientos reportados fueron preocupación (14.4\%), tristeza (12.1\%) y estrés (11.8\%). En general, las mujeres reportaron sentirse más estresadas y tristes y los hombres más preocupados o "bien".

\section{Aislamiento, estrés y ansiedad durante la pandemia}

Un mayor porcentaje de mujeres adolescentes y jóvenes se han sentido aisladas, comparadas con los hombres. Entre las personas adolescentes que participaron en la encuesta, $12.6 \%$ reportaron haberse sentido aisladas casi siempre o siempre desde el inicio de la 
pandemia, siendo este porcentaje mayor entre mujeres que entre hombres (19.2\% vs. 4.3\%; valor-p<0.05). Entre las personas jóvenes, $16.2 \%$ reportó haberse sentido aislada desde el inicio de la pandemia, igualmente con un mayor porcentaje de mujeres que se sintieron así, comparadas con los hombres (19.4\% vs. 11.4\%; valor-p<0.05) (ver Figura 9).

"Como soy mamá, al mismo tiempo soy ama de casa, soy maestra, era doctora, era enfermera. Este... era el momento en el que el estrés de todo... Porque no puedes decirle a los hijos "espérate un momento, ahorita te atiendo".... Es un estrés que hasta las mamás, me imagino, hasta ellas se sienten sofocadas de tanto trabajo y realmente sí afecta en lo, ¿cómo se llama?, en lo mental. Además de eso también afectaba en lo emocional. Porque si hay un momento en que los amigos te hablan, te saludan. En esto de la pandemia se olvidaron de que existías. Como que te quedaste en ese punto en el que nadie está para ti y tú debes estar para todos".
Las mujeres reportaron haberse sentido más estresadas desde el inicio de la pandemia, comparadas con los hombres. Para entender mejor que tan estresadas se habían sentido las personas participantes desde el inicio de la pandemia, se les solicitó indicar en una escala del 1 al 10 (1 era nada estresadas y 10 muy estresadas) qué tan estresadas se habían sentido desde el inicio de la pandemia. Entre las personas adolescentes, la mediana del puntaje de la escala fue de 3 puntos (rango: 1 - 7), siendo esta mediana significativamente mayor entre las mujeres (5 puntos; rango: 1 - 8) que entre los hombres (2 puntos; rango: 1 - 6). La mediana del grado de estrés entre personas jóvenes fue mayor que para el caso de las personas adolescentes (5 puntos; rango: 2 - 8), y al igual que para las y los adolescentes, la mediana del grado de estrés fue significativamente mayor entre las mujeres jóvenes (5 puntos; rango: 2 - 8) que entre los hombres jóvenes (4 puntos; rango: 1 - 7).

Mujer joven, Mayapán.

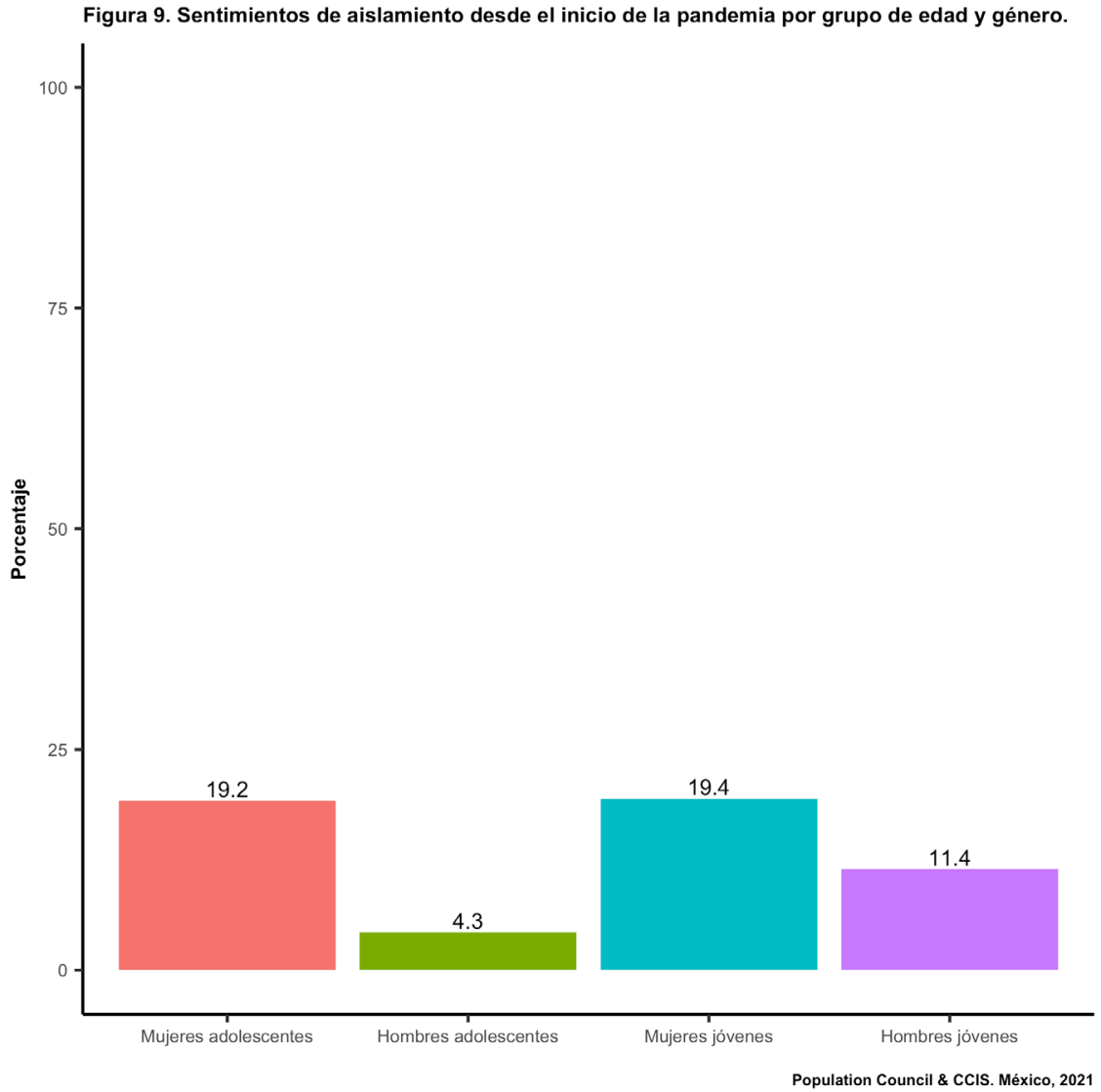


Las personas adolescentes y jóvenes han implementado diversas estrategias para manejar los sentimientos de estrés y ansiedad ocasionados por la pandemia. Las principales estrategias mencionadas por las y los participantes para manejar los sentimientos de ansiedad y estrés debidos a la pandemia fueron ayudar más con las actividades y tareas en sus hogares, hacer deporte, dibujar, escuchar música, hablar con sus amistades y familiares, y aprender nuevas actividades. Solamente cinco personas participantes mencionaron que acuden a terapia psicológica o toman medicamentos recetados. El $7 \%$ del total de participantes mencionaron que no sabían qué hacer para manejar los sentimientos de ansiedad y estrés.

En el conversatorio las personas jóvenes nos compartieron otras estrategias que habían implementado o de las cuáles habían sido parte y que habían impactado positivamente en su salud mental durante la pandemia. Por ejemplo, nos compartieron sobre cómo el formar parte de grupos de WhatsApp con personas que tienen intereses similares a los suyos tuvo un impacto positivo. El ejemplo que nos compartieron estaba relacionado particularmente con plantas, semillas y jardinería.

Programas, medidas y decisiones adoptadas por el gobierno estatal y gobiernos locales con respecto a la salud mental de las personas jóvenes

Tanto el gobierno federal como el gobierno estatal pusieron a disposición de la población líneas telefónicas gratuitas con el objetivo de orientar y ofrecer apoyo emocional a la población. A nivel federal, también se identificó el programa ConTacto Joven, implementado por el Instituto Mexicano de la Juventud a través del cuál, personas jóvenes capacitadas brindan atención telefónica a la salud mental a las juventudes en México.

Aún cuando la perspectiva cultural en programas de prevención y atención de la salud mental no fue una línea identificada en las fuentes oficiales de información, se identificó que en algunas ocasiones se publica información de los programas en lengua Maya, pero solo de manera escrita. Sin embargo, esta medida no es recurrente ni permanente. Sería de interés en futuros estudios analizar si estos programas tienen la capacidad de atender a personas que no hablan español a través de intérpretes o personas bilingües.

Sin embargo, no se identificaron medidas o decisiones adicionales para prevenir o atender problemas de salud mental en el estado. En el conversatorio con personas jóvenes, ninguna de ellas identificó programas, medidas o decisiones en sus municipios relacionados con la prevención o atención de problemas de salud mental en población joven.

\section{SALUD SEXUAL Y REPRODUCTIVA}

En este apartado nos interesaba conocer más sobre el uso de métodos anticonceptivos por las personas participantes, acceso a servicios de salud sexual y reproductiva, embarazo durante la pandemia y algunos aspectos sobre cómo las y los jóvenes han experimentado su sexualidad desde el inicio de la pandemia, así como los programas, decisiones y medidas adoptadas por los gobiernos estatal y municipales relacionados con la salud sexual y reproductiva de las juventudes en el estado. Debido a que del total de personas adolescentes solamente 19 reportó que ya habían iniciado su vida sexual, el análisis de esta sección se realizó solamente con participantes jóvenes (18+ años).

\section{Uso de métodos anticonceptivos}

El principal método anticonceptivo utilizado por las personas jóvenes que participaron en la encuesta fue el condón masculino. Del total de jóvenes que ya habían iniciado su vida sexual al momento de la encuesta ( $n=514$ ), $73 \%$ de las mujeres y $80 \%$ de los hombres se encontraba utilizando un método anticonceptivo al momento de la encuesta. El principal método anticonceptivo utilizado tanto por mujeres como por hombres fue el condón masculino (29.4\% 
de las mujeres y 51.8\%) de los hombres. Un porcentaje menor de mujeres reportaron estar utilizando el implante subdérmico (8\%), pastillas anticonceptivas (6.6\%), e inyecciones (6.1\%). Los métodos que se reportaron con menor frecuencia fueron uso de espermicidas $(0.2 \%)$, el anillo vaginal $(0.8 \%)$, parches anticonceptivos $(2.7 \%)$, el condón femenino (3.3\%), la anticoncepción de emergencia (AE) (3.9\%) y el Dispositivo Intrauterino (3.9\%) (ver Figura 13).

Un porcentaje tanto de mujeres como hombres reportaron utilizar métodos que han demostrado menor eficacia para la prevención de embarazos no deseados. $6.6 \%$ de las mujeres y $4.9 \%$ de los hombres reportaron estar utilizando el coito interrumpido como método anticonceptivo y $3 \%$ de las mujeres y $2.8 \%$ de los hombres reportaron utilizar el método del ritmo (ver Figura 10).

\section{Acceso a métodos anticonceptivos}

Tres de cada diez personas participantes tuvieron acceso a información sobre métodos anticonceptivos desde el inicio de la pandemia. Les preguntamos a las personas jóvenes sobre si habían tenido acceso a información sobre métodos anticonceptivos desde el inicio de la pandemia. Del total de mujeres y hombres jóvenes que ya habían iniciado su vida sexual, 32.5\% de las mujeres y $33.3 \%$ de los hombres habían tenido acceso a información sobre métodos anticonceptivos desde el inicio de la pandemia. El acceso a esta información lo obtuvieron principalmente a través de personal de salud (personal médico, personal de enfermería y promotoras y promotores comunitarios).

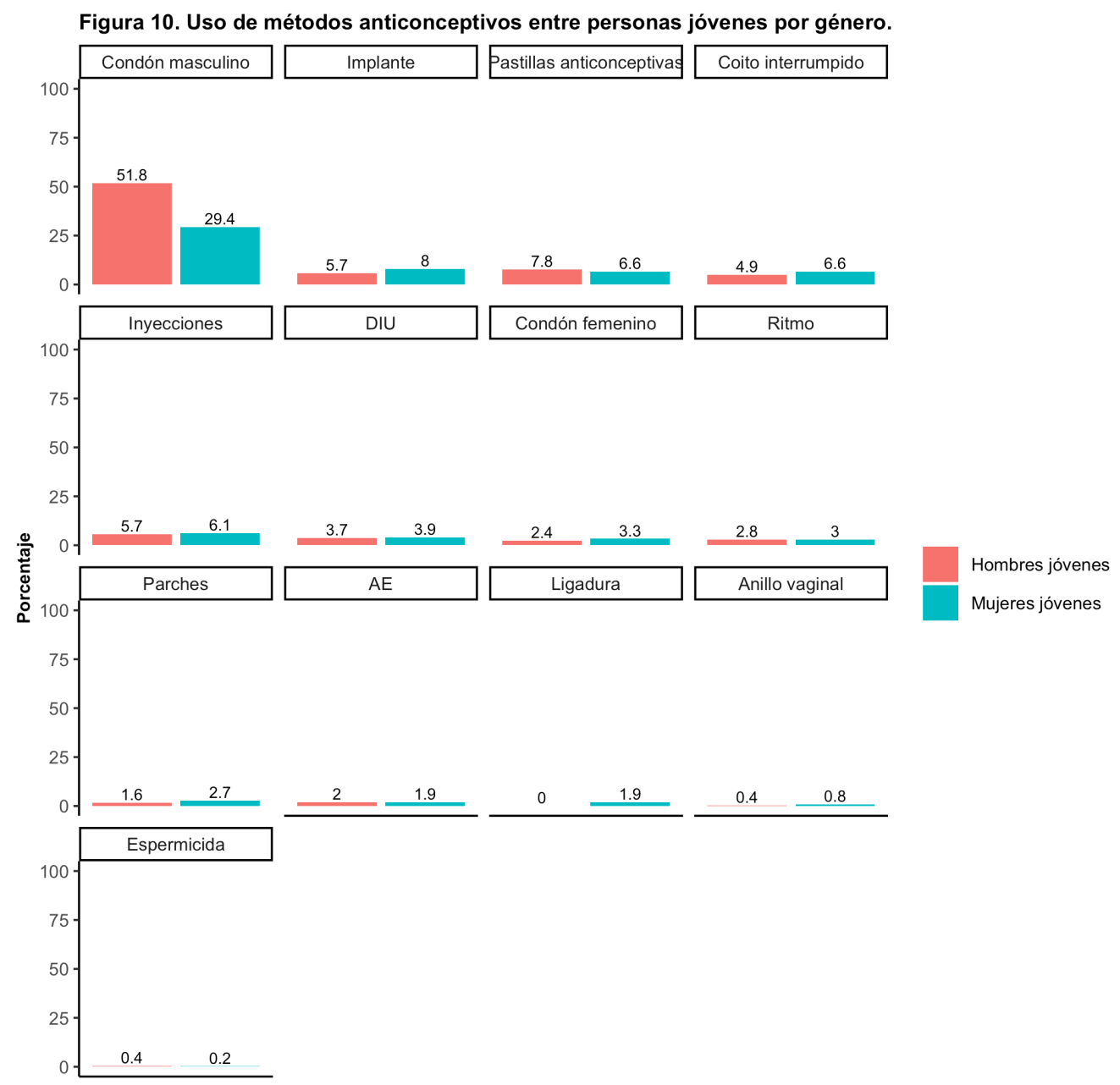

Population Council \& CCIS. México, 2021 
Casi 9 de cada 10 personas participantes que intentaron acceder a un método anticonceptivo desde el inicio de la pandemia lograron acceder a ellos. Sin embargo, un porcentaje importante accedió a ellos a través de la compra directa en farmacias. Del total de mujeres jóvenes que ya habían iniciado su vida sexual, 22\% intetaron acceder a un método anticonceptivo desde el inicio de la pandemia, de las cuales 89\% pudieron acceder al método anticonceptivo que querían, 9.5\% pudieron acceder, pero a un método anticonceptivo distinto al que querían, y solamente una mujer reportó no haber podido acceder al método anticonceptivo. La mayoría de las mujeres accedieron a los métodos en una unidad de salud (50\%) y 39\% a través de la compra directa en farmacia. Para el caso de los hombres, $30.7 \%$ intentó acceder a un método anticonceptivo durante la pandemia, de los cuáles 93\% pudieron acceder al método anticonceptivo que querían y $7 \%$ accedieron, pero a un método anticonceptivo distinto al que querían. La mayoría de los hombres jóvenes (64\%) accedió a estos métodos en una farmacia y $28 \%$ en una unidad de salud.

\section{Acceso a otros servicios de salud sexual y reproductiva}

El servicio de salud sexual y reproductiva al que buscaron más acceso las y los jóvenes desde el inicio de la pandemia fueron servicios relacionados con la atención prenatal. Del total de mujeres jóvenes que ya habían iniciado su vida sexual, 53.5\% intentó acceder a servicios de atención prenatal desde el inicio de la pandemia, $40.2 \%$ a servicios de orientación sobre métodos anticonceptivos, $27.8 \%$ a servicios de atención del parto y $23.2 \%$ a pruebas diagnósticas de infecciones de transmisión sexual. Un menor porcentaje intentó acceder a servicios para el tratamiento de infecciones de transmisión sexual (10.6\%) y servicios para la interrupción del embarazo (9\%). En el caso de los hombres, 36.8\% intentaron acceder (ellos o sus parejas) a servicios de atención prenatal, $24 \%$ a pruebas diagnósticas de infecciones de transmisión sexual, $19.2 \%$ a orientación de métodos anticonceptivos y $8 \%$ a tratamiento de infecciones de transmisión sexual (ver Figura 11).

"En cuanto a la salud sexual y reproductiva ahí si el acceso, antes o después de pandemia aquí en mi comunidad ha sido un poco complicado acceder primero a los métodos anticonceptivos y a la información,

porque hay muchos tabúes relacionados a eso que tú como joven o cómo adolescente que vayas a preguntar sobre métodos anticonceptivos o estés preguntando información sobre este tema es malo. Es lo primero que me dicen, que es malo y te genera... te hace tener este sentimiento, no se si es un sentimiento, como de vergüenza de preguntar las cosas, las dudas que tienes".

Mujer joven, Maní

Casi tres de cada diez personas jóvenes mencionaron que percibían que su acceso a servicios de salud sexual y reproductiva se habían visto afectados y $7 \%$ que se habían visto muy afectados desde el inicio de la pandemia. muy afectados desde el inicio de la pandemia. Para conocer la opinión de las y los jóvenes sobre el impacto de la pandemia en el acceso a servicios de salud sexual y reproductiva, les preguntamos si percibían que desde el inicio de la pandemia el acceso a estos servicios se había visto afectado en cierta medida (e.j., cancelaron alguna(s) cita(s) o les ofrecieron la consulta médica por teléfono) o muy afectado (e.j., no pudieron tener acceso a una prueba diagnóstica o a un tratamiento, o cancelaron todas las citas que tenían programadas). Para el caso de las mujeres, de las 111 mujeres que intentaron acceder a alguno de los servicios de salud sexual y reproductiva preguntados, $32.4 \%$ mencionaron que se habían visto afectados en cierta medida y $6.3 \%$ que se habían visto muy afectados. En el caso de los hombres, $17.9 \%$ identificaron que su acceso a estos servicios se había visto afectado en cierta medida y $8.9 \%$ que se había visto muy afectado. 
Figura 11. Porcentaje de jóvenes que buscaron acceder a servicios de salud sexual y reproductiva.

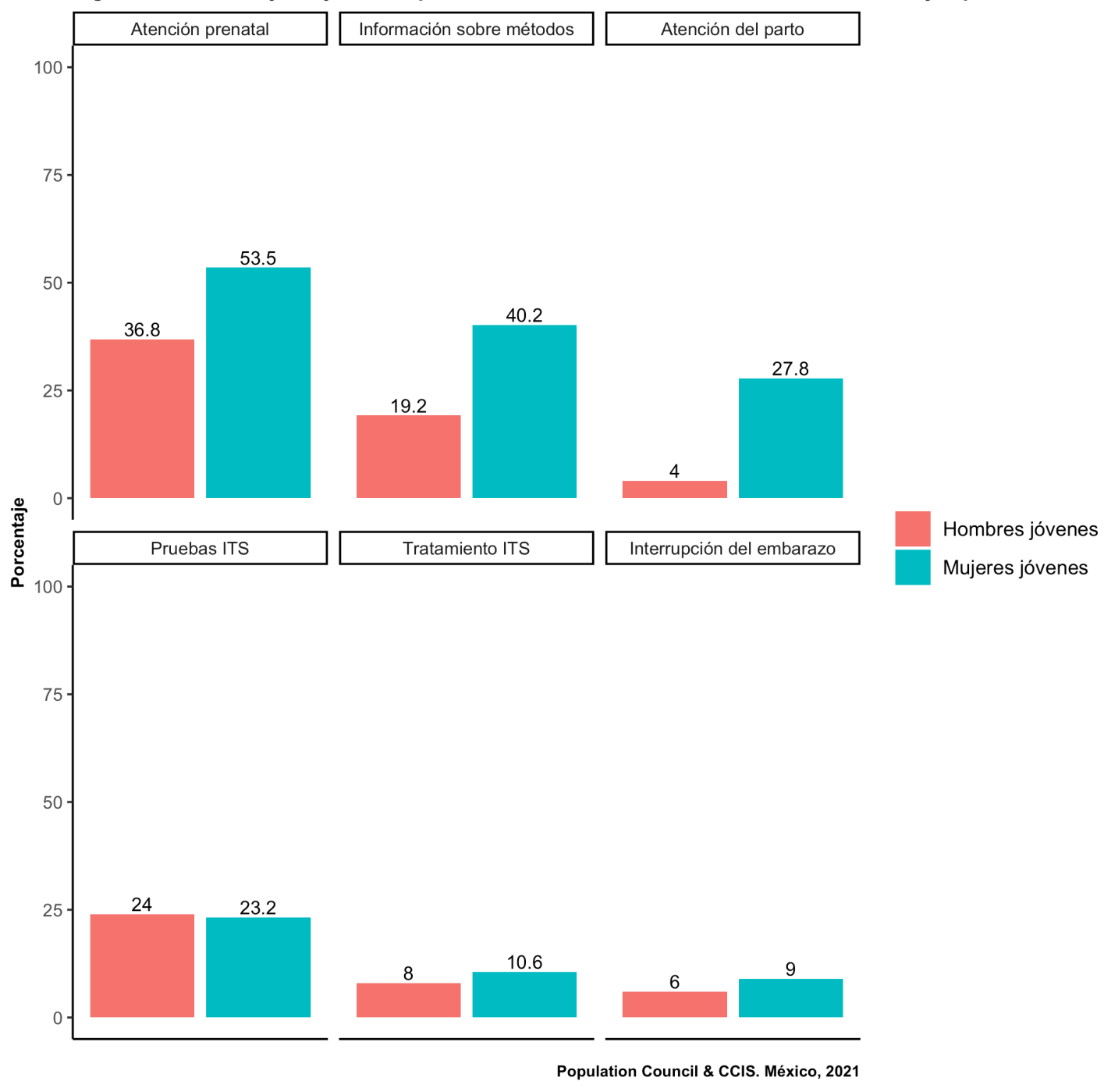

\section{Embarazo, mujeres jóvenes y CoVID-19}

$29 \%$ del total de mujeres que estaban embarazadas al momento de la encuesta o que habían estado embarazadas en algún momento desde el inicio de la pandemia no buscaban un embarazo. De las mujeres jóvenes que habían iniciado su vida sexual, $6.5 \%$ se encontraban embarazadas al momento de la encuesta y $9.8 \%$ habían estado embarazadas en algún momento desde el inicio de la pandemia. La mediana de la edad de las mujeres que estaba o habían estado embarazadas desde el inicio de la pandemia fue de 24 años (rango: 21-26 años). De las mujeres que estaban o habían estado embarazadas, 29.4\% no querían quedar embarazadas en el momento en el que quedaron embarazadas.
Entre estas mujeres ( $n=18$ ), el principal motivo por el que quedaron embarazadas aún cuando no estaban buscando un embarazo fue el no haber utilizado un método anticonceptivo ( $\mathrm{n}=$ 11/18 mujeres). Otros motivos mencionados fueron porque su pareja quería tener más hijos ( $n=2 / 18$ ), por razones religiosas ( $n=2 / 18$ ), por no tener suficiente información sobre los métodos anticonceptivos ( $n=2 / 18$ ), porque no pudo acceder a un método anticonceptivo durante la pandemia $(n=1 / 18)$.

\section{Sexualidad, juventudes y COVID-19}

Un porcentaje importante de las juventudes reportaron que desde el inicio de la pandemia no han podido disfrutar de su sexualidad como 
desde antes de la pandemia, siendo la principal barrera el no poder ver a su pareja sexual. $44.7 \%$ de las mujeres jóvenes y $51 \%$ de los hombres jóvenes que ya habían iniciado su vida sexual perciben que no han podido disfrutar de su sexualidad desde el inicio de la pandemia, como lo hacían antes del inicio de la pandemia. Las barreras más mencionadas por las mujeres para disfrutar de su sexualidad fueron el no poder ver a su pareja sexual (28.7\%), no tener un lugar para los encuentros sexuales (18\%), deseo sexual disminuido (13.9\%) y que desde el inicio de la pandemia han tenido menos actividad sexual con su pareja (13.8\%). Entre los hombres, las barreras más mencionadas fueron no poder ver a su pareja sexual (23.3\%), no tener un lugar para sus encuentros sexuales (18.3\%), no poder conocer nuevas parejas sexuales (11.6\%) y menor oportunidad para explorar su sexualidad (masturbación) (11.4\%) (ver Figura 12).
Ocho de cada diez personas jóvenes mencionaron haber explorado una nueva experiencia sexual desde el inicio de la pandemia. Del total de personas jóvenes que ya habían iniciado su vida sexual, 5.8\% de las mujeres y $10.6 \%$ de los hombres reportaron haber explorado una nueva experiencia sexual por primera vez desde el inicio de la pandemia. Entre las mujeres, las experiencias sexuales que se exploraron por primera vez en mayor frecuencia desde el inicio de la pandemia fueron sexting (3.9\%), envío de fotos íntimas a personas conocidas (3.6\%), utilizar un juguete sexual (1.9\%), ver contenido pornográfico (1.6\%) y sexo telefónico (1.6\%). Entre los hombres, las experiencias más mencionadas fueron intercambio de contenido íntimo en un chat en línea (4.6\%), ver contenido pornográfico (4.6\%), sexting (3.7\%) y envío de fotos íntimas a personas conocidas (2.3\%) (ver Figura 13).

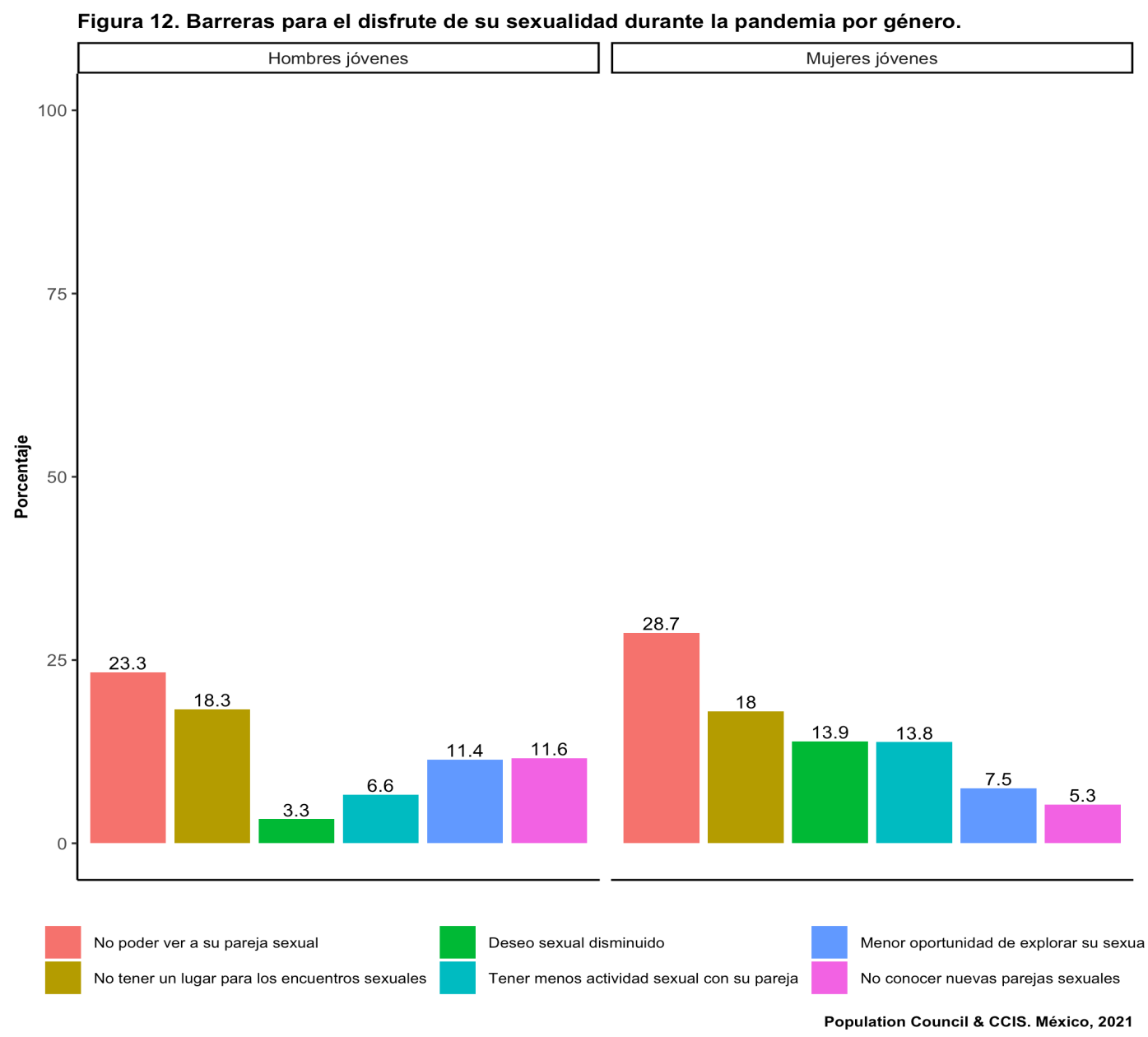




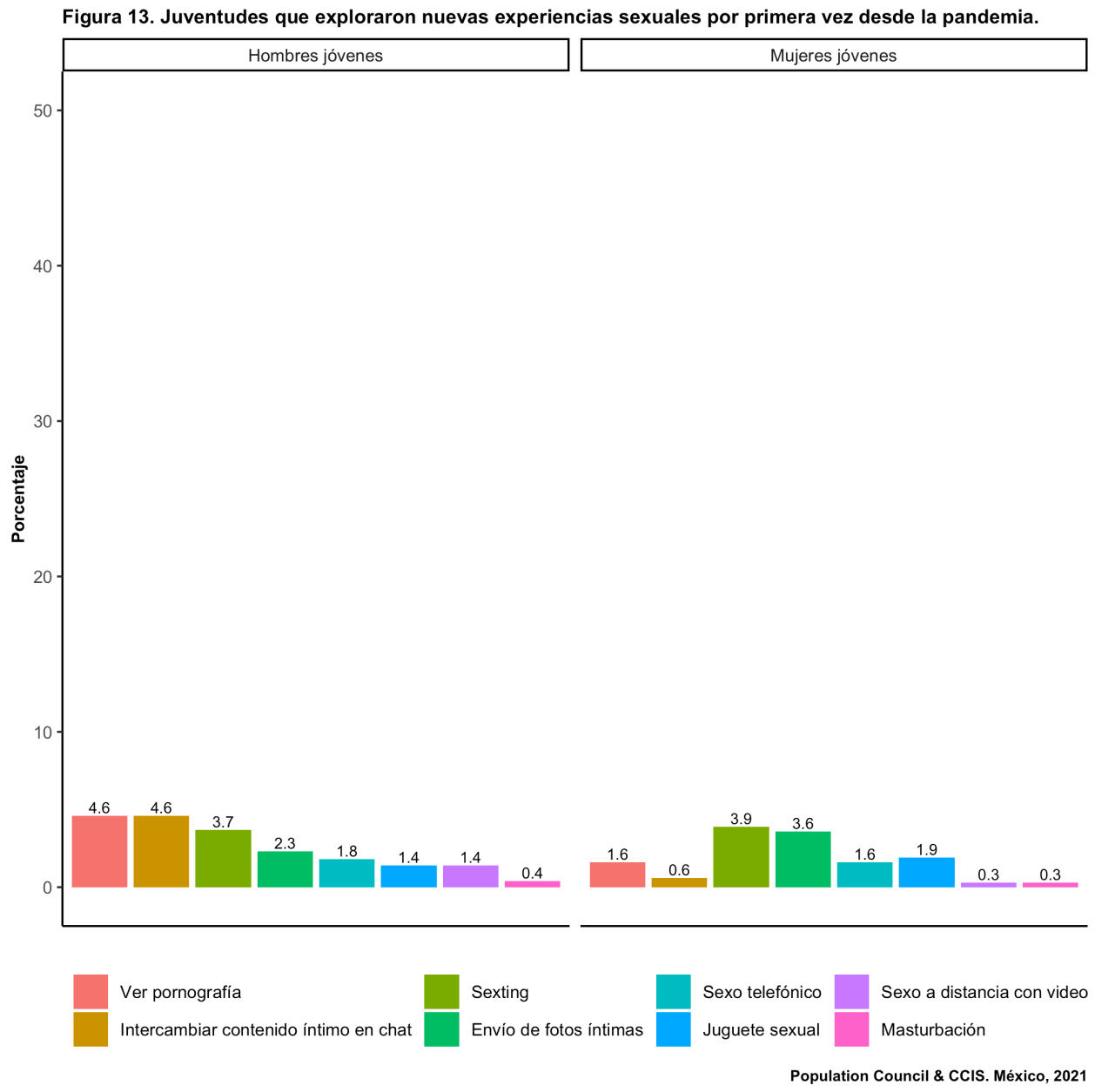

\section{Programas, medidas y decisiones} adoptadas por el gobierno estatal y gobiernos locales con respecto a la salud sexual y reproductiva de las personas jóvenes

Se conoce que en ciertos municipios operan los Servicios Amigables para adolescentes, los cuales son espacios dentro de las unidades de salud que brindan atención en materia de salud sexual y reproductiva a las y los adolescentes. Sin embargo, en las fuentes oficiales de información del gobierno del estado no se identificaron programas, decisiones o medidas adicionales relacionadas con la salud sexual y reproductiva de las juventudes implementadas durante la pandemia.

En el conversatorio con juventudes se mencionó la persistencia de tabúes relacionados con la sexualidad en las comunidades. Debido a esto, persiste la "pena" por parte de personas adolescentes y jóvenes de preguntar sobre estos temas y solicitar más información ya sea en las familias o con el personal de salud. Esto tiene implicaciones importantes en el dercho a vivir una sexualidad libre y sin violencia, en el acceso a métodos anticonceptivos, en la prevención y en la detección temprana y tratamiento de infecciones de transmisión sexual.

\section{VIOLENCIA}

Una de las principales preocupaciones durante la pandemia, sobre todo durante los meses de confinamiento, era el incremento de la violencia intrapersonal a nivel familiar hacia las mujeres y niñas. En este estudio nos interesaba conocer las experiencias de violencia familiar, de pareja y violencia digital entre las y los participantes, así como su percepción sobre el incremento de 
violencia hacia las mujeres en sus comunidades.

\section{Violencia familiar y juventudes durante la pandemia}

Las mujeres jóvenes (18+ años) son las que reportaron haber experimentado violencia en sus hogares por lo menos una vez en la vida en mayor frecuencia. El $4.1 \%$ del total de personas participantes reportaron haber experimentado violencia en sus hogares por lo menos una vez en su vida. Entre adolescentes, $3.4 \%$ de las mujeres y $2.1 \%$ de los hombres han experimentado violencia en sus hogares y, entre las personas jóvenes, $6.3 \%$ de las mujeres y $2 \%$ de los hombres reportaron haber experimentado violencia en sus hogares (valor-p<0.05) (ver Figura 14).

El principal tipo de violencia experimentado por las y los participantes en sus hogares es la violencia piscológica ${ }^{1}$. Del total de participantes que han experimentado violencia en sus hogares por lo menos una vez en la vida $(n=43)$,
90.7\% reportaron que experimentaron violencia psicológicay 44\% mencionóhaber experimentado violencia física. Tres participantes, todas mujeres jóvenes, reportaron haber experimentado abuso o violencia sexual y dos mujeres jóvenes reportaron haber experimentado violencia económica.

\section{Casi cuatro de cada diez personas participantes} que han experimentado violencia en sus hogares, reportaron que la violencia había aumentado a partir del inicio de la pandemia. Para conocer si los actos de violencia habían aumentado desde el inicio de la pandemia, les preguntamos a las personas participantes si percibían que la violencia a las que eran sujetas en sus hogares había incrementado en pandemia. De las 43 personas que reportaron haber experimentado violencia en sus hogares por lo menos una vez en la vida, 38\% consideran que los actos de violencia incrementaron en frecuencia $y / 0$ severidad desde el inicio de la pandemia ( $7 / 8$ hombres y $9 / 35$ mujeres).

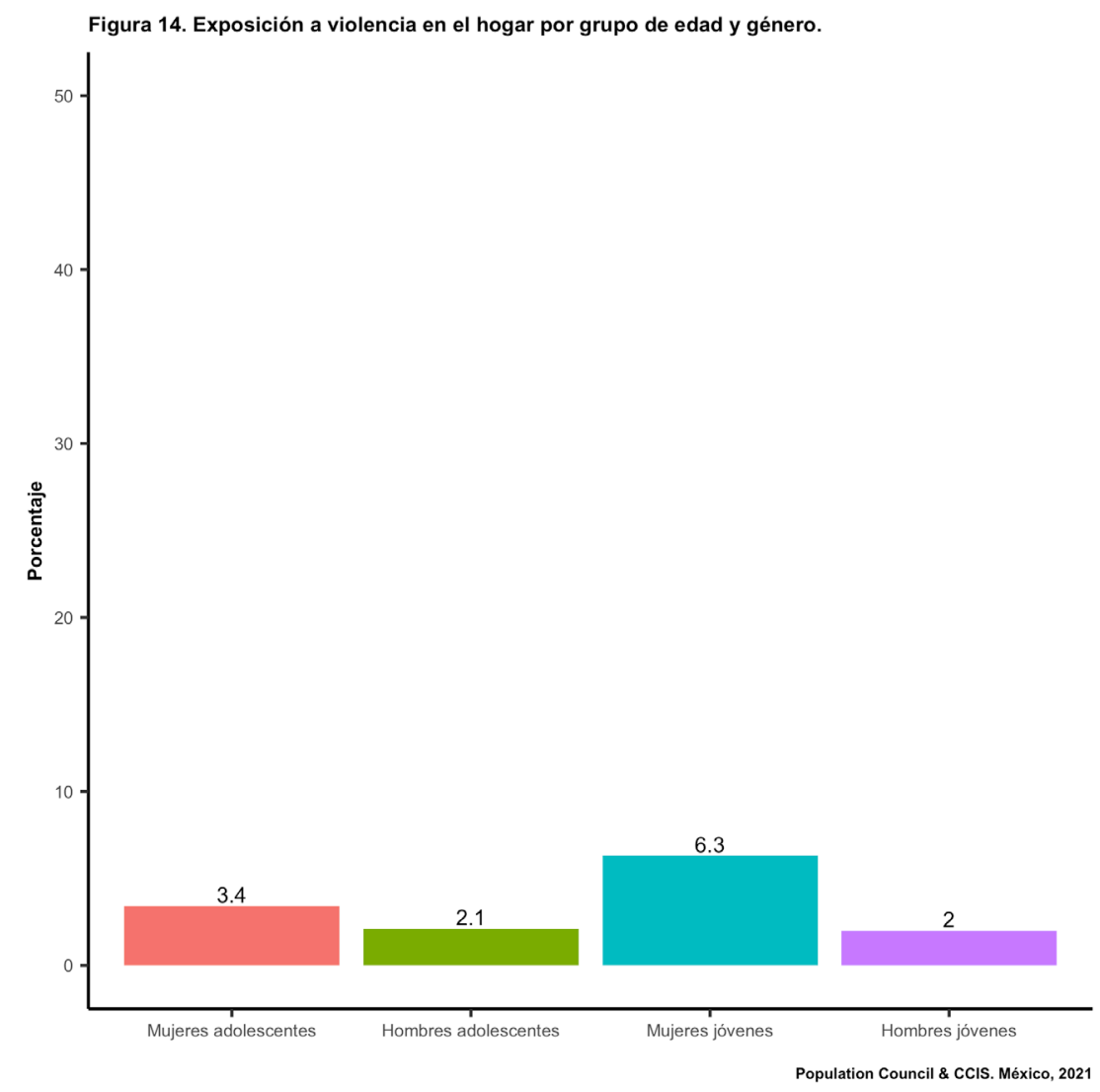

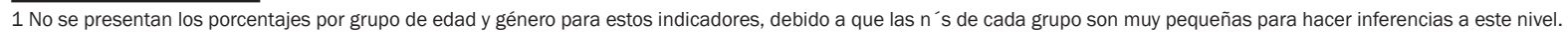


"Al principio nos dijeron que teníamos que salir sólo por lo necesario. Pero sí se fue afectando y fue reproduciendo la parte de la violencia, porque estamos encerrados todos en casa y a veces el papá toma, se droga, entonces en estos casos fue afectando a cada una de ellas [las adolescentes]. Fue como tomado de la mano".

Mujer joven, Chacsinkín

La mayoría de las juventudes no reportan los actos de violencia a las que son sujetas en sus hogares. De las 38 personas que han experimentado violencia en sus hogares y que contestaron esta pregunta, 21\% reportó los eventos de violencia (una mujer adolescente, cinco mujeres jóvenes y un hombre joven). Las principales razones por las cuáles las personas no reportaron los eventos de violencia en sus hogares fueron porque el evento no les pareció algo tan grave como para reportarlo (60\%), no sabían con quién o cómo reportarlo (13.3\%) y les dio miedo reportarlo por si la persona que ejerció la violencia llegaba a tener conocimiento del reporte $(6.6 \%)$.

"Sí hubo como un incremento de violencia en la casa. De niñas que decían que solo ellas tenían que hacer las actividades. El platicar con otras personas y que nos cuenten que tenían problemas en su casa. Que nos digan que quizás es porque todo el tiempo están en la casa y ya se vieron mucho, hay estrés y empezaban a discutir entre ellos y no buscaban como un punto, un equilibro para estar bien".

Mujer joven, Maní.

\section{Violencia de pareja y juventudes durante la pandemia}

\section{Ocho de cada diez participantes que reportaron} haber experimentado violencia de pareja por lo menos alguna vez en su vida son mujeres. Del total de participantes $2.2 \%(n=27)$ han experimentado violencia de pareja por lo menos alguna vez en su vida; $81.4 \%$ de las personas participantes que reportaron esto son mujeres.
De las 27 personas que han experimentado violencia de pareja alguna vez en la vida, 10 contestaron la pregunta sobre si los actos de violencia aumentaron en frecuencia $y / o$ severidad desde el inicio de la pandemia. De estas 10 personas, cuatro identificaron que los actos de violencia habían aumentado en frecuencia $\mathrm{y} / \mathrm{o}$ severidad desde el inicio de la pandemia.

\section{Al igual que para la violencia familiar, la mayoría} de las personas que han experimentado violencia de pareja no han reportado el evento. Del total de personas que han experimentado violencia de pareja por lo menos una vez en la vida $(n=27), 59.3 \%$ no han reportado el evento a ninguna autoridad. Las principales razones para no reportar el evento mencionadas por las y los participantes fueron porque no les pareció algo tan grave como para reportarlo (37.5\%), les daba miedo reportarlo por si la persona agresora se enteraba (31.3\%) y porque no sabían cómo o con quién reportarlo (18.8\%).

\section{Violencia digital y juventudes durante la pandemia}

La violencia digital es el principal tipo de violencia a la que se han visto expuestas las personas participantes, sobre todo las mujeres adolescentes. $16 \%$ del total de participantes han experimentado violencia digital por lo menos una vez en la vida. El principal grupo que ha experimentado este tipo de violencia son las mujeres adolescentes (18.9\% vs. $14.8 \%$ de los hombres adolescentes; valor-p $=0.33$ ). En el caso de las personas jóvenes, $10.3 \%$ de los hombres jóvenes y $8.1 \%$ de las mujeres jóvenes reportaron haber experimentado violencia digital por lo menos una vez en la vida (valor-p $=0.26$ ) (ver Figura 15).

\section{El principal tipo de violencia digital} experimentado por las y los participantes son los apodos ofensivos. Para casi todos los tipos de violencia digital, las mujeres las experimentan con mayor frecuencia comparadas con los hombres (aunque no todas las diferencias son significativas). Al preguntar a las y los participantes por los tipos de violencia digital a 


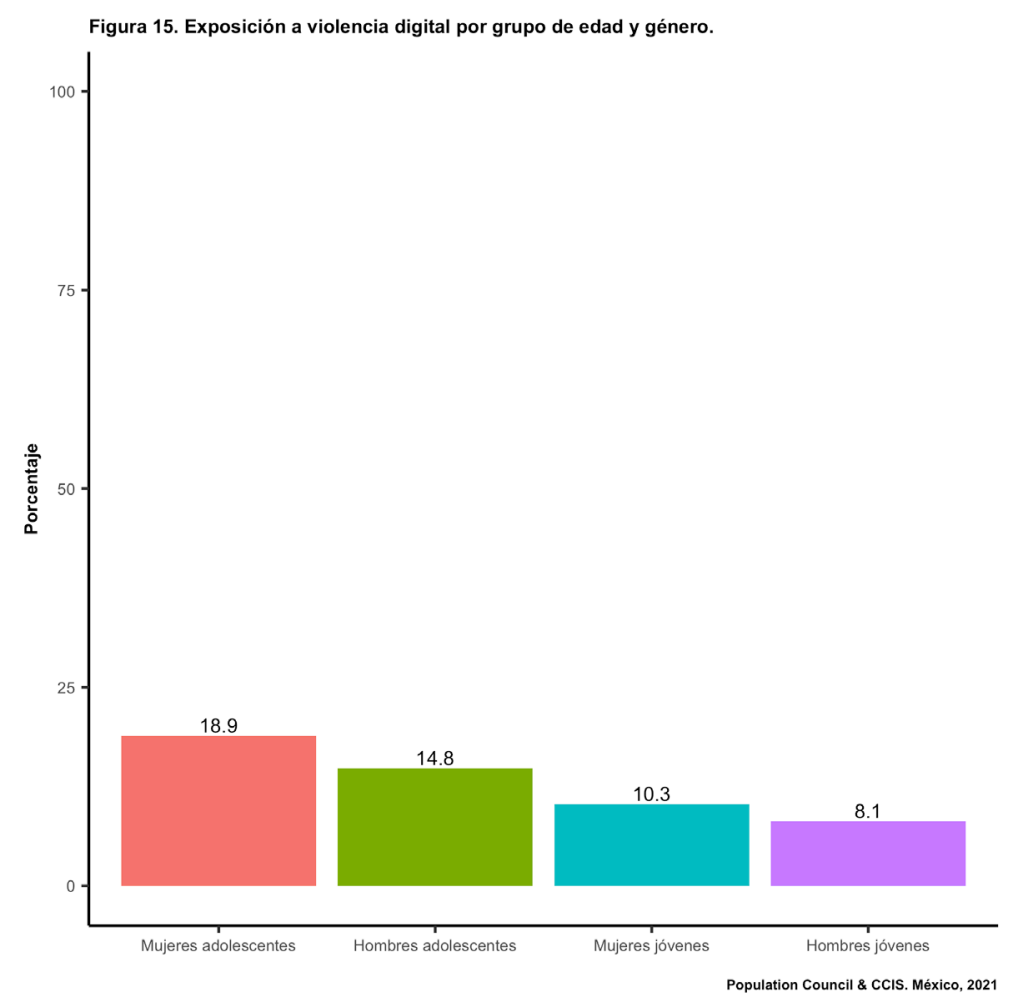

los cuáles se habían visto expuestos, los apodos ofensivos fueron el tipo más mencionado por todos los grupos de edad, tanto entre mujeres como entre hombres. Se observan diferencias significativas entre mujeresy hombres para haber experimentado comentarios con la finalidad de avergonzarles (13.2\% mujeres adolescentes vs. $4.4 \%$ de hombres adolescentes; valor-p<0.05), acoso sexual $(5.1 \%$ de mujeres adolescentes vs. $0.7 \%$ de hombres adolescentes y $6.7 \%$ de mujeres jóvenes vs. 1.5\% de hombres jóvenes; valor-p<0.05) y para amenazas físicas $(2.8 \%$ de mujeres adolescentes vs. $0 \%$ de hombres adolescentes; valor-p<0.05) (ver Figura 16).

Casi 9 de cada 10 personas participantes que han experimentado violencia digital alguna vez en la vida, identificaron que este tipo de violencia había incrementado desde el inicio de la pandemia. Al igual que para la violencia familiar y de pareja, les preguntamos a las y los participantes si percibían que la violencia digital había incrementado en frecuencia y/o severidad desde el inicio de la pandemia. Entre las personas adolescentes, $93.1 \%$ de las mujeres y $70 \%$ de los hombres percibió este incremento, y entre las personas jóvenes, $86.6 \%$ de las mujeres y $89.5 \%$ de los hombres.
La principal razón para no reportar los eventos de violencia digital fue porque no sabían cómo o con quién reportarlos. Del total de personas participantes que habían experimentado violencia digital por lo menos una vez en la vida, 87.3\% no reportó el evento. Las principales razones para no reportarlo fueron porque no sabían cómo o con quién reportarlo (65\%) y porque el evento no les pareció algo tan grave cómo para reportarlo (27\%).

\section{Incremento de la violencia hacia las mujeres en las comunidades durante la pandemia}

\section{Las y los participantes identifican un incremento} de las violencias hacia las mujeres en sus comunidades desde el inicio de la pandemia, principalmente de la violenciafísica. Paraconocer la percepción de las personas participantes sobre un incremento de las violencias hacia las mujeres en sus comunidades, les preguntamos si consideraban que la violencia psicológica, física, sexual y económica hacia las mujeres en sus comunidades era menos frecuente, igual de frecuente o más frecuente desde el inicio de la pandemia en comparación con antes de la pandemia. El $54 \%$ de las mujeres y $46 \%$ de 
Figura 16. Tipo de violencia digital experimentada por grupo de edad y género.

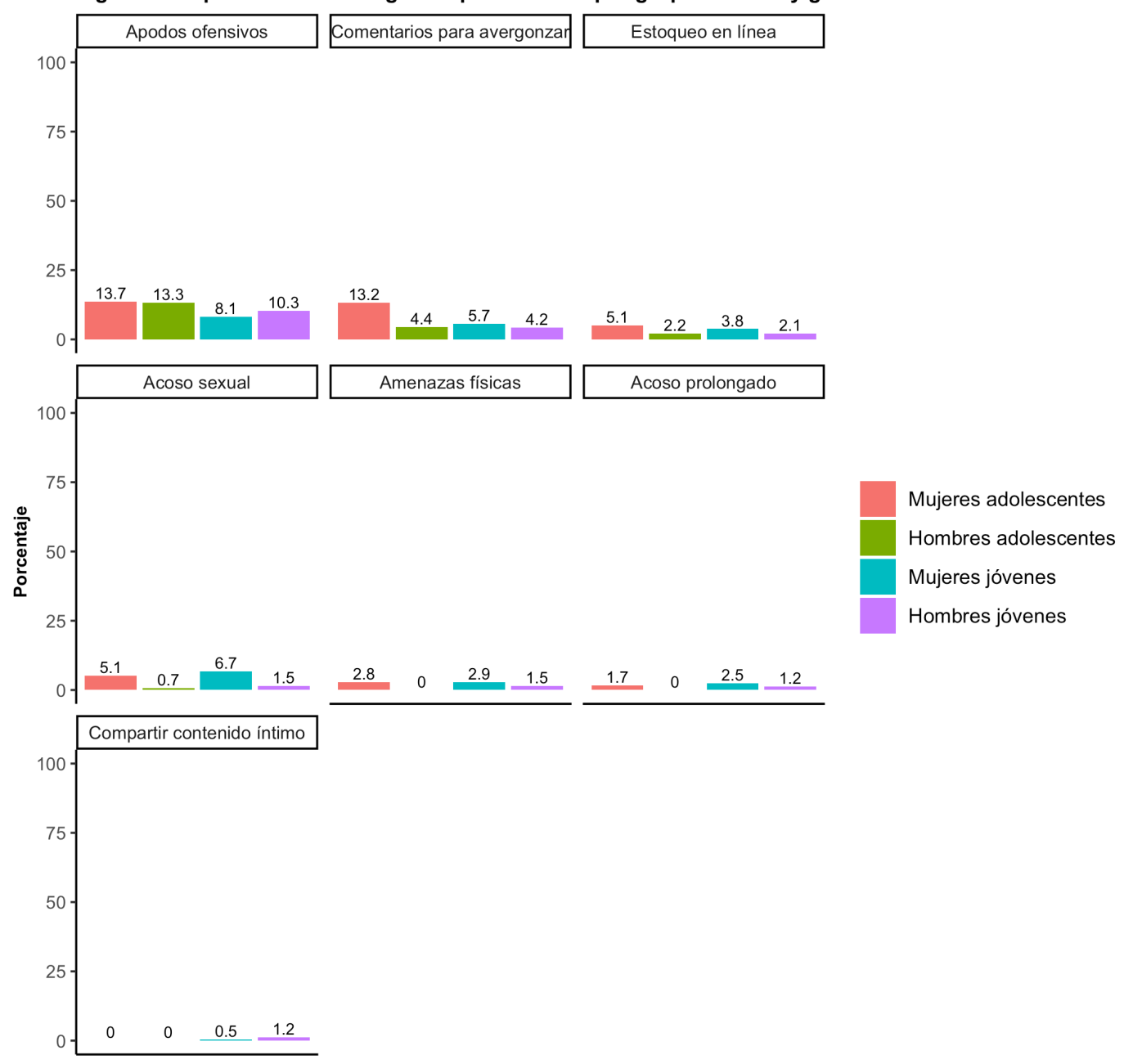

Population Council \& CCIS. México, 2021

los hombres percibían que la violencia física hacia las mujeres en sus comunidades era más frecuente desde el inicio de la pandemia, 49\% de las mujeres y $46 \%$ de los hombres percibían un incremento en la violencia psicológica, $44 \%$ de las mujeres y $39 \%$ de los hombres un incremento en la violencia sexual y $37 \%$ de las mujeres y $32 \%$ de los hombres un incremento en la violencia económica.

\section{Programas, medidas y decisiones adoptadas por el gobierno estatal y gobiernos locales con respecto a COVID-19 y violencia}

Al igual que para el tema de salud mental, tanto el gobierno federal como el gobierno estatal implementaron líneas telefónicas para facilitar el reporte de violencia (principalmente de violencia hacia las mujeres y niñas). También se identificaron acciones estatales contra la violencia de género mediante el fortalecimiento de los institutos dedicados a proteger a la mujer.

No se identificaron programas, medidas o acciones adicionales para prevenir o atender las violencias por razón de género, edad y orientación sexual. Tampoco estrategias centradas en la prevención y atención de la violencia digital ni en su incremento durante la pandemia.

Durante el conversatorio con las juventudes, el confinamiento fue mencionado como una de las principales causas del incremento de la violencia hacia las juventudes (particularmente hacia las mujeres) desde el inicio de la pandemia. Se comentó que la convivencia por periodos prolongados aunado al impacto económico y el 
aumento en el estrés en los hogares pudiera estar relacionado con este aumento en las violencias. Las personas participantes en el conversatorio no hicieron mención sobre programas para la prevención y atención a la violencia en sus comunidades y tampoco respuestas por parte del gobierno para hacer frente al incremento de la violencia desde el inicio de la pandemia.

\section{COVID-19 Y JUVENTUDES}

En este apartado nos interesaba conocer si las y los participantes seguían implementando las medidas de mitigación relacionadas con la pandemia a un año y 4 meses de su inicio, así como sus percepciones sobre la vacuna contra la COVID-19 y la existencia de mitos relacionados con la vacuna.

\section{Medidas de prevención}

\section{Se observó un grado de cumplimiento elevado} con las medidas de prevención a un año y cuatro meses del inicio de la pandemia entre todas las personas participantes. No se observaron diferencias significativas entre mujeres y hombres, excepto en el grupo de edad de jóvenes entre 18 y 24 años, donde un mayor porcentaje de mujeres cumplía con todas las medidas en comparación con los hombres. La principal medida que las y los participantes seguían implementando al salir de sus casas fue eluso de cubrebocas, más del $90 \%$ de las personas participantes en la encuesta reportaron usar cubrebocas al salir de casa. Otras medidas con un porcentaje elevado de cumplimiento fueron el lavado de manos y el uso de gel antibacterial. Se observaron diferencias significativas en el cumplimiento de estas medidas entre mujeres y hombres en el grupo de edad de 18 a 24 años para el cumplimiento con todas las medidas de prevención (61.4\% de las mujeres vs. $50.2 \%$ de los hombres; valor-p<0.05), el lavado de manos (87.9\% de las mujeres vs. $80.5 \%$ de los hombres; valor-p<0.05), el mantenimiento de la sana distancia $(75.4 \%$ de las mujeres vs. $62.5 \%$ de los hombres; valor-p<0.05) y salir de casa solo lo necesario (68.4\% de las mujeres vs. $59.4 \%$ de Ios hombres; valor-p<0.05) (ver Figura 17).

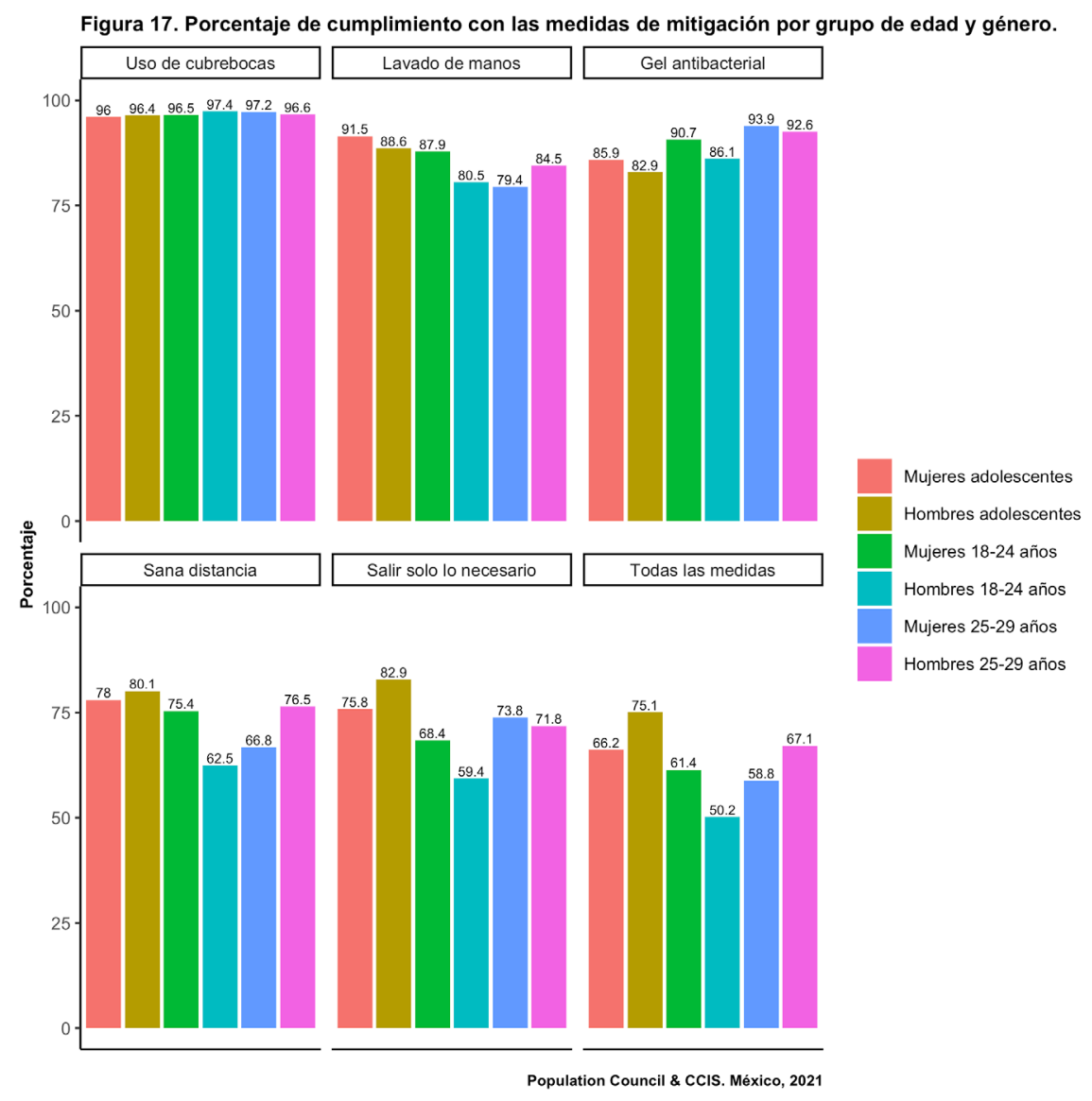




\section{Vacunación y COVID-19}

La mayoría de las personas adolescentes y jóvenes que participaron en la encuesta reportaron que se vacu narían con tra la COVID-19. Entre las y los adolescentes y personas jóvenes participantes, solamente $2.08 \%$ respondieron que no pensaban vacunarse contra la COVID-19 (1.6\% de mujeres y $2.9 \%$ de los hombres; valor-p $=0.06)$. De las 25 personas que mencionaron que no se vacunarían contra la COVID-19, sieté (28\%) contestó que no se vacunaría porque les da miedo que les de COVID-19 si se vacunan, cinco (20\%) porque no creen que la vacuna funcione, cinco (20\%) porque prefieren esperar más tiempo para que haya más información sobre si la vacuna tiene reacciones graves, dos (8\%) porque creen que la vacuna hace más daño que la COVID-19, una persona reportó que le da miedo que la vacuna modifique sus genes (modificación genética) y cinco personas no quisieron contestar la pregunta.

Programas, medidasydecisionesadoptadas por el gobierno estatal y gobiernos locales con respecto a las medidas de mitigactón y vacunación

De las más de 922 medidas identificadas en el mapeo, $76 \%$ son de carácter sanitario. Estas medidas están relacionadas con la difusión de información sobre el SARS-COV-2, con la prevención, detección y atención de casos, con la entrega de tanques de oxígeno, el reconocimiento al personal médico y la campaña de vacunación; así como con la suspensión de eventos y clausura de establecimientos e imposición de multas por incumplimiento de protocolos sanitarios. 


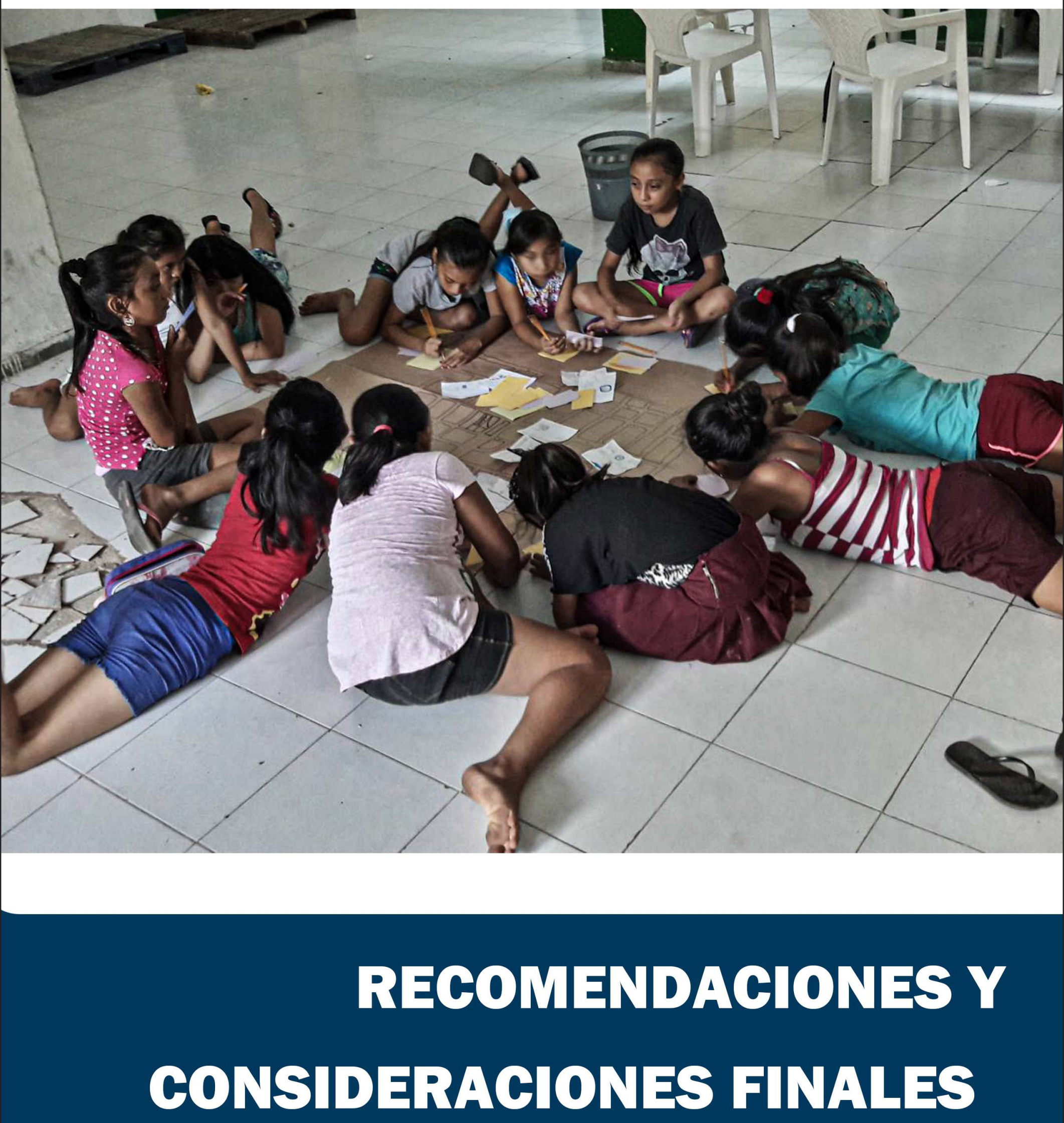


presente reporte identifica cómo la pandemia ha impactado la vida de las juventudes en seis municipios de Yucatán, así como los programas, medidas y decisiones implementadas por los gobiernos estatal y municipales para contrarrestar estos impactos. Una recuperación social y económica inclusiva y resiliente, con enfoque de derechos humanos, es posible. Sin embargo, para lograr esto, es indispensable que las opiniones necesidades y preocupaciones de todas las juventudes, incluyendo las mujeres y hombres jóvenes indígenas, sean escuchadas y tomadas en cuenta a través de estudios y otras estrategias de participación pública, así como que se involucre a las juventudes en el diseño y planeación, ejecución y evaluación de las políticas, programas, decisiones y medidas tomadas por el gobierno.

En esta sección final presentamos las necesidades y áreas de oportunidad identificadas a través del estudio en cada una de las dimensiones, así como una lista de recomendaciones generales y específicas para las autoridades competentes y organizaciones que trabajan en los territorios que esperamos puedan ser de utilidad para la identificación de prioridades a atender en la población adolescente y joven del estado.

\section{Áreas de oportunidad y} recomendaciones

\section{RECOMENDACIONES GENERALES}

1. Divulgar proactivamente las decisiones 0 medidas adoptadas en fuentes oficiales de información, y en otros canales y medios adecuados a los hombres y mujeres jóvenes indígenas de todo el Estado, asegurando la pertinencia cultural de la información y el uso de lenguaje común y no técnico.

2. Diseñar reglas de operación para los distintos programas y apoyos, con enfoque de derechos y medidas no disciminatorias.

3. Evaluar la implementación de las decisiones o medidas en y desde los territorios, así como la satisfacción o insatisfacción de las personas adolescentes y jóvenes atendidas (contraloría social) y de las no atendidas.

4. Abstenerse de adoptar decisiones o medidas que suponen una distinción, restricción, exclusión o preferencia, no basadas en criterios objetivos, razonables o proporcionales que tenga como objeto o fin anular o menoscabar derechos.

5. En el ejercicio de los recursos públicos, dar prioridad a las personas, grupos, pueblos, comunidades, localidades y municipios que enfrenten más desigualdades (por razón de género, edad, características etnoraciales, idioma, apariencia física, entre otros motivos o razones).

6. Observar el principio de acción sin daño en los programas, decisiones y medidas adoptadas en el contexto de la emergencia sanitaria por COVID-19 y en particular de la reactivación económica

7. Incorporar las voces y opiniones de las juventudes y sus necesidades y derechos en la planeación y diseño de programas y estrategias que estén dirigidos a esta población.

8. Promover el aprendizaje y colaboración horizontal entre organizaciones de la sociedad civil que trabajan en los territorios y las instituciones de gobierno, para intercambiar buenas prácticas y lecciones aprendidas sobre los programas que han sido o están siendo implementados.

\section{ESPECIFICAS}

\section{Educación}

\section{Áreas de oportunidad identificadas}

1. La presencia de deserción escolar entre las y los participantes desde el inicio de la pandemia, sobre todo entre las juventudes 
de 18 a 24 años.

2. Falta de acceso a tecnologías de la información (sobre todo a computadoras y tabletas electrónicas) y a internet privado en casa entre las juventudes participantes.

3. Presencia de retos importantes para continuar con su educación durante la suspensión de las clases en persona, asociado a la falta de acceso a tecnologías de la información e internet, pero también relacionados a no entender las actividades y tareas escolares.

4. Algunos de las y los participantes que seguían estudiando al momento de la encuesta han pensado seriamente en abandonar sus estudios desde el inicio de la pandemia.

5. Desconocimiento entre las y los participantes sobre los programas a su disposición que tienen como objetivo el apoyar a las y los estudiantes para que sigan en la escuela.

6. Los programas, decisiones y medidas identificadas en el mapeo no cubren todos los niveles de educación básica obligatoria y excluyen a estudiantes de escuelas privadas cuyas familias tienen ingresos por debajo de la línea mínima de bienestar.

7. No se identificó la presencia de programas, decisiones o medidas enfocadas a prevenir la deserción escolar o promover la reinserción escolar para las juventudes que abandonaron la escuela por razones económicas.

\section{Recomendaciones}

1. Realizar diagnósticos para identificar los grupos con mayor grado de rezago escolar e intención de deserción e implementar medidas de recuperación focalizadas.

2. Mejorar el acceso a internet y tecnologías de la información en las comunidades con menor acceso a estos recursos. Algunas acciones específicas para lograr esto podrían ser la implementación de hot spots gratuitos para el acceso a internet en áreas concurridas y el incremento en el acceso a computadoras en espacios públicos (e.j. centros culturales, centros comunitarios, escuelas y bibliotecas públicas).

3. Incrementar la difusión de programas en las comunidades y disminuir las barreras vinculadas al tipo de requisitos solicitados. También, diversificar los lugares y vías mediante las cuáles las personas se pueden inscribir a los programas.

4. Ampliar la cobertura de los programas estatales del sector educativo, para cubrir a toda la educación básica obligatoria (incluyendo la media superior).

5. Ampliar la población objetivo del programa Impulso Escolar, para cubrir a estudiantes en escuelas públicas y privadas con familias con ingresos por debajo de la línea mínima del bienestar.

6. Implementar programas dirigidos a prevenir la deserción escolar y promover la reinserción escolar, con énfasis en jóvenes de 18 a 24 años.

\section{Trabajo y economia famillar}

\section{Áreas de oportunidad identificadas}

1. Presencia de trabajo infantil (menores de 15 años que se encuentran trabajando) entre las y los adolescentes que participaron en el estudio.

2. Hay un porcentaje de participantes que no se encontraban recibiendo un pago por el trabajo realizado.

3. Persistencia de los roles de género en los trabajos realizados por las y los participantes, ya que la mayoría de las mujeres trabaja como trabajadoras domésticas y la mayoría de los hombres en albañilería y construcción.

4. Porcentaje bajo de participantes que trabajan como profesionistas o empleados/ as en instituciones del gobierno, la mayoría 
trabaja en oficios y como empleados/as en tiendas.

5. Deterioro de la economía familiar, asociado a la pérdida laboral y la reducción de ingresos tanto entre participantes como en sus familias a raíz de la pandemia.

6. Dificultad para encontrar trabajo como persona joven en estas comunidades, particularmente entre las mujeres.

7. Exclusión de las y los adolescentes de entre 15 y 17 años de los programas, decisiones y medidas relacionadas con el empleo y la reactivación econónima (e.j., el seguro de desempleo).

8. Desconocimiento entre las juventudes de programas, decisiones o medidas de los gobiernos federal, estatal y municipales relacionadas con el empleo e inserción en el campo laboral (e.j., Jóvenes Construyendo el Futuro).

9. Barreras para inscribirse a los programas, asociado a los procesos para realizar el trámite, así como la gran cantidad de documentos que se solicitan.

\section{Recomendaciones}

1. Implementar y/o reforzar los mecanismos de monitoreo de trabajo infantil y las medidas para evitar y sancionar el trabajo infantil.

2. Eliminar la distinción y exclusión (no objetiva, razonable o proporcional) para personas de entre 15 y 17 años, para personas mayores de 65 años y para población migrante, desplazada, solicitante de asilo o refugiada en el Estado.

3. Eliminar requisitos y criterios de elegibilidad de programas de subsidios y apoyos potencialmente discriminatorios para personas jóvenes.

4. Verificar que las personas jóvenes que se encuentren trabajando reciban una remuneración por hacerlo (por encima de la línea de pobreza laboral).

5. Impulsar la creación de empleos y retención de personas jóvenes (más allá del emprendurismo y empresariado) en trabajos dignos, libres y seguros, con salarios justos y acceso a seguridad social que les permitan desarrollarse personal y profesionalmente en sus propias localidades, sin tener que migrar para poder ingresar al mercado laboral.

6. Incorporar la perspectiva de género y promover la no reproducción de estereotipos e imposición de roles de género que profundizan la desigualdad en contra de las mujeres.

7. Difundir información sobre los programas, medidas y decisiones en lenguaje claro y no técnico y en lengua maya, por canales y medios que sean utilizados por las personas jóvenes en los distintos municipios.

8. Considerar acompañamiento y asesoría para las y los jóvenes para facilitar la comprensión y cumplimiento de requisitos para poder aplicar a un programa de gobierno.

9. Promoverestrategias de desarrollo económico solidario con la participación de diversos sectores, incluyendo las organizaciones de la sociedad civil que ya trabajan en estas comunidades.

\section{Salud mental}

\section{Áreas de oportunidad}

1. Presencia de sentimientos de aislamiento, estrés y ansiedad entre las juventudes participantes, particularmente entre las mujeres.

2. Poco acceso a servicios de salud mental en los municipios. Esto se identifica en el bajo número de participantes que ha recibido tratamiento psicológico para el manejo de los sentimientos negativos que han surgido desde el inicio de la pandemia. 
3. Desconocimiento sobre los programas, medidas y decisiones implementadas por los gobiernos federal, estatal y municipales relacionados con la salud mental.

4. No se identificaron programas, medidas o decisiones adicionales para prevenir o atender problemas de salud mental en el estado.

\section{Recomendaciones}

1. Difundir tanto en las ecuelas como mediante campañas de comunicación en los municipios sobre la importancia de la salud mental, así como información para facilitar la detección oportuna de problemas de salud mental graves (e.j., depresión mayor, trastornos de ansiedad genralizados y conductas suicidas).

2. Asegurar que la salud mental de la población joven sea una prioridad de los gobiernos estatal y municipales.

3. Diseñar e implementar estrategias para disminuir el impacto de la pandemia en la salud mental de adolescentes y jóvenes y para fomentar el bienestar psicosocial de las juventudes desde un marco de prevención.

4. Ampliar el acceso a tratamiento psicológico y psiquiátrico gratuito y de calidad en las comunidades y municipios (sobre todo en rurales), con enfoque de género y de derechos humanos.

5. Implementar estrategias a nivel escolar para la detección oportuna de problemas de salud mental entre la población estudiantil.

6. Fomentar la presencia de psicólogas/os en los planteles educativos.

7. Asegurar que las estrategias de apoyo psicoemocional consideren en su diseño reducir las barreras culturales y de lenguaje

\section{Salud sexual y reproductiva}

\section{Áreas de oportunidad}

1. Se identifica la necesidad de incrementar el conocimientoyacceso de lasjuventudesa una mayor variedad de métodos anticonceptivos, ya que fuera del condón masculino, los demás métodos son poco utilizados y un porcentaje importante de juventudes reportó acceder a los métodos a través de farmacias. Esto implica un gasto de bolsillo para ellas y ellos, aún cuando los métodos son de acceso gratuito en las unidades de salud.

2. Persistencia del uso entre las juventudes de métodos que han demostrado ser poco efectivos para prevenir embarazos no deseados, como el ritmo y el coito interrumpido.

3. Alta prevalencia de embarazos no deseados entre las mujeres participantes, sobre todo asociado al no uso de métodos anticonceptivos.

4. Presencia de barreras para disfrutar su sexualidad entre las juventudes, sobre todo durante los meses de confinamiento.

5. Incursión en experiencias sexuales a través del uso de tecnología en un entorno con prevalencia alta de violencia digital.

6. Persistencia de tabúes sobre la sexualidad en las comunidades, lo cual tiene implicaciones en el derecho a vivir una sexualidad libre y sin violencia, en el acceso a métodos anticonceptivos y en la prevención, detección y tratamiento de infecciones de transmisión sexual.

7. No se identificaron programas, decisiones o medidas adicionales relacionadas con la salud sexual y reproductiva de las juventudes que hayan sido implementadas durante la pandemia, aún cuando las juventudes reportaron que su acceso a estos servicios se vió impactado por la pandemia. 


\section{Recomendaciones}

1. Evaluar a mayor profundidad las barreras de acceso a los servicios de salud sexual y reproductiva para las personas jóvenes, con enfoque de género, pertinencia cultural y diversidad sexual.

2. Implementar estrategias específicas para disminuir las barreras en el acceso a los servicios de salud sexual y reproductiva en las comunidades y municipios.

3. Trabajar hacia la disminución de tabúes existentes alrededor de la sexualidad entre las personas de las comunidades y municipios, para que las juventudes puedan vivir una sexual libre, segura y sin prejuicios.

4. Incrementar la difusión de los diferentes métodos anticonceptivos, y el acceso a los mismos en las unidades de salud como un asunto de derechos humanos.

5. Asegurar el acceso a la interrupción legal del embarazo para las mujeres que viven en comunidades indígenas.

6. Asegurar que exista información sobre ciberseguridad y mecanismos que garanticen el uso seguro y privado de las tecnologías de la información como herramienta para expresar su sexualidad.

7. En servicios de salud públicos de las comunidades y municipios, asegurar el acceso gratuito a todos los métodos anticonceptivos, así como a servicios de orientación sobre métodos anticonceptivos para que las juventudes tengan todo el conocimiento y herramientas para elegir libremente el método de su elección.

\section{Violencla}

Áreas de oportunidad

1. Presencia de violencia familiar en los hogares de las juventudes participantes, sobre todo de las mujeres jóvenes y un incremento en la frecuencia $\mathrm{y} / \mathrm{o}$ severidad de la violencia familiar hacia las juventudes desde el inicio de la pandemia.

2. Percepción de incremento de la violencia contra las mujeres en las comunidades a raíz de la pandemia.

3. Las mujeres participantes son las que reportaron en mayor frecuencia haber experimentado violencia de pareja.

4. La violencia digital es la principal forma de violencia a la cual se enfrentan las juventudes participantes. Este tipo de violencia incrementó en frecuencia $y / 0$ severidad a partir del inicio de la pandemia.

5. La mayoría de las juventudes no reporta los actos de violencia. Las principales razones para no reportarlos son porque consideran que estos actos no son lo suficientemente graves como para reportarlos, porque no saben cómo o con quién reportarlos y porque les da miedo que la persona que ejerció la violencia se entere de que fue denunciada.

6. No se identificaron programas, medidas o acciones adicionales a los números telefónicos puestos a disposición de las personas (sobre todo mujeres) para denunciar los actos de violencia.

7. Tampoco identificamos estrategias centradas en la identificación, prevención y atención de la violencia digital ni de su incremento durante la pandemia.

\section{Recomendaciones}

1. Promover acciones para fomentar normas de género y masculinidades positivas en las comunidades y municipios.

2. Fortalecer el conocimiento sobre los tipos de violencia, incluyendo la violencia de género y la violencia digital. 
3. Ampliar el conocimiento sobre la Ley Olimpia ${ }^{2}$ en las escuelas y en las comunidades.

4. Evaluar a mayor profundidad la exposición a violencia digital entre las juventudes, para identificar los determinantes de este tipo de violencias y poder incidir en ellos.

5. Implementar programas para la prevención y atención de las violencias en las comunidades y municipios que respondan a las necesidades de las mujeres adolescentes y jóvenes, pero también de juventudes que no se identifican como mujeres cis (hombres, comunidad trans, agénero, bigénero y no binaria).

6. Incrementar los esfuerzos de difusión sobre mecanismos seguros, gratuitos, accesibles y confidenciales para reportar los eventos de violencia.

7. Incrementar y diversificar los mecanismos de denuncia en las comunidades y municipios que sean realmente confidenciales y que no revictimicen a las personas que realizan la denuncia, particularmente a las mujeres.

\section{Vacunación y COVID-19}

\section{Áreas de oportunidad}

1. La gran mayoría de las personas participantes siguen llevando a cabo las medidas de mitigación de la COVID-19 a un año y 4 meses del inicio de la pandemia.

2. La gran mayoría de las personas participantes estaba dispuesta a vacunarse contra la COVID-19. Sin embargo, identificamos mitos relacionados con la vacunación entre aquellas juventudes que no se querían vacunar al momento de la encuesta: creen que la vacuna les va a ocasionar COVID-19, no creen que la vacuna funcione, están a la expectativa de tener más información sobre los efectos adversos de la vacuna antes de decidir si se vacunarán o no, creen que la vacuna hace más daño que la COVID-19 y piensan que la vacuna va a modificar sus genes.

\section{Recomendaciones}

1. Identificar los mitos que existen entre las juventudes sobre la vacuna para prevenir la COVID-19.

2. Diseminar información sobre los beneficios de la vacuna contra la COVID-19 y la importancia de vacunarse. Dicha información debe ser diseminada en canales y medios adecuados a los hombres y mujeres jóvenes indígenas de todo el Estado, asegurando la pertinencia cultural de la información y el uso de lenguaje común y no técnico.

3. Diseminar información sobre los distintos mitos alrededor de la vacuna contra la COVID-19 y porque son considerados mitos. Dicha información debe ser diseminada en canales y medios adecuados a los hombres y mujeres jóvenes indígenas de todo el Estado, asegurando la pertinencia cultural de la información y el uso de lenguaje común y no técnico. 


\section{Referencias}

- Fernández Nieto, B. (2020, May 3). Violencia doméstica en México durante el confinamiento Covid-19. Data-Pop Alliance. https://datapopalliance.org/violencia-domestica-en-mexico-durante-el-confinamiento-por-la-pandemia-covid-19/

- Instituto Nacional de Estadística y Geografía. (2021a). Censo de Población y Vivienda 2020. Panorama sociodemográfico de México. https://www.inegi.org.mx/programas/ccpv/2020/tableros/ panorama/

- Instituto Nacional de Estadística y Geografía. (2021b). INEGI presenta resultados de la Encuesta para la Medición del Impacto COVID-19 en la Educación (ECOVID-ED) 2020. INEGI. https://www. inegi.org.mx/contenidos/saladeprensa/boletines/2021/OtrTemEcon/ECOVID-ED_2021_03.pdf

- Johns Hopkins University. (2021, November 13). COVID-19 Map. Johns Hopkins Coronavirus Resource Center. https://coronavirus.jhu.edu/map.html

- Larrea-Schiavon, S., López-Lalinde, L., Martínez, I., Regules, R., Gutiérrez, J., Nevárez, R., MacGregor, C., López, P., Haberland, N., \& Ngô, T. (2021). Resultados del estudio sobre violencia en la era COVID-19 (VoCes-19): Línea base reporte. Population Council. https://knowledgecommons.popcouncil.org/departments_sbsr-pgy/1523

- Secretaría de Salud. (2021a). COVID-19 México: Panorama en población que se reconoce como indígena. Secretaría de Salud. https://coronavirus.gob.mx/wp-content/uploads/2021/05/A_COVID_19_29_abril_2021_PoblacionIndigena.pdf

- Secretaría de Salud. (2021b, November 13). Datos Abiertos Dirección General de Epidemiología. https://www.gob.mx/salud/documentos/datos-abiertos-152127. http://www.gob.mx/salud/documentos/datos-abiertos-152127

- UNICEF. (2020). Youth speak up about violence during COVID-19. https://www.unicef.org/lac/en/ youth-speak-about-violence-during-covid-19

- Vieitez Martínez, I., Larrea, S., Romero, F., \& Cicolella, L. (2020). Conocimientos, actitudes y prácticas relacionadas a la pandemia del COVID-19 en comunidades indígenas de Yucatán y Chiapas. Population Council. https://knowledgecommons.popcouncil.org/departments_sbsr-pgy/1134 


\section{(9) POPULATION COUNCIL}

Ideas. Evidencia. Impacto.
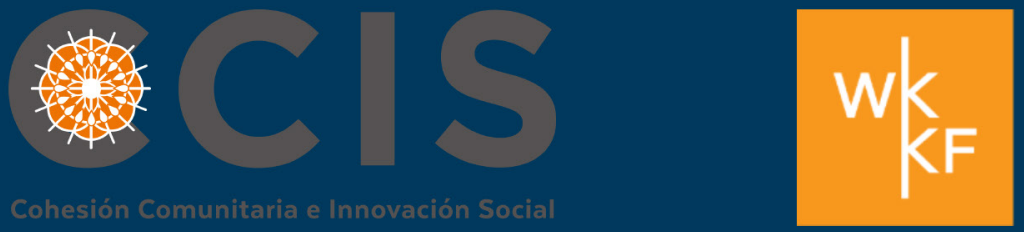

W.K. KELLOGG FOUNDATION $^{\circ}$ 